(11) Nordregio

\title{
GOVERNING THE DIGITAL TRANSITION IN NORDIC REGIONS: The human element
}

By Linda Randall \& Anna Berlina NORDREGIO REPORT 2019:4

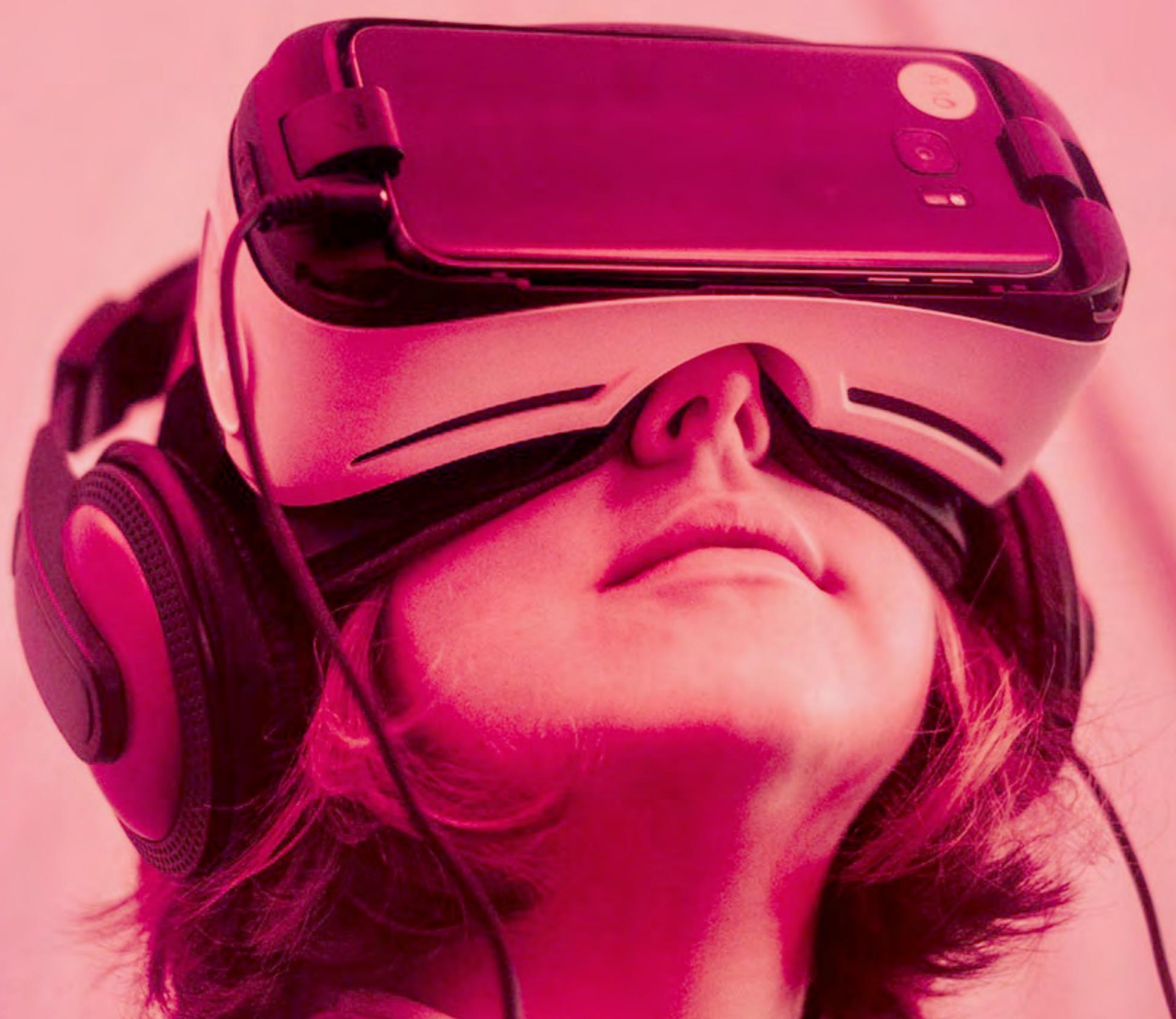





\section{GOVERNING THE DIGITAL TRANSITION IN NORDIC REGIONS: The human element}

By Linda Randall \& Anna Berlina

NORDREGIO REPORT 2019:4

Prepared on behalf of the Nordic Thematic Group for Innovative and Resilient Regions 2017-2020, under the Nordic Council of Ministers Committee of Civil Servants for Regional Affairs. 
Governing the digital transition in Nordic Regions: The human element

Nordregio Report 2019:4

ISBN: 978-91-87295-68-3

ISSN: $1403-2503$

DOI: doi.org/10.30689/R2019:4.1403-2503

(C) Nordregio 2019

Nordregio

P.O. Box 1658

SE-111 86 Stockholm, Sweden

nordregio@nordregio.org

www.nordregio.org

www.norden.org

Analyses and text: Linda Randall \& Anna Berlina

Contributors: Mari Wøien, Laura Fagerlund, Tuulia Rinne, Lise Smed Olsen, Hjördis Rut Sigurjonsdottir, Jukka Teräs \& Eeva Turunen

Cover: Samuel Zeller / unsplash.com

\section{Nordregio}

is a leading Nordic and European research centre for regional development and planning, established by the Nordic Council of Ministers in 1997. We conduct solution-oriented and applied research, addressing current issues from both a research perspective and the viewpoint of policymakers and practitioners. Operating at the international, national, regional and local levels, Nordregio's research covers a wide geographic scope, with an emphasis on the Nordic and Baltic Sea Regions, Europe and the Arctic.

\section{The Nordic co-operation}

Nordic co-operation is one of the world's most extensive forms of regional collaboration, involving Denmark, Finland, Iceland, Norway, Sweden, and the Faroe Islands, Greenland, and Åland. Nordic co-operation has firm traditions in politics, the economy, and culture. It plays an important role in European and international collaboration, and aims at creating a strong Nordic community in a strong Europe. Nordic co-operation seeks to safeguard Nordic and regional interests and principles in the global community. Common Nordic values help the region solidify its position as one of the world's most innovative and competitive.

\section{The Nordic Council of Ministers}

is a forum of co-operation between the Nordic governments. The Nordic Council of Ministers implements Nordic co-operation. The prime ministers have the overall responsibility. Its activities are co-ordinated by the Nordic ministers for co-operation, the Nordic Committee for co-operation and portfolio ministers. Founded in 1971.

\section{The Nordic Council}

is a forum for co-operation between the Nordic parliaments and governments. The Council consists of 87 parliamentarians from the Nordic countries. The Nordic Council takes policy initiative s and monitors Nordic co-operation. Founded in 1952. 


\section{Table of contents}

Foreword

Executive summary.

Introduction

1. Digitalisation in a regional development context ....................................................11

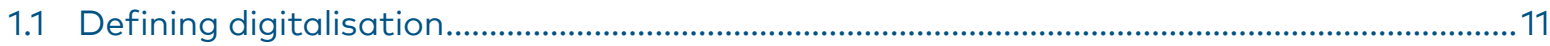

1.2 Digitalisation in the Nordic Region-The European and global contexts .............................. 12

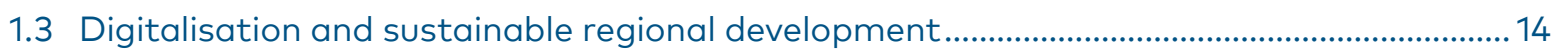

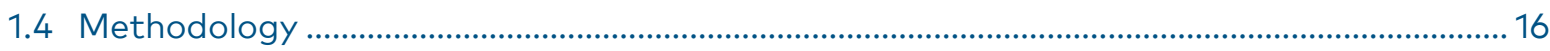

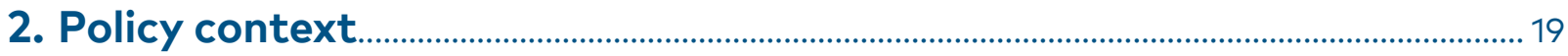

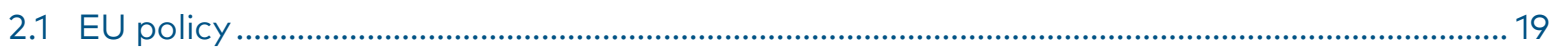

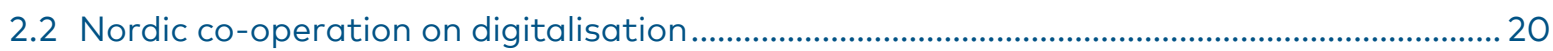

2.3 Digitalisation policy in the Nordic countries and independent territories ........................... 21

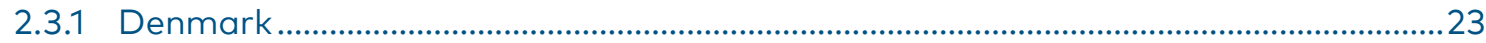

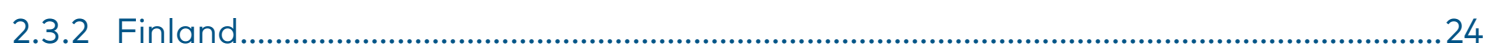

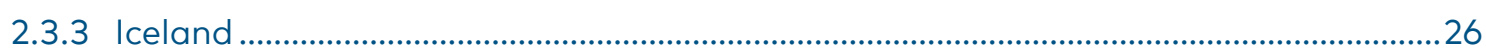

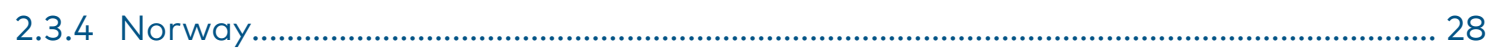

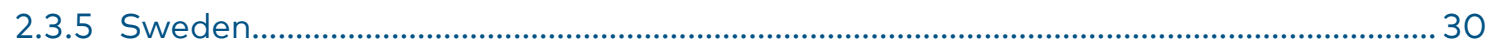

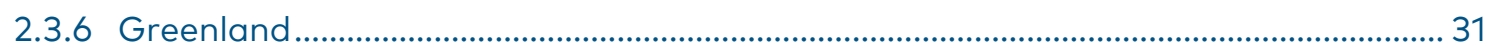

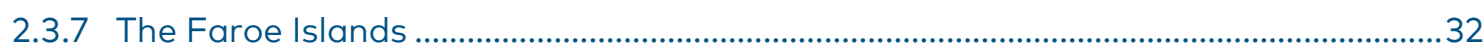

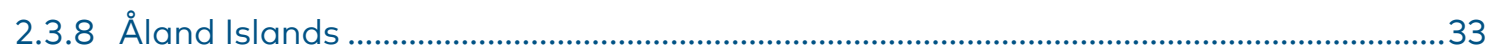

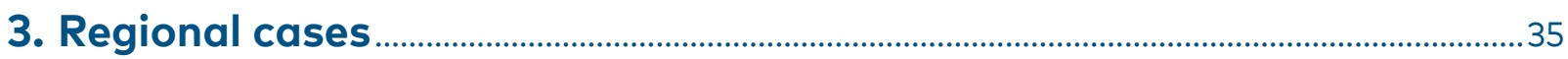

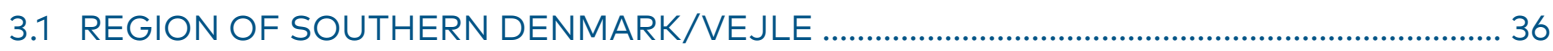

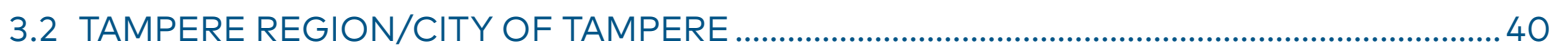

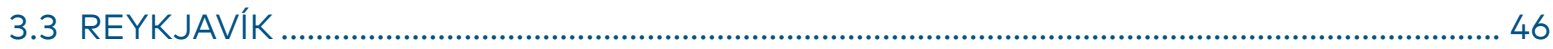

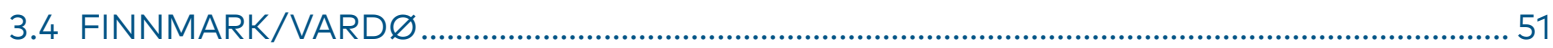

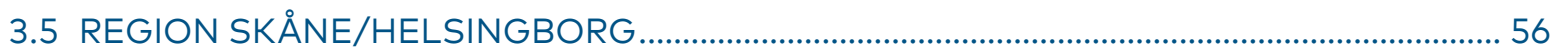

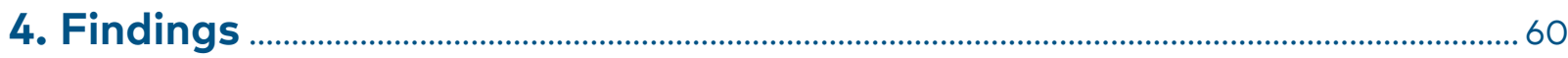

4.1 What are the focus areas of digitalisation strategies in Nordic regions?............................60

4.2 How is digitalisation approached in Nordic regions? ..............................................................61

4.3 How are regions dealing with the challenges and opportunities related to

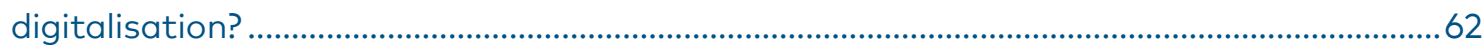

4.4 Where are the strongest potentials for knowledge-sharing/collaboration on

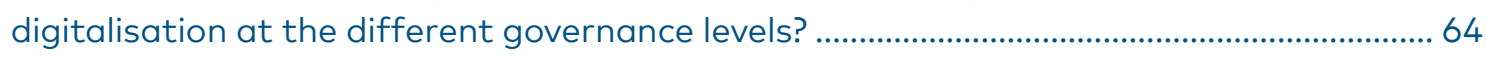

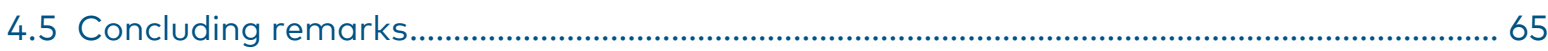


Appendix II. List of interviewees.

\section{List of figures:}

Map 1. Regions examined in the case studies

Map 2. Administrative borders of Tampere region

40

Table 1. Short description of the regional cases

18

Table 2. Digitalisation policies in the Nordic countries: An overview

Figure 1 Digital Economy and Society Index, 2018 rankings................................................................ 13

Figure 2. Digitalisation through a sustainable development lens .......................................................... 14

Figure 3. Next-generation access coverage in rural areas............................................................... 15

Figure 4. Elements of Smart Tampere ecosystem programme...........................................................43 


\section{Foreword}

This report arose from the research undertaken by Nordregio on behalf of the Nordic Thematic Group for Innovative and Resilient Regions 20172020 under the Nordic Council of Ministers' Committee of Civil Servants for Regional Affairs. The work program for the Nordic Thematic Group for Innovative and Resilient Regions 2017-2020 has listed three themes that should lay the basis for understanding the factors that support the creation of innovative and resilient regions across the Nordic countries. These prioritised themes were digitalisation, resilience and smart specialisation that were explored in the three indepth studies conducted in 2017-2018.

Among the activities of the thematic group for 2019 will be a synergy report that aims to identify linkages and complementarities among the three in-depth studies on digitalisation, resilience and smart specialisation from a regional development perspective. Year 2019 and 2020 will also be the years of dissemination for the thematic group, and besides publications and policy briefs, a series of stakeholder workshops will be arranged across the Nordic regions to disseminate our findings and to engage into a discussion with the Nordic practitioners and to receive important feedback and future ideas from the regional and local actors. The work of the thematic group will be disseminated during the Nordregio Forum in Reykjavik in autumn 2019.

This report summarises the work and results achieved within the study on digitalisation titled Governing the digital transition in Nordic regions: The human element. This report explored digitalisation in Nordic regions by studying how local and regional authorities are implementing national and regional digital strategies. By looking at five regional Nordic case studies, the study explored how the Nordic regions were dealing with the challenges and opportunities related to digitalisation and aimed to identify the strongest potential for knowledge sharing and collaboration at the different levels. The in-depth study on digitalisation in the Nordic regions was carried out in the period from 2017 to 2018 and drew on the insights and experiences of regional stakeholders and relevant national actors considered in this report.

I would like to take the opportunity to thank Nordregio for coordinating and disseminating the work of the thematic group. I also want to thank the members of the thematic group for their engagement with the projects and the important contributions that they have made. I am also grateful to all our partners and other stakeholders in the Nordic regions who have provided invaluable help and input to our work.

I hope that you, as a reader, will find this report and other publications of the thematic group useful and relevant. We would also love to hear your comments, so please contact us if you have ideas and feedback to share.

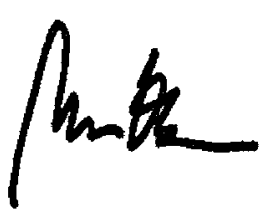

Mikko Huuskonen

Chair of the Nordic thematic group for Inovative and Resilients Regions 2017-2018 


\section{Executive summary}

This in-depth study, Governing the digital transition in Nordic regions: The human element, conducted by Nordregio on behalf of the Nordic thematic group for innovative and resilient regions 20172020, explored digitalisation in Nordic regions by studying how local and regional authorities are implementing national and regional digital strategies. Further, it sought to identify the different types of actors (public sectors, companies and civil society) and actor constellations that are key in the digital transformation of Nordic regions. The study explored how the Nordic regions were dealing with the challenges and opportunities related to digitalisation and aimed to identify the strongest potential for knowledge sharing and collaboration at the different levels. Five regional Nordic case studies were chosen for in-depth analysis: Southern Denmark (Vejle), Tampere Region, Reykjavík, Finnmark (Vardø) and Skåne Region (Helsingborg). The following describes the responses to the major research questions.

Focus areas of digitalisation strategies in Nordic regions. The Nordic countries are widely accepted as digital front-runners in the European and even global context. Thus, perhaps unsurprisingly, all Nordic countries are in the process of implementing national strategies related to digitalisation. Overall, these policies have fairly similar goals, with a focus on digital public services, supporting growth and innovation in business and ensuring digital security. Digital competence is also addressed by each country in varying ways. At the local and regional levels, digital technologies are viewed as tools to fulfil existing responsibilities and realise local and regional goals. As such, specific priorities varied based on the issues that were most pressing in each specific place, and they mirrored the tasks and responsibilities of the authorities in question. It was possible to identify several digital focus areas that were consistent across the case study regions, including digitising government services, digital infrastructure, e-health, creating 'smart' cities, promoting public participation and growing local business and a startup culture.

Approaches to digitalisation in Nordic regions. Perhaps the most consistent finding across the re- gional case studies was the idea that digitalisation is more a human process than a technical one. A common analogy was that $20 \%$ of digitalisation involves technology and $80 \%$ involves people, with the people component largely being a process of change management. Although this process looked different in each case, some elements considered as important success factors for working with digitalisation in a public sector context were the existence of a specific internal team to support digitalisation work, including a trusted and visionary leader, finding achievable goals and possessing a 'just-do-it' approach, creating a shared sense of pride in achievements, taking a customer-centred approach and avoiding strategy documents, targets and action plans that are too detailed or long term in their approach.

Challenges and opportunities related to digitalisation. All interview participants noted the current and future labour market impacts of digitalisation and saw these as presenting both challenges and opportunities. Specific themes that were discussed across multiple cases included embracing job change by shifting mindsets from a culture of fear to enthusiasm about how different work roles could be improved by removing the more menial elements, exploring creative responses to unemployment (e.g., universal basic income and redundancy packages to encourage entrepreneurship), attracting a younger and more dynamic workforce to the public sector and exploring new ways of thinking about education and training (e.g., shifting to competence-based learning and a greater focus on developing transferable skills and the introduction of flexible degree programmes).

Regarding the green transition, most interviewees could point to positive environmental outcomes occurring as a result of digital initiatives. In many cases, the underlying assumption was that smart solutions were green solutions by their nature and that the city itself acts as a 'living lab' for testing new ideas and solutions. At the same time, environmental sustainability appears to be an outcome of digitalisation rather than a driver. In addition, interviewees raised the potential of digi- 
talisation to act as a tool for socio-economic inclusion, e.g., through developing online services and increasing public participation and democracy.

The strongest potential for knowledge-sharing and collaboration. Digitalisation is clearly an issue with broad political support and it presents substantial opportunities for long-term, considered collaboration across local, regional and even national borders. What is less clear, however, is how the different levels of government should interact and which roles are best suited to each level. This research found that the most effective attempts to harness digital opportunity involved a bottomup approach, embracing technology as appropriate to respond to local challenges, needs and priorities. As such, digital priorities should be defined in line with the specific responsibilities of the governance level in question. The study concludes with a summary of potential roles for the different levels of government based on the findings from the case study regions. 


\section{Introduction}

Digital technologies have the potential to dramatically transform our lives. Despite this, research providing direct insight into regional governance in the digital age is limited. To address this gap, this in-depth study, Governing the digital transition in Nordic regions: The human element was conducted by Nordregio during 2017 and 2018, on behalf of the Nordic thematic group for innovative and resilient regions 2017-2020, under the Nordic Council of Ministers' Committee of Civil Servants for Regional Affairs. It explored digitalisation in Nordic regions by studying how local and regional authorities are implementing national and regional digital strategies, and the different types of actors (public sectors, companies and civil society) and actor constellations that are key in the digital transformation of Nordic regions. Specifically, it addresses the following questions:

1. What are the focus areas of digitalisation strategies in Nordic regions?

2. How is digitalisation approached in Nordic regions?
3. How are regions dealing with the challenges and opportunities related to digitalisation (particularly with respect to the green transition and labour market impacts)?

4. Where are the strongest potentials for knowledge-sharing and collaboration at the different governance levels?

The report is presented in four parts. Part 1 provides an overview of the relevant literature on the topic, with a specific focus on defining digitalisation, positioning the Nordic Region in the global and European contexts and understanding digitalisation in the context of sustainable regional development. Part 1 also describes the methodology used in the project. Part 2 presents an overview of the national contexts for digitalisation in the five Nordic countries and three independent territories. It also addresses Nordic co-operation and briefly touches on the European Union (EU) context. Part 3 presents the five Nordic regional case studies. Part 4 presents the key findings from the regional cases to answer the four research questions above. 


\section{Digitalisation in a regional development context}

The primary purpose of this knowledge overview is to develop a shared understanding of the concepts associated with digitalisation, with a focus on their relevance in a Nordic sustainable regional development context. This part is based on a discussion paper Digitalisation as a tool for sustainable Nordic regional development ${ }^{1}$ prepared in Janvary 2018 that was further updated in 2018. The first task is to develop a definition of digitalisation based on selected literature. Then, we proceed by positioning the Nordic Region in the European and global contexts, and present an overview of the main theoretical considerations relevant to digitalisation in a regional development context. The section concludes by outlining the research questions and the methodological approach used to address them.

\subsection{Defining digitalisation}

As with many emerging concepts, there is no shortage of definitions from which to choose. According to Sabbagh et al. (2013: 35), 'Digitalisation is the mass adoption of connected digital services by consumers, enterprises and governments, and is a key economic driver that accelerates growth and facilitates job creation'. This definition understands digitalisation as an active process that requires not only the development of new technologies, but also their large-scale adoption by different groups in society. It regards digitalisation as a positive development from an economic perspective, focusing on job creation and economic growth. However, even if the ultimate outcome of digitalisation is a net gain with respect to jobs, defining digitalisation in relation to job creation alone may be somewhat simplistic (Degryse, 2016). This perception also has the potential to alienate those who are negatively affected by changes to the labour market in the short term.

1 The discussion paper is available on Nordregio's website
Furthermore, the definition from Sabbagh et al. (2013) fails to highlight the transformative element of digitalisation. As the European Commission (2015: 3) explains:

Information and Communications Technology (ICT) is no longer a specific sector but the foundation of all modern innovative economic systems. The Internet and digital technologies are transforming the lives we lead, the way we work-as individuals, in business and in our communities as they become more integrated across all sectors of our economy and society.

Thus, although the technologies themselves are new, digitalisation-the large-scale adoption of these technologies into different parts of society-can be understood more accurately as a series of changes to the existing facets of life. This is a vital detail from a policy perspective as it signals a societal change that goes beyond the purview of a specific government department and instead has the power to reshape every element of our societies. Given this, the transformative qualities of digital technologies are perhaps as equally important as the novel aspects.

This is further elaborated by Alm et al. (2016: 14), who define digitalisation as 'the broad adoption of digital technology in homes, businesses and the society as a whole', explaining that:

Digitalisation constitutes a transformative shift in technology across industries and society in general. It fundamentally changes the way people live, work and communicate, and how they shop for and produce goods and services. It changes the way companies are run, how customers are acquired and how enterprises do business.

This definition incorporates both the actions associated with digitalisation (large-scale adoption of digital technologies) and its transformative qualities. Where it falls short, however, is that it fails 


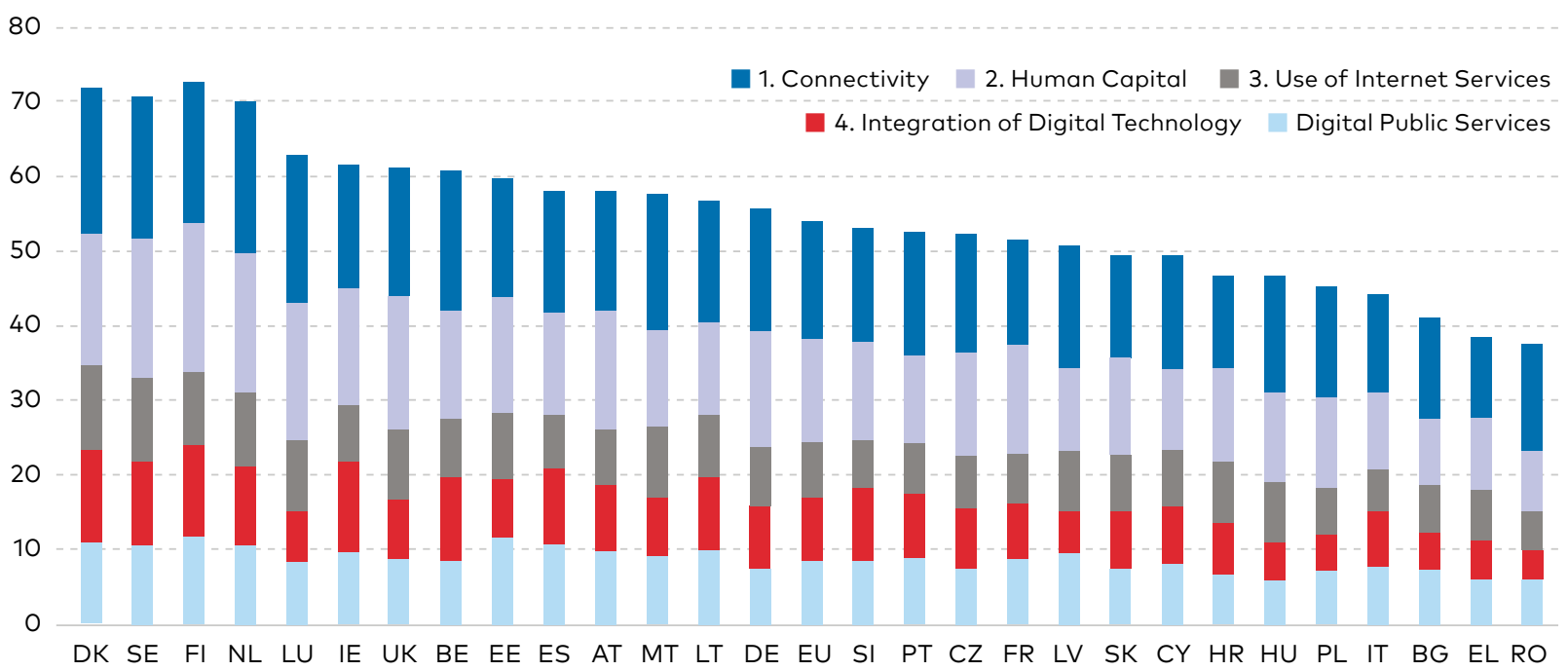

Figure 1 Digital Economy and Society Index, 2018 rankings.Source: (European Commission, 2017c).

affordability); 2) human capital (digital skills); 3) use of the Internet (content, communication and transactions); 4) integration of digital technology (business digitisation and e-commerce); and 5) digital public services (e-government)(European Commission, 2017c). ${ }^{3}$ We find that Nordic countries also rank highest in the tables for each of these aspects. Finland leads the way on human capital and digital public services, Denmark on integration of digital technology and Norway on Internet use.

Alongside the agenda at the European scale, work has also occurred to map the state of play with respect to digitalisation in the Nordic-Baltic Region (Wernberg and Andersson, 2016). To date, two reports have been released that map indicators across the Nordic-Baltic states, with the most recent having a particular focus on cities (see Baltic Wernberg and Andersson, 2016). The Nordic countries perform well in the Nordic-Baltic context. Again, however, there is substantial variation in performance based on different indicators. For example, there are quite large gaps between the countries when it comes to the use of e-procurement in firms or private R\&D expenditure in science and technology, whereas rather small gaps exist when it comes to fixed broadband penetration and startups in ICT across the Nordic-Baltic countries (Wernberg and Andersson, 2016).

Another report based on the Boston Consulting

3 Note that the index weights the five aspects or domains differently, with connectivity and human capital considered the most important (weighted at $25 \%$ each), followed by integration of technology (20\%) and then the use of Internet and digital public services ( $15 \%$ each).
Group's E-Intensity Index 4 includes Denmark, Finland, Norway and Sweden among nine European 'digital front-runners' ${ }^{5}$ (Alm et al., 2016). ${ }^{6}$ The report highlights the higher share of e-GDP 7 in these countries ( $8 \%$ on average) compared with what it terms the 'EU Big 5'8 (where e-GDP is $5.1 \%$ on average). Accordingly, the research suggests that these countries stand to make the greatest gains from further digital advancement, particularly full realisation of the European digital single market and further digitalisation in emerging fields (e.g., IoT, advanced robotics, big data analysis and augmented/virtual reality).

At the same time, the authors argue that these countries have more to lose if Europe fails to keep up with the rest of the world. They are highly critical of European action on digitalisation, suggesting that 'the window of opportunity is closing fast' for Europe to position itself as a global leader in this space (Alm et al., 2016: 19). The report estimates that, based on the current pace of develop-

\footnotetext{
4 The E-intensity index is a global index based on three equally weighted dimensions: 1 ) enablement (mobile Internet, fixed Internet and overall bandwidth); 2) expenditure (online retail, mobile retail and online advertisements); and 3) engagement, which is broken down for: business (business Internet use and ICT impact), consumers (Internet use, online media and social activity) and government (e-Government and e-Education). 5 The five remaining 'digital front-runners' in Europe are Belgium, the Netherlands, Estonia, Ireland and Luxembourg. 6 It should be noted that this report was commissioned by Google.

7 E-GDP is a measure that incorporates all economic activity that is conducted online. It encompasses other sectors and could theoretically reach $100 \%$ if all economic activity was conducted online.

8 The 'EU Big 5' are Germany, France, the UK, Spain and Italy.
} 
ment, even the front-runner nations in Europe will be behind China, South Korea, Singapore and Taiwan by 2025 (Alm et al., 2016). It suggests that the front-runners should work together to share good practice (all are strong in different areas) and take a leadership role. This includes both ideological leadership-to address the concerns of more pessimistic nations-and practical leadership to target the currently broad EU strategy (Alm et al., 2016).

Nordic cities are also front-runners when it comes to various smart technology solutions, including the management of urban systems and environments. Nordic cities have been early adopters of ICT infrastructure in cities, and of knowledge expansion through the implementation of 'smart city' solutions. This builds on a long tradition of developing infrastructure to support the digitalisation of public services. For example, Finland was the first country to declare that broadband access was a legal right for every citizen and Sweden ranks fourth in the world in the percentage of fixed broadband subscriptions on fibre-optic networks (Borges et al., 2017). Sweden is among the most successful countries in developing communitybased broadband initiatives, so-called 'local fibre networks'. The Swedish Local Fibre Alliance has supported local governments and communities to plan and launch municipally owned and managed networks (ENRD, 2017). The Swedish government is committed to providing expanded high-speed Internet to rural areas and Stockholm is expected to be the first city in the world with a $5 G$ network in 2020 (Borges et al., 2017; NyTeknik, 2018).

In terms of the provision of public services, recent research found that the Nordic cities were the most digitally advanced in Europe, independent of city size (ESPON, 2017). The study also showed that there is a generally high confidence level regarding the readiness of cities to respond to digital transition and seize the opportunities of digitalisation.

\subsection{Digitalisation and sustainable regional development}

When thinking about digitalisation as a tool for sustainable Nordic regional development, it is useful to consider social, economic and environmental aspects. Figure 2, although simplistic in its acknowledgment of the dynamic nature of these fields and the way they interact, provides a basic overview of how some of the key issues related to digitalisation can be considered through a sustainable development lens.

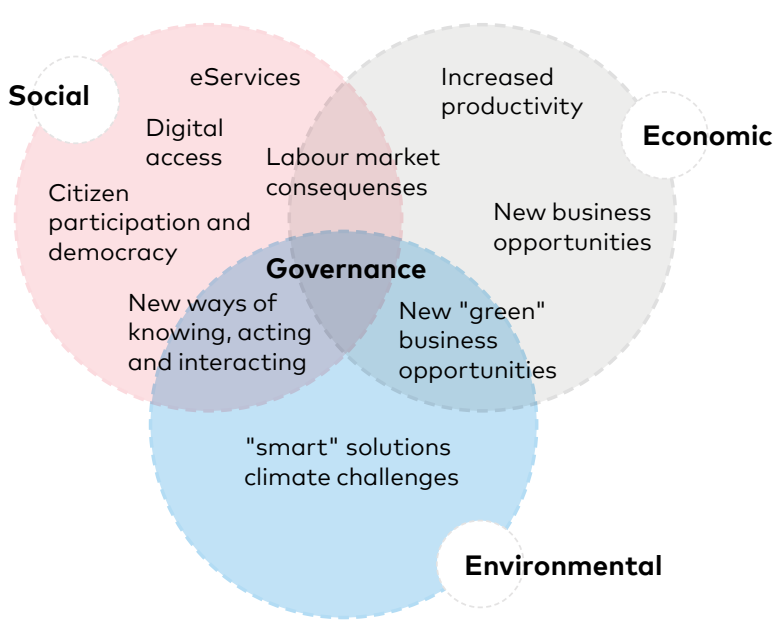

Figure 2. Digitalisation through a sustainable development lens.

From a social perspective, the first priority is to ensure equal access to digital technologies. Persistent disparities remain between urban and rural areas with respect to the availability of digital infrastructure and the adoption of digital technologies-a situation often referred to as the digital divide. On the supply side, rural areas are lagging when it comes to the provision of next-generation access infrastructure (see Figure 3). On the demand side, a lack of digital skills among rural populations can limit the possibilities for innovative service provision and business or customer use (ENRD, 2017). The term digital divide can also be used to describe access challenges related to socio-economic status, age, gender and health. Consequently, a large proportion of citizens in urban areas lack the infrastructure and competencies required for full participation in a digital life. As with other forms of social stratification, elements of disadvantage are cross-cutting. For example, an elderly person living in a rural community may be subject to a 'double digital divide' (ENRD, 2017).

Closing the digital divide is vital, particularly if we consider the increasing shift of other elements of social life to online mediums. Government services, e.g., are increasingly delivered online, with a view to improving citizen experience and increasing internal efficiency (ESPON, 2017). This is occurring across Europe to varying degrees, with the highest levels of digitalisation reported in the fields of spatial planning and construction, tourism, culture, leisure, sports, e-inclusion in governance and education (ESPON, 2017). Digital technologies are also being used to promote democratic and collab- 


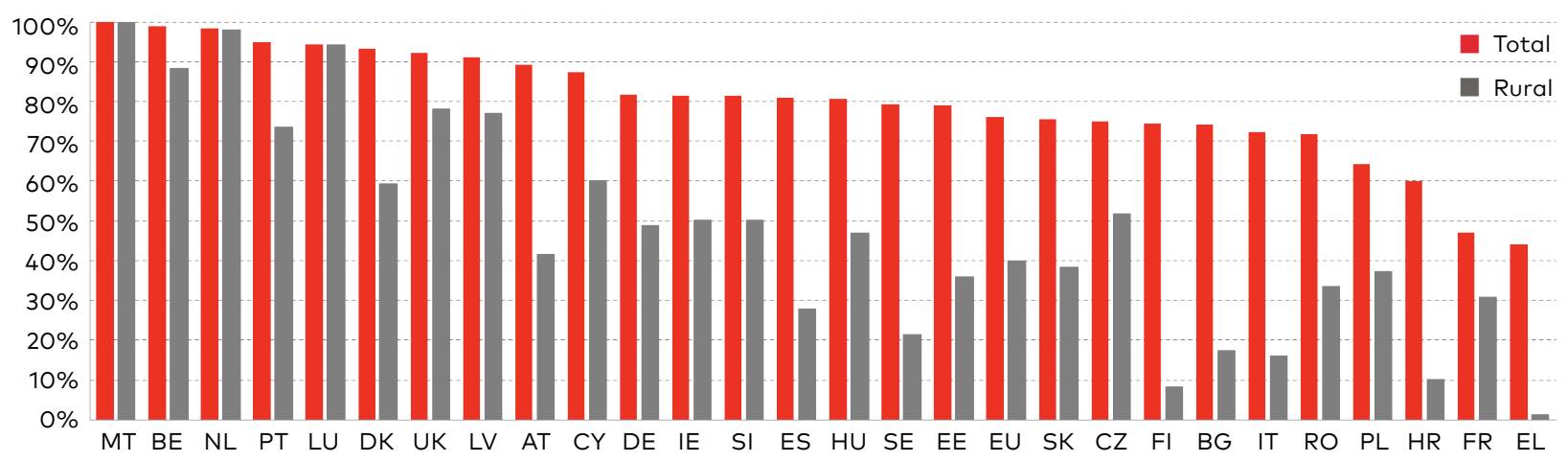

Figure 3. Next-generation access coverage in rural areas. Source: European Commission, 2017 .

orative approaches to public policy making, creating more open, transparent and participatory governments (OECD, 2014) and they can foster citizen-driven approaches (citizens and businesses formulating and determining their needs in partnership with governments).

From an economic perspective, digitalisation has substantial implications for the labour market. Several forces are at play here. First, there is considerable discussion about the potential for automation to destroy or change the nature of existing jobs (Autor, 2015; Berger and Frey, 2016; Degryse, 2016). Typically, tasks that can be automated are those which achieve consistent results by following well understood and predictable procedures and which do not require flexibility, judgement or common sense. Importantly, automation does not necessarily mean replacing humans altogether and may apply only to certain tasks within a work role. In most cases, this results in a greater demand for high-level analytical and/or interpersonal skills in the remaining human component (Berger and Frey, 2016). This can result in skills shortages, slowing down digital development in some sectors (Berger and Frey, 2016; ESPON, 2017). Until now, the most substantial job destruction has occurred in middle-skilled professions (e.g., book-keeping, clerical work and data entry). However, Al is increasingly raising the possibility of automation in high-skilled professions (Autor, 2015; Berger and Frey, 2016).

At the same time, there is considerable discussion about the potential for job creation through digital technologies (Alm et al., 2016; Degryse, 2016; Sabbagh et al., 2013). From a regional development perspective, it is important to consider the territorial conditions under which job creation will occur. During the late 1990 s to the early 2000 s, a body of literature emerged suggesting that digital technologies would signal the 'death of distance', allowing socio-economic activities to become increasingly detached from physical proximity. This idea has been widely refuted subsequently, perhaps most succinctly by Morgan (2004), who argues that:

[The 'death of distance'] thesis grossly over-estimates the distance-destroying capacity of ICT by conflating spatial reach with social depth. Because information diffuses rapidly across organisational and territorial borders, it wrongly assumes that understanding does too. (Morgan 2004: 3, emphasis in original)

In fact, rather than the role of physical proximity declining, territorial factors have become increasingly important to business innovation. This is evidenced in the emergence of regional innovation clusters (Morgan, 2004; Soete, 2006), as well as in the increasing competitiveness between cities on the global stage in different industries (Kourtit, 2016; Scott, 2011).

This has substantial consequences for regional development in the context of digitalisation. Evidence suggests that new industries (and the associated jobs) are mostly emerging in cities already rich in high-skilled jobs (Alm et al., 2016; Berger and Frey, 2016; Degryse, 2016). Thus, the places where jobs are least vulnerable to automation are also the places that are most likely to experience job creation (Berger and Frey, 2016). This presents particular challenges for socio-economic sustainability in the context of the Nordic Region, which is characterised by high levels of urbanisation and substantial peripheral, rural and sparsely populated areas. 
From an environmental perspective, digital technologies have the potential to make cities and regions 'smarter', reducing consumption, lowering carbon emissions and improving quality of life for residents. So-called smart city initiatives have received considerable attention in the literature. Solutions generally involve adopting technologies such as automation, machine learning and the loT to support city functions such as public transportation, traffic, lighting, energy systems and waste and water management (Borges et al., 2017). Moreover, smart city solutions can used for monitoring, the provision of data to support decisionmaking and to monitor progress towards environmental goals (Borges et al., 2017; IoT Agenda, 2017).

More recently, the smart city has been given a rural twist, through the adoption of the 'smart villages' concept. In the 'Cork 2.0 Declaration' (2016), the European Commission, the rural networks as well as rural stakeholders call for policies to pay 'particular attention to overcoming the digital divide between rural and urban areas and to develop the potential offered by connectivity and digitisation of rural areas' (European Commission, 2016c: 3). This work recognises that innovation and digitisation are equally important for green and sustainable rural areas and has a particular focus on developing a circular bioeconomy and creating high-quality jobs in the agricultural sector.

Digitalisation also contributes to the green transition by enabling business models that promote sustainable consumption through the 'sharing' of goods and services through digital platforms. This phenomenon is generally referred to as the sharing economy. In 2015, the sharing economy was estimated to have a global net worth of \$150BN USD (Alm et al., 2016). Commonly cited international examples include Airbnb (users rent their home or part of their home to other users), Uber (users provide lifts to other users using their own vehicle) and Upwork (links freelance workers with potential employers, generally for the purpose of performing short-term, project-based work). The term itself is heavily contentious, primarily because the so-called 'sharing' often (though not always) involves a financial exchange between the two parties (Degryse, 2016). However, there are many local-level examples that do promote 'sharing' in the traditional sense (e.g., Skjutsgruppen, the Swedish ride-sharing platform). More information about the sharing economy in the Nordic context can be found in the report, Nordic Labour Markets and The Sharing Economy-Report from a Pilot Project (Dølvik and Jesnes, 2017).

Finally, and perhaps most importantly, it is vital to acknowledge that technologies themselves neither produce nor preclude sustainable development outcomes. As such, the digital transition requires innovative, co-ordinated and multi-level governance approaches that foster interaction between citizens, business, non-governmental organisations and public administrations. Governments have a responsibility to create the conditions in which other sectors can make the most of the digital opportunity. They may also need to respond in different ways to negative consequences, e.g., the potential job losses described above. Successful digital transition requires multi-level governance arrangements, including both vertical and horizontal dimensions. Cross-sectoral collaboration is a key approach in realising digital transformation. The EU eGovernment Action Plan 2016-2020 emphasises the need to foster more systematised interaction of citizens, business and non-governmental organisations with public administrations (European Commission, 2016b).

\subsection{Methodology}

As demonstrated above, digitalisation is a broad concept with far-reaching consequences for all levels of government, business and society. Regional policy making in this field is in its infancy and specific approaches appear to be broad in nature, as well as differing based on the specific characteristics of countries and regions. There is much to be learned about the specific ways in which regional actors are responding to the challenges highlighted above, as well as the interaction between policies and actors at the different levels of governance. As such, this study has taken a broad approach, exploring digitalisation as a tool for sustainable Nordic regional development with respect to social, economic and environmental aspects, as well as considering governance implications.

The research explored the following questions: 1. What are the focus areas of digitalisation strategies in Nordic regions?

2. How is digitalisation approached in the Nordic regions?

3. How are regions dealing with the challenges and opportunities related to digitalisation (particularly with respect to the green transition and labour market impacts)? 
criteria. The selection criteria were established with the aim of including a rich selection of Nordic cases related to the following elements:

1. Regional characteristics: Type of region (predominantly urban, intermediate, predominantly rural); ${ }_{i}^{9}$ population; economic structure; and other specific characteristics

2. Digitalisation approach: Evidence of a holistic and/or regional focus (i.e., digitalisation is addressed beyond the smart city); and diversity of practices highlighting the social, economic and environmental aspects of sustainability

The final selection of the regional cases is shown in Table 1. Empirical data was gathered for the cases through a combination of desktop research and semi-structured stakeholder interviews held during several field trips to the selected regions. The different nature of the cases resulted in slight variations in the stakeholders interviewed in each region. However, as a general rule, they included: one 'local champion' (a key player in the field); one to two representatives of the regional authority; one to three representatives of a selected municipal authority within the region; one representative of a research institute or university; and one to two representatives from the private sector (e.g., cluster organisation, technology company and so on). This resulted in between six to eight interviews for each case study, most of which were between 45 and 75 minutes in length (a full list of interviewees is provided in Appendix II).

In each case, the 'local champion' acted as the initial informant, recommending other interview participants based on the desired target groups. The snowballing method was then used to identify further interviewees. In the small number of instances where it was not possible to interview all stakeholders during the field trip, a skype interview was conducted at a later date. A pilot case was conducted initially to test the methodology (Tampere, Finland). This resulted in some minor adjustments to the interview questions but none so substantial as to affect the comparability of this case.
The case study interviews were transcribed for the purpose of carrying out an in-depth cross-case analysis that laid the basis for developing findings and making recommendations for the policy makers and practitioners. The relevant input and comments provided by the members of the Nordic thematic group for innovative and resilient regions 2017-2020 during the regular meetings were used to improve the study.

\section{Table 1. Short description of the regional cases}

\section{Regional characteristics}

\begin{tabular}{|c|c|c|}
\hline Denmark & $\begin{array}{l}\text { Southern } \\
\text { Denmark }\end{array}$ & $\begin{array}{l}\text { Intermediate region, } \\
\text { remote; } 1.2 \text { million } \\
\text { inhabitants; sustainable } \\
\text { energy, health innovation }\end{array}$ \\
\hline Finland & Tampere & $\begin{array}{l}\text { Intermediate region, close } \\
\text { to a city; } 500 \text { o00 inhabi- } \\
\text { tants; ICT, engineering, } \\
\text { game industry }\end{array}$ \\
\hline Iceland & Reykjavík & $\begin{array}{l}\text { Intermediate region, close } \\
\text { to a city (capital region); } \\
220000 \text { inhabitants; } \\
\text { tourism, creative and } \\
\text { knowledge-based } \\
\text { industries, fisheries, energy } \\
\text { production }\end{array}$ \\
\hline Norway & Finnmark & $\begin{array}{l}\text { Predominantly rural } \\
\text { region, remote; } 75 \text { 000 } \\
\text { inhabitants; fisheries } \\
\text { and aquaculture, culture, } \\
\text { tourism, oil and gas, } \\
\text { military, agriculture, energy } \\
\text { and mining }\end{array}$ \\
\hline Sweden & Skåne & $\begin{array}{l}\text { Intermediate region, } \\
\text { close to a city; } 1.34 \\
\text { million inhabitants; life } \\
\text { sciences, food sector, } \\
\text { telecommunications, } \\
\text { health tech and game } \\
\text { development }\end{array}$ \\
\hline
\end{tabular}




\section{Policy context}

This section presents an overview of EU policy and Nordic digitalisation strategies at the national level, providing a basis for the study of regional digital agendas that follows in Part 3: Regional case studies. It also provides a brief overview of other joint Nordic work in this field.

\subsection{EU policy}

Digitalisation is highly important to the EU, and the policy agenda in this area is both vast and complex. The aim of this section is to briefly examine the most relevant aspects of the EU policy to provide the broader context for the more detailed account of Nordic digitalisation policy that follows. The EU Digital Agenda 2020 is one of five pillars of the Europe 2020 Strategy, and provides an overarching framework for European efforts towards a digital society (European Commission, 2014). Central to the agenda is the Digital Single Market Strategy for Europe, which focuses on maximising the growth potential of the digital economy, emphasising the benefits of digital services for businesses and industries, and also for EU citizens (European Commission, 2015). The policy has recently undergone a mid-term review, with key achievements including the abolition of roaming charges, portability of content and setting the stage for the development of $5 G$ technology (European Commission, 2017c). The review identifies three main areas where further EU action is necessary, including development of the European data economy, addressing cybersecurity challenges and promoting online platforms (European Commission, 2017b).

Other EU policies of relevance are those aimed at societal aspects of digitisation. The EU eGovernment Action Plan 2016-2020 identifies three priority areas, including modernising public administrations using key digital enablers, enabling mobility of citizens and businesses by cross-border interoperability and facilitating digital interaction between administrations and citizens/businesses for high-quality public services (European Commission, 2016b). The European Commission's eHealth
Action Plan 2012-2020 prioritises the achievement of wider interoperability of e-health services, support for research development and innovation, ensuring wider deployment and facilitating uptake of e-health services and the promotion of international co-operation (European Commission, 2012). The Digital Education Action Plan (2018) prioritises making better use of technologies for teaching and learning, developing relevant skills and competencies for digital transformation and improving education systems through better data analysis and foresight (European Commission, 2018b). The New Skills Agenda for Europe (2016) outlines specific actions to support and ensure delivery of the right training and skills for EU citizens (European Commission, 2016e).

The European Commission also highlights the importance of cities and regions as enablers of digital transformation, as outlined in the Blveprint for cities and regions as launch-pads for digital transformation, developed by the European Commission's Strategic Policy Forum on Digital Entrepreneurship 2014-2016 (European Commission, 2016a). The blueprint underlines the strategic role of urban and regional ecosystems in the digital transformation, calling for strong leadership and mobilisation of all local actors. The European Commission supports digitalisation through smart city initiatives and projects and actions that aim to build regional and local capacity in digital transformation (European Commission, 2016d). The Urban Agenda for the EU (2016) also includes digitalisation as a focus area (European Commission, 2016f).

Finally, it is worth noting the new data protection rules that came into effect in May 2018, based on the General Data Protection Regulation, which was adopted in May 2016. The new rules provide consistency across the continent (including nonEuropean companies offering services in the EU), stronger and new rights for citizens, stronger protection against data breaches and the power to impose fines for breaches (European Commission, 2018a). 


\subsection{Nordic co-operation on digitalisation}

During the Norwegian chairmanship of the Nordic Council of Ministers, the ad hoc council of ministers for digitalisation (MR-Digital) was established for the period from 2017 to 2020, which laid the foundation for increasing co-operation on digitalisation in the Nordic regions (NCM, 2017). In 2017, the joint declaration for digitalisation, The NordicBaltic Region: A Digital Front-runner, was signed by Nordic and Baltic ministers at a ministerial meeting during the Digital North conference. The main objectives of the declaration are:

1. Strengthening the ability for digital transformation of governments and societies, especially by creating a common area for cross-border digital services in the public sector;

2. Strengthening the competitiveness of the region's enterprises through digitalisation;

3. Enhancing the digital single market in the NordicBaltic region.

In 2018, the declaration on Artificial Intelligence in the Nordic-Baltic Region was introduced. The overall objective of this declaration is to develop and promote the use of Al to serve humans better through skills development, enhancing access to data and developing ethical and transparent guidelines, standards, principles and values.

Among the recent initiatives is a Nordic-Baltic Action Plan for 5G, 2018-2020 that was presented to the Nordic prime ministers at the session of the Nordic Council on 30 October 2018. The Action Plan contains specific initiatives and goals for cooperation up to 2020 , such as the development of new testing facilities, removing obstacles to the expansion of the $5 G$ network and monitoring the development of $5 G$, particularly for certain sectors (e.g., transport and manufacturing).

Nordic Innovation received funding under the Nordic Co-operation Programme for Innovation and Business Policy 2014-2017 for several lighthouse projects, one of which is entitled Innovative Nordic Digital Solutions. This project will contribute to the ambitious goal of making the Nordic Region a digital pioneer and includes three tracks:

Track 1: Nordic electronic identity (e-ID) was led by the Norwegian Directorate for Administration and ICT and has documented similarities and differences between the e-ID systems in Denmark,
Finland, Iceland, Norway and Sweden, with the overall aim of promoting cross-border co-operation on e-ID (for the full report, see Hansteen et al., 2016). As a follow-up, the Nordic-Baltic elD Project was launched, which is being led by Norway and the Agency for Public Management and eGovernment (DiFi) during 2018-2020.

- Track 2: Nordic SmartGovernment, led by the Danish Business Authority, seeks to develop a new digital infrastructure that will streamline interactions between business and government via the automated exchange of business data (for more details visit https://nordicsmartgovernment.org).

- Track 3: Data-driven innovation, led by Nordic Innovation, includes the Hack4Norden challenge that aims to support the development of companies using data in new and innovative ways (for more information, see Nordic Innovation, 2016).

The project also resulted in the comprehensive report The Nordic Digital Ecosystem: Actors, Strategies, Opportunities. The research found that, although the Nordic countries share common goals, they are working in quite different ways to achieve these goals (van Marion and Honerud Hovland, 2015). As such, the authors suggest that bilateral or trilateral co-operation may be a more fruitful starting point (van Marion and Honerud Hovland, 2015). In a survey informing the report, most respondents ( $80 \%)$ stated that their organisation was involved in Nordic collaboration of some kind, but even more (90\%) believed that potential exists for future co-operation. Interestingly, despite all five Nordic countries reporting working on, or planning to begin work on, a digital strategy, none had plans to include a Nordic agenda in these strategies (van Marion and Honerud Hovland, 2015). Finding a common platform from which to negotiate in the EU arena was noted as a particular priority for collaboration work.

The bilateral co-operation recommended in the report is already evidenced at a regional scale through cross-border co-operation, which forms a vital part of Nordic co-operation. By way of exploring digitalisation in the context of cross-border co-operation, Nordregio will collaborate with Svinesundskommittén (a Swedish-Norwegian cross-border organisation) to conduct a crossborder study around the theme of digitalisation as a tool for blue growth and sustainable Nordic regional development. 
Other relevant reports taking a pan-Nordic perspective include:

Digitalisation and Automation in the Nordic Manufacturing Sector-Status Potentials and Barriers (Iris Group, 2015). This report provides an overview of the Nordic manufacturing sectors, highlighting their similarities and differences and looking into the status and potentials for digitalisation from both business and political perspectives.

- Nordic Labour Markets and the Sharing EconomyReport from a Pilot Project (Dølvik and Jesnes, 2017). This report was funded by the Labour Market Committee of the Nordic Council of Ministers and is based on background reports prepared by experts in each of the five Nordic countries. Its aim was to develop a knowledge base from which to consider the potential impact of the sharing economy on Nordic labour markets, with a view to developing future Nordic studies.
Catching Up With Society-A Digital Reality Check for Nordic NGOs (Accenture, 2017). This report examines the digital readiness of 60 non-government organisations (NGOs) (15 each from Denmark, Finland, Norway and Sweden) based on a digital performance index, interviews with stakeholders that aimed to tap into their unmet needs and a creative workshop with Nordic NGOs to innovate new services. The findings set out a roadmap for NGOs to catch up and thrive using digital technologies.

\subsection{Digitalisation policy in the Nordic countries and independent territories}

All Nordic countries have adopted digital agendas or strategies at the national level in some form or another. Table 1 provides an overview of these policies, highlighting the national priorities and the regional policies in each country. The text that follows provides a more detailed overview of these themes for each country and the independent territories.

\begin{tabular}{|c|c|c|c|}
\hline Country & $\begin{array}{l}\text { Relevant agendas and } \\
\text { programmes (for a full list, } \\
\text { check each country separately) }\end{array}$ & Main themes and focus areas & Regional agenda \\
\hline Denmark & $\begin{array}{l}\text { Digital Strategy 2016-2020: A } \\
\text { Stronger and More Secure Digital } \\
\text { Denmark } \\
\text { Strategy for Denmark's Digital } \\
\text { Growth (2018) }\end{array}$ & $\begin{array}{l}\text { Boosting growth (trade and } \\
\text { industry) } \\
\text { Effective and user-centric public } \\
\text { sector and services to businesses } \\
\text { and citizens } \\
\text { Digital skills for all }\end{array}$ & $\begin{array}{l}\text { Regional digital agendas } \\
\text { contribute to national } \\
\text { goal setting. These are } \\
\text { often sector-specific, e.g., } \\
\text { regarding e-health } \\
\text { Support for digital } \\
\text { enhancement of small- } \\
\text { to-medium enterprises } \\
\text { (SMEs) (SME: } \\
\text { Digital) and digital skills } \\
\text { development in the fields } \\
\text { of science, technology, } \\
\text { engineering and } \\
\text { mathematics }\end{array}$ \\
\hline Finland & $\begin{array}{l}\text { The Finnish Government } \\
\text { Programme (2015) } \\
\text { Digital Agenda 2011-2020: } \\
\text { Productive and Inventive Finland }\end{array}$ & $\begin{array}{l}\text { Digitalised public services } \\
\text { Growth environment for future } \\
\text { digital businesses; includes } \\
\text { information security }\end{array}$ & $\begin{array}{l}\text { No push for special } \\
\text { regional digital agendas } \\
\text { from the national level. } \\
\text { Some regions and } \\
\text { municipalities have } \\
\text { drawn up digital agendas } \\
\text { by their own initiative }\end{array}$ \\
\hline
\end{tabular}




\begin{tabular}{|c|c|c|c|}
\hline Iceland & $\begin{array}{l}\text { Iceland } 2020 \\
\text { National Cyber Security } \\
\text { Strategy 2015-2026 } \\
\text { Green Paper on Statistics, } \\
\text { Registration and Information } \\
\text { (2018) }\end{array}$ & $\begin{array}{l}\text { Focus on e-participation and } \\
\text { e-government } \\
\text { Better and more digital public } \\
\text { services } \\
\text { Digital infrastructure including } \\
\text { interoperability between IT } \\
\text { systems }\end{array}$ & $\begin{array}{l}\text { No specific focus on } \\
\text { digitalisation in the } \\
\text { municipalities, but high- } \\
\text { speed broadband for } \\
\text { everyone by } 2020 \text { is a } \\
\text { priority. }\end{array}$ \\
\hline Norway & $\begin{array}{l}\text { Digital Agenda for Norway: ICT } \\
\text { for an Easier Everyday Life and } \\
\text { Increased Productivity (2016) } \\
\text { White Paper } 27 \text { (2016-2017): The } \\
\text { Industry-Greener, Smarter and } \\
\text { Creative } \\
\text { Digitalisation Strategy for } \\
\text { Municipalities and Counties } \\
2017-2020 \\
\text { Digital21 (2017-2018) is the } \\
\text { government's cross-sectoral } \\
\text { expert group, recommending } \\
\text { strategies for furthering } \\
\text { digitalisation in the area of } \\
\text { growth in industry and businesses }\end{array}$ & $\begin{array}{l}\text { Digital public services and } \\
\text { efficient public sector } \\
\text { Develop the digital technological } \\
\text { infrastructure that the business } \\
\text { sector will require in the future } \\
\text { Digital competencies and skills } \\
\text { Cybersecurity }\end{array}$ & $\begin{array}{l}\text { The Association of Local } \\
\text { and Regional Authorities } \\
\text { has encouraged } \\
\text { municipalities and } \\
\text { regions to formulate } \\
\text { digital strategies } \\
\text { individually or in } \\
\text { collaboration. Regional } \\
\text { or municipal digital } \\
\text { agendas contribute to } \\
\text { national goal setting }\end{array}$ \\
\hline Sweden & $\begin{array}{l}\text { Digital Agenda, For a Sustainable } \\
\text { Digitalised Sweden (2017) } \\
\text { Digital First Policy for the } \\
\text { Digitalisation of the Public Sector } \\
\text { (2015-2018) } \\
\text { Digital Agenda, ICT for Everyone } \\
\text { (2011) } \\
\text { Digilyft (2016-2019) stimulates } \\
\text { increased digitalisation of SMEs } \\
\text { in the industrial sector }\end{array}$ & $\begin{array}{l}\text { Digital skills } \\
\text { Digital security } \\
\text { Digital innovation } \\
\text { Digital management } \\
\text { Digital infrastructure }\end{array}$ & $\begin{array}{l}\text { Regions were encouraged } \\
\text { to develop their own } \\
\text { digital agendas drawing } \\
\text { from the } 2011 \text { National } \\
\text { Digital Agenda, and } \\
\text { almost all regions have } \\
\text { done it. Regional agendas' } \\
\text { biggest priority areas } \\
\text { lay in infrastructure and } \\
\text { e-services }\end{array}$ \\
\hline Greenland & $\begin{array}{l}\text { The Digital Society: National } \\
\text { Digitalisation Strategy 2018-2021 }\end{array}$ & $\begin{array}{l}\text { Digitalisation of public services } \\
\text { to promote quality of life and } \\
\text { business development } \\
\text { Security and privacy } \\
\text { One IT architecture }\end{array}$ & $\begin{array}{l}\text { The implementation of } \\
\text { the digitalisation } \\
\text { strategy is expected } \\
\text { to lead to increasing } \\
\text { connectivity and } \\
\text { accessibility of services } \\
\text { and increasing digital } \\
\text { opportunities for citizens } \\
\text { and businesses across } \\
\text { Greenland }\end{array}$ \\
\hline $\begin{array}{l}\text { The Faroe } \\
\text { Islands }\end{array}$ & $\begin{array}{l}\text { The National Digitalisation } \\
\text { Programme of the Faroe Islands } \\
\text { (2015) }\end{array}$ & $\begin{array}{l}\text { Digitalisation of public services } \\
\text { Increasing efficiency in the } \\
\text { public sector } \\
\text { Increasing the competitiveness, } \\
\text { growth, and production strength } \\
\text { IT architecture }\end{array}$ & $\begin{array}{l}\text { Digitalisation efforts in } \\
\text { the municipalities are } \\
\text { focused on addressing } \\
\text { the demographic changes } \\
\text { and promoting growth in } \\
\text { the IT industry }\end{array}$ \\
\hline $\begin{array}{l}\text { Åland } \\
\text { islands }\end{array}$ & $\begin{array}{l}\text { The Digital Agenda (2012) } \\
\text { The IT Strategy (2018) } \\
\text { The IT Strategy 2018-2020 for } \\
\text { the Education Sector on Aland }\end{array}$ & $\begin{array}{l}\text { E-administration and } \\
\text { digitalising public services } \\
\text { Co-operation in IT support and } \\
\text { IT services } \\
\text { Green IT and developing digital } \\
\text { infrastructure }\end{array}$ & $\begin{array}{l}\text { Digitalisation is seen as } \\
\text { a tool to increase the } \\
\text { attractiveness of the } \\
\text { Åland Islands in } \\
\text { general, including e.g., } \\
\text { young people }\end{array}$ \\
\hline
\end{tabular}




\subsubsection{Denmark \\ Priority areas}

- Trade and industry must tap into the potential for growth inherent in digitalisation

- The best conditions for digital transformation of business (regulation)

- Everyone should be equipped to operate in the digital transformation

- The public sector shall deliver digital services to businesses and citizens

\section{Key policies/strategies}

- Digital Strategy 2016-2020 A Stronger and More Secure Digital Denmark (2016)-sets the course for Danish public sector digitisation efforts and their interaction with businesses and industries; contains 33 initiatives

- Strategy for Denmark's Digital Growth (2018)

- Danish Cyber and Information Security Strategy 2018-2021

- Strategy for Digital Welfare 2013-2020 Empowerment, Flexibility and Efficiency-accelerates the use of ICT and welfare technology in front-line public service delivery

- Research and Innovation Strategy, DenmarkReady for the Future (2017)

\section{Key actors (steering groups/committees)}

- The Agency for Digitisation (Digitaliseringsstyrelsen) under the auspices of the Ministry of Finance, 2011-responsible for the implementation of digitalisation in the public sector

- The Ministry of Industry, Business and Financial Affairs and the Danish Business Authority are responsible for business-focused digital initiatives in co-operation with several ministries, e.g., the Ministry of Higher Education and Science

- The Government's Disruption Council-Partnership for Denmark's Future: how to maintain a robust labour market when many jobs are transformed by digitisation

The Agency for Digitisation was established in 2011 under the auspices of the Ministry of Finance to oversee the overall implementation of the Government's digital objectives. Digitalisation initiatives cut across policy areas and levels of government, while the Ministry of Industry, Business and Financial Affairs and the Danish Business Authority hold overall responsibility for digital growth initiatives. Below, two key strategies for public and private sector digitalisation are introduced.
The Digital Strategy 2016-2020, A Stronger and More Secure Digital Denmark is a joint strategy created collaboratively by the government, municipalities and regions, which therefore binds all levels of public administration. Joint municipal and regional digital strategies and sector-specific strategies, such as the Strategy for Digital Welfare 2013-2020 (The Danish Government, 2013) are also available. A steering committee has been established to ensure co-ordination and adaptation of the digital strategy and realisation of goals by central, regional and local governments.

With the Strategy for Denmark's Digital Growth, the government establishes directions for Denmark to create the best framework to enable businesses to utilise the opportunities inherent in digital transformation. The strategy has three overall objectives: 1. trade and industry must tap into the potential for growth inherent in digitalisation to ensure that Danish businesses are among the best in Europe when it comes to the use of digital technology; 2 . creating the best conditions for digital transformation of business, including addressing regulatory barriers; and 3. a goal for the Danish people to become the most digitally prepared within the $\mathrm{EU}$, ready to operate in the digital transformation, with education and continuous training to ensure that everyone is ready for the labour market of the future. To assist in achieving the objectives, there are six main strategic focus areas, as follows: 1. establish a digital hub for stronger digital growth; 2. digital enhancement of SMEs; 3. ensure digital skills for all; 4. utilise data as a driver of growth in trade and industry; 5 . agile regulation of trade and industry; and 6. strengthened cybersecurity in companies.

A total of 38 specific initiatives are introduced with the Digital Growth Strategy. DKK 75 million has been allocated in 2018, followed by DKK 125 million each year until 2025 and DKK 75 million in perpetuity for the implementation of the strategy's initiatives. The pool is intended as 'seed capital' that will help to establish a range of initiatives (The Danish Government, 2018: 10).

\section{Regional perspective}

Through their interest organisations, Danish Regions (Danske Regioner) and Local Government Denmark $(K L)$, the regions and municipalities provided input to the Digital Growth Strategy. For example, Danish Regions produced specific recommendations aimed 
at solving the challenges involved in the digital transition of the health-care sector.

Going forward, six cross-municipal business support centres (including six sub-branches) will play a role in engaging SMEs in relevant initiatives and provide input to future publicly funded, decentralised business support initiatives. This is part of a reform of the Danish business support system from 1 January 2019, under which the regions no longer will responsible for business development.

The Danish Government's digital growth initiatives do not target specific regions, with the intention being that they will be implemented across the country, and will involve the education system, the business support system and other systems. Below, two examples of the implementation of the strategic focus areas are briefly outlined, namely 'digital enhancement of SMEs', occurring through SME:Digital, and 'digital skills for all', occurring through the Technology Pact.

SME:Digital: The initiative addresses the digital competence challenges that SMEs in particular are facing. SME:Digital will focus on business needs by offering: economic support to SMEs seeking private consultancy and assistance in the development of digital transformation business cases; better potential for e-commerce and e-exports via an e-commerce centre; improving the skills of business leaders; and a digital design consultancy..$^{10}$ SME:Digital will be accessible through the onepoint-of-entry platform that will be launched in 2019 and will include an overview of business support measures (e.g., grants, loans, equity).

The Technology Pact: The government has established a Technology Pact in co-operation with trade, industry, educational institutions and others to provide initiatives aimed at strengthening the of science, technology, engineering and mathematics (STEM) skills of the population. The Technology Pact has been set up with inspiration from a successful initiative in the Netherlands. The Government's primary objectives in establishing the Technology Pact are to get more people interested in STEM, encourage more people to educate themselves within STEM and enable more people to apply STEM skills in their job. The Technology Pact is a platform where initiatives can be instigated, developed and expanded to inspire and motivate more people to work with STEM and apply these

10 For further information, see https://em.dk/english/publications/2018/strategy-for-denmarks-digital-growth skills to innovation and business development. ${ }^{11}$ Role models and ambassadors will be used actively in the initiatives. Although initiatives originate centrally, the main aim is for the Pact to be implemented through bottom-up initiatives.

\subsubsection{Finland Priority areas}

- Digitalised public services-public services will be user-responsive and primarily digital to achieve a productivity leap in public administration

- Creating a favourable operating environment for digital services and new business models (with a special focus on big data and robotisation); includes information security

\section{Key policies/strategies}

- Finnish Government Programme (2015)-overarching document guiding all activities of the Finnish Government for 2015-2020; there are five strategic priorities, one of which is 'digitalisation, experimentation and deregulation'

- Digital Agenda 2011-2020: Productive and Inventive Finland-details the steps and actions required to update the National Information Society Strategy 2007-2015, and encourages different sectors to formulate digital strategies; however, it does not serve as an action plan

\section{Key actors (steering groups/committees etc.)}

- Ministry of Transport and Communications (responsible for the Digi 2, which involves creating a growth environmental for digital business operations, as well as for broadband and the promotion of 5G), Ministry of Economic Affairs and Employment, Ministry of Finance (digitalising public sector services)

- JulkICT (public sector ICT department)-responsible for the overall development of digital services of public administration and the integration of joint development projects

- DigiNYT (monitoring group)-monitors and coordinates (the implementation of) public sector projects related to digitalisation and automation following the Finnish Government Programme's objectives in digitalisation

11 For further information, see http://www.teknologipagten. $\mathrm{dk} /$ teknologipagten/om-teknologipagten and https://em.dk/ english/publications/2018/strategy-for-denmarks-digital-growth. 
Business Finland-innovation funding and programmes, includes a programme for digitalisation. Business Finland is a new organisation formed from Tekes

The Finnish Government Programme (2015) lays out five strategic priorities of which 'digitalisation, experimentation and deregulation' addresses the most relevant national policy objectives regarding digitalisation. Work with digitalisation is divided into two key projects: 'Digi 1', which focuses on digitalising public services and 'Digi 2', which focuses on creating a growth environment for digital business operations. In addition, digitalisation is mentioned as a cross-cutting theme in the Government Programme.

Actioning digitalisation is largely the responsibility of the Ministry of Transport and Communications, the Ministry of Economic Affairs and Employment and the Ministry of Finance. The exact roles and responsibilities of each ministry within the theme is yet to be resolved. Officially, the Min- istry of Transport and Communications is responsible for realising the objectives of Digi 2; in reality, the other two ministries have increased their roles in promoting the Digi 2 objectives.

At the Ministry of Economic Affairs and Employment, digitalisation work is realised in various themes that touch upon data and digital or platform economies. Current programmes and projects include the Al programme, the transport sector growth programme and work in advancing the digital platform economy. In addition, the Ministry is working on a growth programme for cybersecurity. The broad objectives are that digitalisation would be utilised as efficiently as possible in all economic affairs and all lines of business and that businesses should, wherever possible, grasp the new possibilities that digitalisation brings about.

The Ministry of Economic Affairs and Employment is responsible for policy preparation, legislative work and raising awareness, as well as the allocation of its funds and steering of its bureaus

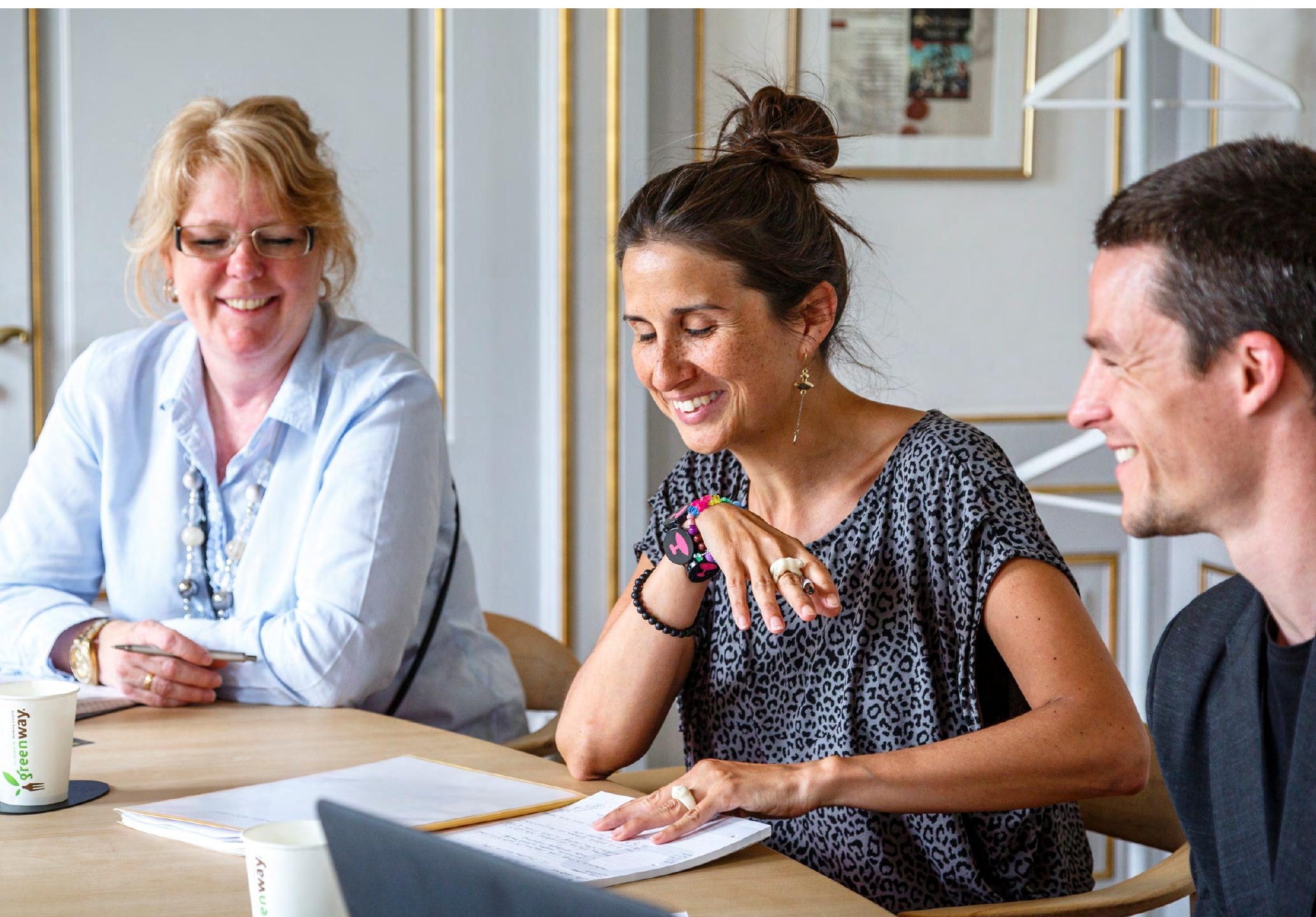


with regard to the digitalisation issues. Business Finland, which supports companies in digitalisation, and the Technical Research Centre of Finland, which promotes advancement of digitalisation on the research and innovation side, are central players in actual operations.

At the national level, the main opportunity for digitalisation is through the growth of companies that utilise $\mathrm{Al}$ and other forms of digitalisation or that seek to develop their operations by adding digital layers. Further, automatisation of some operations may enable businesses to relocate their activities back to Finland. The concerns mostly relate to the speed of change and whether Finland as a society is ready or will be agile enough at the time when the changes take place, especially in the cases of job losses as a result of automation. In a 2018 report on work in the age of $\mathrm{Al}$ developed by the Ministry of Economic Affairs and Employment of Finland, it is highlighted that digitalisation engenders re-education needs, but that the change itself is not a threat for Finland (The Ministry of Economic Affairs and Employment of Finland, 2018).

In conclusion, digitalisation is not a priority per se in Finland, but it has been identified as a key means to achieve growth in the business sector. Even though an all-encompassing digitalisation strategy does not yet exist, digitalisation is a priority in sectoral strategies (e.g., education). Digitalisation is seen as a great opportunity, with the Finnish attitude being 'full speed ahead'.

\section{Regional perspective}

There is no push to developing regional digitalisation agendas at the national level. However, some regions have introduced their own digital agendas (e.g., Lapland in 2013) supporting aspects of digitalisation, such as broadband coverage and digital skills development. In addition, digital programmes have been drawn up and implemented at the municipal level (e.g., in Helsinki and Tampere). In 2018, Helsinki recruited a chief digital officer to guide the digital regeneration of the city.

Another example of national and regional co-operation is The Six City Strategy-Open and Smart Services (2014-2020), under which the state promotes collaboration on developing smart city services among the six largest cities in Finland and contributes financially to this work. However, there is little scope to add new openings in the developmental work during the remainder of the project. Further, regional perspectives have been taken into consideration, for instance, in the Smart Countryside project. One of the project's key aims is to support living and entrepreneurship in rural areas through digitalisation and experimentation.

The spearheads of the national 'Digi 2' work address broad global issues such as platform and data economy but with weak or no links to regions. Thus, there is not much interaction between the regions and the national level. However, the policies at the EU level may encourage closer collaboration. An example is the creation of a network of digital innovation hubs, under which hubs could be located in the municipalities.

\subsubsection{Iceland}

\section{Priority areas}

- Digital services (island.is)

- Digital infrastructure, including interoperability between IT systems

- Consolidating data centres

\section{Key policies/strategies}

- Green Paper on Statistics, Registration and Information (Grænbók um hagskýrlugerð, grunnskrár og upplýsingamál) (2018)

- Iceland 2020-a general governmental policy statement that establishes Iceland's digitalisation goals as lying in the spheres of e-participation and e-government

- Icelandic National Cyber Security Strategy 2015-2026-addresses the protection of Icelandic infrastructure starting from knowledge development and skills in digital security

\section{Key actors (steering groups/committees)}

- Ministry of Finance has the overarching responsibility for digitalisation work

- Information Society Taskforce-co-ordinates central e-government projects and operates under the auspices of the Ministry of the Interior (Transport and Local Government)

- Registers Iceland-operates most of the relevant common e-government solutions and operational measures

- Cyber Security Council-supervises the implementation of the National Cyber Security Strategy

Following Iceland's most recent change of government in December 2017, the responsibility for digitalisation shifted from the Ministry of Transport and Local Authorities to the Ministry of Finance. 
This means that, for the first time in many years, all ICT is under one ministry. A Green Paper has been developed, which will be followed by a White Paper and then by policies. The Green Paper lays the foundation for a long-term strategy that will be revised and renewed each year. This is based on a recognition of the rapidly changing nature of digitalisation. The focus areas in the Green Paper include increasing synergies and data flow between public systems and making electronic self-service the first option in public service. Emphasis is also placed on the public system to fulfil demands for security and privacy and enhancing transparency in administration.

There are three parts to the digitalisation approach. The first is centralising and renewing digital services through the national portal, island.is. There is high demand from citizens for such services as well as large financial and environmental incentives to cut down on physical correspondence (e.g., sending letters). The second part of the approach focuses on digital infrastructure, more specifically, interoperability between IT systems. This work is occurring through collaboration with Finland and Estonia to test the X-Road infrastructure. ${ }^{12}$ The $X$-Road ensures interoperability between IT systems. Rather than having a connection point to point between systems, it provides a service layer taking care of all communication between various IT systems. This focus area also seeks to centralise IT architecture-moving from 160-170 institutes with their own IT architecture and policy to one centralised IT architecture. The final priority in the digitalisation approach is the consolidation of data centres and a move to purchasing licences through one central contract. For example, previously there were approximately 6 000 contracts between Microsoft and the Icelandic State; following this work, there will only be two.

Iceland is working closely with the other Nordic countries on implementing the declaration The Nordic-Baltic Region: A Digital Front-Runner, as well as electronic identification. Iceland has very strong infrastructure regarding electronic signatures and identification cards. Al, $5 \mathrm{G}$ and electronic procurement are also important topics. Iceland will have the presidency of the Nordic Council of Ministers in 2019 and will continue to prioritise these areas, as well as taking a broader perspec- tive and examining, e.g., how digitalisation can support tourism, youth inclusion and a cleaner environment.

\section{Regional perspective}

Iceland does not have a formal level of governance between the local and national levels. However, eight Regional Associations of Local Authorities operate around the country and deal with regional planning issues. These associations do not currently have a strong focus on digitalisation. Local governments have a great deal of independence in Iceland. Nevertheless, there is strong co-operation between the municipal and national levels on digitalisation. Municipalities have the option of using the systems developed at the national level, although they are not required to do so. This is particularly beneficial for small municipalities without the resources to develop these systems themselves. The municipalities will also use X-Road.

Given its sparsity, connectivity is key issue in Iceland and having high-speed broadband for everyone by 2020 is a priority. Many communities are lagging behind in this regard. Another concern is to ensure that rural areas can benefit (or at least not lose) from the broader changes brought about by digitalisation. Although it is possible to find individual cases of connectivity enabling innovation in small communities, the majority of new jobs brought about through digitalisation are found in the urban centres. As such, there is a concern that rural communities may become simply 'receivers' when it comes to technology, with online services gradually replacing physical ones. Although this may improve access to services in the short term, the related job losses may have a negative impact on the sustainability of rural communities in the long term. One strategy to counter this threat is a new initiative that involves advertising a set portion of government jobs with no fixed location. In other words, someone living in any part of the country could apply for such a job and, if successful, work remotely. It is too early to judge the success of this initiative but it will be interesting to observe the outcomes. Another approach to decentralisation is to have different teams located in different parts of the country; as yet, no concrete initiatives have occurred in this area.

12 e-estonia interoperability services. 


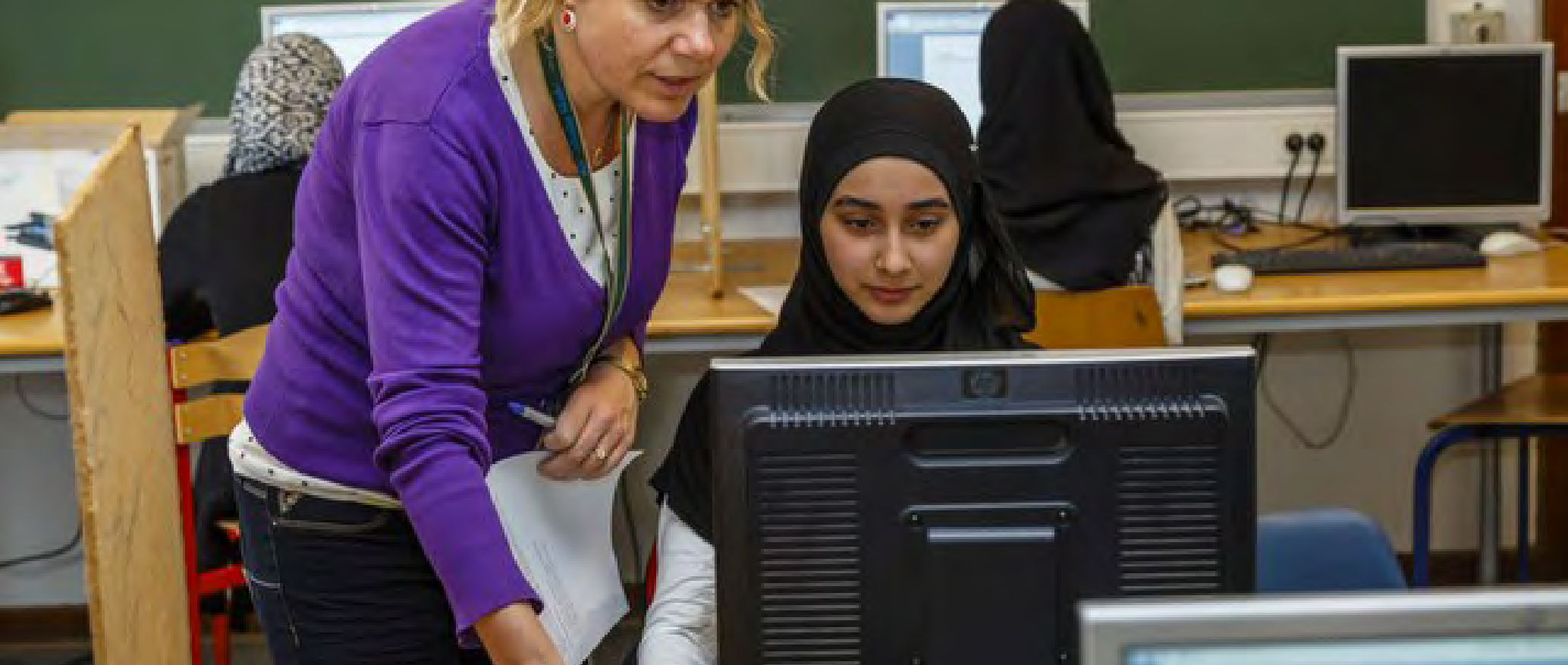

Computer-based learning has been widely used for language training of migrants in Nordic countries. Source: Yadid Levy / norden.org

\subsubsection{Norway Priority areas}

Develop the digital technological infrastructure that the business sector will require in the future

Ensure cybersecurity

Ensure sufficient and necessary competences and skills

- Develop a public framework that enables innovation and digitalisation

- Digital public services

\section{Key policies/strategies}

- White Paper 27 (2016-2017): The IndustryGreener, Smarter and Creative highlights the importance of digitalisation and technology development as part of the future Norwegian industrial model

Digital21 (2017-2018) is the government's crosssectoral expert group, recommending strategies for furthering digitalisation in the area of growth in industries and businesses

- Digital Agenda for Norway: ICT for an Easier Everyday Life and Increased Productivity (2016) presents the Government's overall policy on how Norway can utilise ICT in society's best interest

- Digitalisation Strategy for Municipalities and Counties 2017-2020 (Digitaliseringsstrategi 20172020) by the Norwegian Association of Local and Regional Authorities (2017)-a strategy targeted to local and regional public officials and politicians on digitalisation

\section{Key actors (steering groups/committees)}

- Digitalisation Council, 2016-helps government agencies in all phases of their digitisation projects, ensuring that projects run on time and that their scope is in line with their budget

- Difi, 2008-co-ordinates between municipalities, government agencies and the state in relation to digitalisation work

- The Norwegian Association of Local and Regional Authorities-co-ordinates between municipalities and the state in digitalisation work

- The Ministry of Trade, Industry and Fisheries, the Ministry of Education and Research and the Ministry of Local Government and Modernisation

Digitalisation is high on the Norwegian national agenda, as exemplified by the recent attention given to digitalisation as a trend impacting various factions of Norwegian society (cf. Meld. St. 27 2016-2017; Meld St. 29 2016-2017; Digital21; Meld St. $272015-2016)^{13}$. In 2016, the Norwegian government set up a Digitalisation Council to aid dialogue on digitalisation processes and overlapping policy

13 Meld St. (Melding til Stortinget in Norwegian) stands for Government White Paper 
areas across ministries to facilitate potential synergies and avoid conflicts of interest. Issues may be brought forward by ministers, interest groups or private companies for consideration. The establishment of such a digitalisation council without a political mandate to make decisions is considered important in ensuring an agile approach to digitalisation.

In 2016, the Norwegian government produced the White Paper Digital Agenda for Norway (Meld St. 27 2015-2016), which has been the guiding strategy for the past few years. The White Paper is closely aligned with the EU's digitalisation policies for a single market, which would operate through the Norwegian membership to the European Economic Area. The international aspects of the digital agenda in Norway are considered very important and the Nordic co-operation is considered to be highly valuable.

In 2017, the government delivered another White Paper The Industry-Greener, Smarter and Creative (Meld St. 27 2016-2017), which sketches out opportunities and challenges for Norwegian industry, and relevant government objectives (Ministry of Trade, Industry and Fisheries, 2017). Digitalisation plays an important role in this work, especially with regard to business development. The White Paper emphasises the cross-sectoral nature of digitalisation and its impact on the labour market, as it calls for a stronger focus on the development of skills and competencies required for the future labour force to maintain a competitive Norwegian industrial structure. Green perspectives are also at the forefront of this White Paper, as they are considered part of the strategic development of industry and because it is considered that they will be enabled by digitalisation.

This 2017 White Paper (Meld St 27 2016-2017) laid the foundation for establishing the Digital21 committee and process (Digital21, 2018). Digital21 was composed of six expert groups, with representatives from the universities and research centres, companies and branch organisations, alongside a steering committee. In September 2018, it presented a compendium of recommendations to the government on facilitating digitalisation among businesses. The group proposed four areas of strategic importance for Norwegian businesses to capitalise on digitalisation opportunities by utilising new expertise, technology and research. The four areas were based around Al, big data, the loT and autonomous vehicles. The group's recommendations encourage the government to think differently about organisation, emphasising cross-sectoral thinking for building skills and competencies, standardising solutions, cross-sectoral innovation and regulations that work across sectors. The Digital21 process suggested a common platform for synchronising efforts across different ministries, including the Ministry of Trade, Industry and Fisheries, the Ministry of Education and Research and the Ministry of Local Government and Modernisation, to break down traditional silos.

\section{Regional perspective}

The Norwegian Association of Local and Regional Authorities is a key co-ordinator between municipalities, counties and the government, and specific agreements are made between these actors (e.g., on guidance services for citizens) as most public sector services are municipal. The Association of Local and Regional Authorities has a Digitalisation Strategy 2017-2020 for municipalities and counties (Digitaliseringsstrategi 2017-2020), in which it reflects on the priorities set by the national Digital Agenda (2016). It also has an advisory committee on digitalisation (KOMMit). This strategy encourages regions and municipalities to formulate digitalisation strategies. Most counties currently have digital strategies that set an overall agenda for the region, and these tend to focus on the internal functions and the bettering of digital public services for citizens.

There is currently little collaboration between the national and regional levels when it comes to policy making for digitalisation, although, in some cases, digital solutions developed through regional co-operative platforms trickle upwards towards the national level. One such example is the collaboration with County Municipal Optimal Services (Fylkeskommunale Optimale Tjenester). There are also good examples of the regions lobbying the government to provide them with digital infrastructure, e.g., in the case in Finnmark. In terms of developing digital tools for bettering public services, the municipalities are in forefront. A good example is SvarUT, a digital solution developed in 2011 by Bergen Municipality to improve dialogue with residents (e.g., digital communication in relation to health and child welfare services and building permits). SvarUT subsequently became a standardised solution on the national digital platform Altinn 
(Sveinbjornsson and Jorgenrud, 2013) after signing an agreement with Altinn and the Norwegian Association of Local and Regional Authorities. ${ }^{14}$

Given the increased focus on accelerating the digitalisation of industry and trade seen in Digital21 and the White Paper 27 (2016-2017), coupled with the recent regional reform and the new tasks and administrative mandate devolved to the regional level, it is likely that collaborations between the national and regional levels on digitalisation will be strengthened further.

The regional reforms planned for 2020 in Norway envisage a reduction in the number of regions from 19 to 11 , to provide the critical mass required to take on new tasks and responsibilities and ensure service quality (The Norwegian Government, 2018). Digitalisation in the context of the forthcoming reform is closely tied to the regional longterm perspectives on education, culture, health, business development and infrastructure. With regards to education, digitalisation may be a positive force for ensuring equal opportunities throughout a larger region. For example, public libraries in Troms have been working towards solutions through regional collaborations for students living in sparsely populated areas, given that around $40 \%$ of all long-distance students use public libraries for their studies. The extent to which the regional reform will influence digitalisation at the regional level is uncertain, although digitalisation may be an important facilitator in ensuring good public services in the new, geographically larger regions.

\subsubsection{Sweden \\ Priority areas}

- Digital skills: everyone should be familiar with digital tools and services to participate in the digital development

- Digital security: people, companies and organisations should trust and be comfortable with the use of digital services

- Digital innovation: the conditions for new or better solutions that provide value for the environment, society, companies and individuals are created and spread

- Digital management: operations should be streamlined, developed and improved through control, measurement and follow-up

14 Altinn is a digital dialogue platform for the development of digital public services and an Internet portal for businesses, private individuals and public agencies.
Digital infrastructure: the importance of enhancing hard and soft infrastructure is emphasised to allow data to be transported as efficiently as possible

\section{Key policies/strategies}

- Digital Agenda for Sweden: For a Sustainable Digitalised Sweden (2017)-outlines how digitalisation policy will contribute to competitiveness, full employment and economically, socially and environmentally sustainable development

- Digital First policy for the digitalisation of the public sector (2015-2018)-this is a programme to renew the public sector, with a focus on IT and e-governance. The policy also aims to reduce differences in the availability and quality of digital services across municipalities and regions

- Digilyft (2016-2019) stimulates increased digitalisation of SMEs in the industrial sector

- Digital Agenda for Sweden: ICT for everyone (2011)-collated ongoing activities into a cohesive strategy to ensure the full potential of digitisation and worked as a point of departure for the creation of regional agendas

\section{Key actors (steering groups/committees)}

- The Agency for Digital Government, 2018-will co-ordinate and support the overall digitisation in the public sector

- Digitalisation Council, 2017-promotes the implementation of the government's digitalisation policy and co-ordinates between different governmental and public organisations and subject areas and reaches also out to private actors

- Swedish Association of Local Authorities and Regions-ensures that strategies are turned into initiatives and actions, e.g., in the fields of education and e-health

- Swedish National Agency for Growth-administers and runs several support programmes (including Digilyft and regional digitalisation co-ordinators)

Digitalisation is a horizontal priority across all ministries and government agencies in Sweden. The key responsibility for formulating digital policy and co-ordinating the digitalisation work across the different ministries in Sweden lies within the Ministry of Enterprise and Innovation.

A digital strategy, For Sustainable Digital Transformation in Sweden, was launched by the government in 2017. The overall goal of Sweden's 
digital strategy is to establish itself as a world leader in harnessing the benefits of digitalisation. The strategy sets out several target areas to achieve this goal: digital skills, digital security, digital innovation, digital leadership and digital infrastructure. The strategy argues that there is a need to promote not only smart cities but also sustainable rural areas through digitalisation, and stresses the importance of enhanced local and regional commitment to and engagement in digitalisation. It promotes linking the regional development strategies in each county to the digitisation policy and co-operation across various stakeholders (Government Offices of Sweden, 2017). Although the strategy sets out the overall direction and vision for Sweden, it is not supported by concrete policy actions.

\section{Regional perspective}

The local and regional actions supporting digital development are highlighted as crucial for the successful implementation of the Sweden's digital strategy. At the same time, the regions and municipalities are independent in their digitalisation approaches and priorities. Thus, the role of the national-level government is to provide direction, institutional support and funding for digitalisation work in the regions.

With the presentation of the National Digital Agenda (2011), regional actors were invited to sign a voluntary letter of intent to show their support for the Agenda's goals and to indicate that they would draw up a regional digital agenda. All 21 counties have signed the letter of intent, but not all have developed regional digital agendas yet. Digital infrastructure and e-services are the biggest priority areas in regional agendas, as the region's hold responsibility for broadband infrastructure in Sweden.

Recently, the Swedish government launched a support initiative, which will run until 2020, to appoint regional digitalisation co-ordinators who will improve co-ordination and strategic co-operation between relevant actors in the region (Government Offices of Sweden, 2018). The Swedish National Agency for Growth will act as a secretariat and provide support, e.g., by encouraging networking and the exchange of experiences and skills development among the regional digitalisation coordinators (Government Offices of Sweden, 2018).

The Forum for Sustainable Regional Growth and Attractiveness is the main arena for interac- tion between different levels of government and different types of government actors. The forum takes place four times a year and provides an opportunity to influence national-level policy making via dialogue. Digitalisation issues are among the prominent topics addressed.

\subsubsection{Greenland Priority areas \\ - Digitalisation of public services to promote quality of life and business development}

\section{Key policies/strategies \\ - The Digital Society: National Digitalisation Strategy 2018-2021}

\section{Key actors (steering groups/committees) \\ - The Self-Rule Government \\ - The Greenlandic Agency for Digitalisation (im- plementation)}

The Greenlandic Agency for Digitalisation conducted a survey in 2017 on The Citizen and IT. It revealed that $83 \%$ of the Greenlandic population over 15 years has access to the Internet at home and $89 \%$ have smartphones. This indicators show that Greenland is now in line with the EU averages (Greenlandic Agency for Digitalisation, 2018: 8). While the previous digitalisation strategy for the period 2014-2017 was concerned with developing broadband infrastructure, the current strategy is more focused on facilitating the use of technology by citizens and businesses. The strategy has six focus areas that will be implemented during the period 2018-2021, as follows.

The digital citizen: This area focuses on making it easier for citizens and businesses to report to and collect information from the public authorities through one public portal. 'The digital citizen' also involves developing a cross-border compliant e-ID solution.

Security and privacy: This focus area is about enhancing cybersecurity and enabling Greenland to gain the status of a safe third country in the EU (a status achieved recently by the Faroe Islands). This should facilitate international trade and make it easier to exchange personal data. Therefore, third country approval is of high priority for the Self-Rule Government.

Digital formation: As Greenlandic citizens are lagging when it comes to digital competences, initiatives will be implemented to enhance digital 
skills. There is a separate digitalisation strategy for the public schools.

Digital innovation, entrepreneurship and business: This is elaborated further below regarding implications for regional development.

One IT architecture: As elsewhere in the Nordic region, Greenland has chosen to use the Estonian $\mathrm{X}$-Road system for the public digital architecture. Greenland has selected the closed-source version, which means that it depends on external suppliers for development of its system.

A more digitalised health-care system: Digitalisation of patient records and other reforms are under development in co-operation with partners in Denmark.

\section{Regional perspective}

Overall, the implementation of the digitalisation strategy is expected to lead to a reduction of the effects of physical distance by increasing connectivity and accessibility of services and increasing digital opportunities for citizens and businesses.

Ambitions to attract datacentres and other international investments: The Self-Rule Government has ambitions to attract datacentres from international companies to Greenland. It will not be able to fulfil these ambitions until it has gained the status of a safe third country in the EU. However, it meets three preconditions set out in the digitalisation strategy for establishing datacentres: a large untapped potential to use hydropower to ensure stable electricity and green energy; extensive water/sea resources for cooling; and IT infrastructure, in the form of the sea cable that is connected to Canada and Iceland, where there is plenty of unused capacity. With the establishment of datacentres, broadband traffic will increase and prices for using the Internet (which are comparatively high in Greenland) are expected to decrease.

Promoting digital entrepreneurship and innovation: The strategy sets out the objective to promote an innovative environment for digital entrepreneurship and innovation. Initiatives to implement this objective have not yet been decided. However, there are plans to establish funding opportunities, introduce digital competence development initiatives and organise events to create awareness of opportunities for digital entrepreneurship and innovation.

The strategy has set the objective of increasing the number of IT specialists in the country by
$25 \%$ by 2021 . In connection with the solutions that are developed under the national digitalisation strategy, consideration is given to whether tasks can be solved by local businesses. This is not always possible, with consultancies from outside Greenland being contracted to implement solutions in many cases. However, efforts are being made to anchor the knowledge locally. For example, in the development of the X-Road system, although an Estonian consultancy is managing the project, they are involving locals, who are being trained to take charge of second-and third-level support in running the system once it is completed.

\subsubsection{The Faroe Islands \\ Priority areas}

- Modernise the welfare and services of the Faroe Islands

- Produce preconditions for efficiency in the public sector

- Increase competitiveness, growth and production strength

\section{Key policies/strategies}

- The National Digitalisation Programme of the Faroe Islands (2015)

Key actors (steering groups/committees)

- The Ministry of Foreign Affairs, Trade and Industry and the Ministry of Finance (which jointly developed the strategy)

- A project organisation to implement the strategy

The Faroese IT infrastructure is well developed, and the public IT systems are ready to be interconnected. A large majority (92\%) of the Faroese population have access to the Internet from their homes. The outlying islands have good Internet connection, and nearly everyone has a cell phone (1.2 cell phones per citizen) (Ministry of Foreign Affairs, Trade and Industry and the Ministry of Finance, 2018: 6). However, IT systems in some areas and sectors do not meet modern standards and do not intercommunicate, and the Faroe Islands lag when it comes to digital services and businesses.

The Minister of Foreign Affairs, Trade, and Industry and the Minister of Finance co-operated to develop a digital strategy. A project group was established in 2015, which developed the National Digitalisation Programme of the Faroe Islands for the period until 2021, with the aim of digitalising public services. The programme has four subprojects, as follows. 
Development of an e-ID: This solution is under development in co-operation between the national telecom company and a local IT company and is expected to be ready for use in 2019.

Portal and digital services: The online portal for citizens to access all public services and, in future, private services, such as banks and insurance companies, is under development.

Basic Data: This sub-project concerns the development of the data systems required to support and realise the first two projects, with individual, business, land and GIS data required, among others.

IT architecture: The IT architecture is also used for the first two sub-projects. The Faroe Islands decided to use the Estonian X-Road solution, which has been developed as part of an EU project using open data. ${ }^{15}$ Before deciding which IT architecture to choose, the local IT industry was consulted, giving them the opportunity to influence the process.

Early in the process, the responsible ministries took inspiration from Denmark and Estonia. Discussions with the Digitalisation Authority in Denmark inspired the strategy development phase. The possibilities for using the Danish e-ID solution (NemID) was discussed but rejected by the politicians, who advocated developing their own Faroese solution. As with Finland and Iceland, the Faroe Islands decided to apply the Estonian X-Road solution for their IT infrastructure. As members of the Nordic Council of Ministers for digitalisation (MRDigital), the Faroe Islands are strong advocates for a digitally integrated Nordic region. Cross-border compatible solutions should also make it easier and more attractive for individuals and businesses to move to the Faroe Islands.

\section{Regional perspective}

Promoting growth in the IT industry: The Faroese IT industry has been in decline for some years after the Danish banks decided to centralise their IT departments to Denmark. The Digitalisation Programme provides an opportunity to promote the development of a stronger local IT industry. The Faroe Islands are not a member of the EU, which allows them to set requirements in their public procurement processes. Consequently, in public tenders, they have required that development of IT

15 For more information, see https://news.err.ee/831293/ faroe-islands-look-to-estonian-example-setting-up-own-egovernment-system. solutions will take place on the Faroe Islands or include a local IT supplier and have emphasised that knowledge and solutions be anchored locally, even if they are sourced internationally. This should assist in ensuring the subsequent local management of their systems.

Addressing demographic challenges: Depopulation has been a challenge for the Faroe Islands for a long time. In general, digitalisation of the public system is expected to facilitate creation of new jobs, including on the remote islands. The IT projects have attracted some individuals working abroad in the industry to move back to the Faroe Islands.

Expected challenges with implementation in smaller municipalities: With 27 municipalities on the Faroe Islands, many are very small administrative units, and many have populations with a high proportion of elderly people. The local government association (Føroya Kommunufelag) will take a role in developing suitable solutions to support implementation of the digital systems in smaller municipalities.

\subsection{8 Åland Islands Priority areas}

E-administration that stems from the citizens' needs, e.g., the availability of public services

- Increasing co-operation in IT support and IT services, e.g., co-operation between public authorities

- Green IT, e.g., using less energy

- Digital infrastructure

\section{Key policies/strategies}

- The Digital Agenda (2012), an overarching regulatory document

- The IT Strategy (2018), a regulatory document supporting decisions for organisational development in the IT sector

- The IT Strategy 2018-2020 for the Education Sector on Åland

- störmig.ax, a website where citizens can submit complaints that can have a digital solution

\section{Key actors (steering groups/committees)}

- The Government of Åland-overall responsibility - Åda Ab-responsible for managing and supporting the IT services in the public sector

- The Digital Council (2016-2017)-activities to support the digital transformation

- The Digital Commission (established 2017)responsible for störmig.ax 
Digitalisation has been an important topic on the Åland Islands for several years and makes up a substantial part of the Government of Aland's policy platform. A Digital Agenda was adopted in 2012 with the aim of modernising the society and creating socio-economic opportunities through digital technology. The agenda puts citizens' needs at the centre and focuses primarily on e-administration, organisational service, IT support, green IT and infrastructure. It also promotes increasing efficiency in the public sector by co-ordinating efforts and making it easier for citizens to use welfare services. The agenda was developed in collaboration with Åland's Healthcare, the City of Mariehamn and Åland's Municipal Coalition, and drew inspiration from the digital agendas of Finland, Sweden and the EU.

In 2016, the Government of Åland established a Digital Council with the aim of developing digital actions responding directly to citizens' needs. The Council's final report resulted in the establishment of a Digital Commission in 2017-the primary role of which was to set up website https://stormig. ax/ that helps to resolve digital issues in Åland. On this website the citizens can notify the Aland Government of problems (traffic, maintenance of infrastructure and other issues) and suggest possible solutions. The overall direction for work with digitalisation is set by the Government of Åland and all public authorities and municipalities are responsible for implementation in their area. The private sector plays an important role in delivering systems and services.

A key step in realising the goals of the Digital Agenda was the establishment of Åda AB in 2014, a not-for-profit enterprise responsible for IT services across the public sector. Åda AB offers e-services and various IT functions, as well as managing cooperation between actors to ensure more efficient and effective development of public sector IT solutions. More recently, Åda AB was responsible for developing an IT Strategy for the Government of Aland. The strategy was adopted by the Regional Council in June 2018 and regulates IT development in the public sector (e.g., sustainable recycling of IT equipment). The primary focus of the strategy for 2018 was security and new priorities will be identified each year based on stakeholder workshops.

\section{Regional perspective}

The recently adopted IT Strategy is linked to the Development and Sustainability Agenda for Åland Islands. Digitalisation is employed as a means through which to realise the goal of developing a sustainable society in Åland Islands by 2051 . For example, barkraft.ax, an online platform, is being used to create a dialogue around sustainable development for all who live and work in, or visit, Åland Islands (Government of Åland, 2017).

To adapt to labour market changes, the government is investing in IT training at the higher education level, as well as actively trying to make Åland attractive for young people who have left the territory to study elsewhere. In schools, the IT Strategy 2018-2020 for the Education Sector on Aland is driving the use of digital technologies as a tool to support skill development in areas such as reflection, analysis, problem solving and flexibility. 


\section{Regional cases}

This section presents findings from the five Nordic regional case studies (Map 1) that were implemented in 2018. Each regional case study describes the digitalisation approach and focus areas, collaborations with other actors in the region and beyond in the field of digitalisation, as well as the key challenges and opportunities. The regional case studies are diverse in their practices and initiatives, highlighting the different approaches to digitalisation.

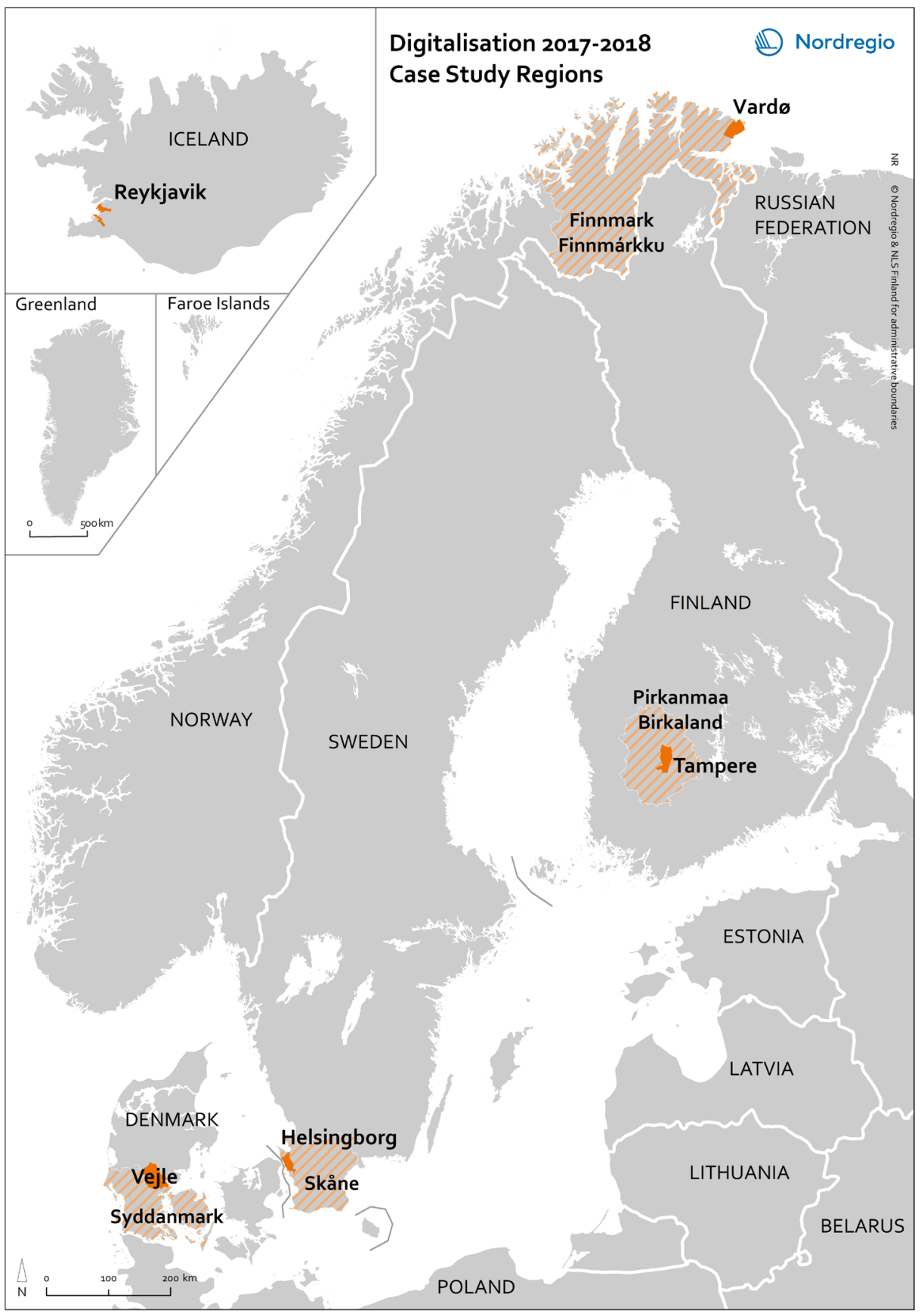

Map 1. Regions examined in the case studies. Source: Eeva Turunen / Nordregio. 


\subsection{REGION OF SOUTHERN DENMARK/VEJLE}

\author{
by Lise Smed Olsen \& Laura Fagerlund
}

\section{About the case study area}

The Region of Southern Denmark (Region Syddanmark in Danish) consists of Southern Jutland and the islands of Fyn and Langeland. It borders with Germany. The administrative centre of the region is Vejle, while the biggest city is Odense. In total, $68.8 \%$ of the labour force work in the private sector, with the food and construction industries employing most people. Tourism is also an important sector in Southern Denmark (Kontur, 2017a). The region is the best-connected region in Denmark in terms of digital infrastructure, which is a considerable strength. Southern Denmark has developed a strong innovation environment and cluster collaboration, with an international impact in the health and welfare and robotics sectors, and strong exports in industrial electronics. The Region of Southern Denmark oversees health care and regional development.

Vejle Municipality is a part of the Region of Southern Denmark and the Triangle Region, which involves a partnership with six neighbouring municipalities to attract residents, businesses and investments to the region (The Triangle Region, 2018). Vejle city itself has around 55000 inhabitants, while the municipality is home to around 114 000 people. Historically, the manufacturing industry has been an important part of Vejle's development. Around $70 \%$ of the citizens in Vejle today are employed in the private sector and, like the Region of Southern Denmark, the biggest sectors are food and construction (Kontur, 2017b). Vejle is strong in city development, sustainability and development of smart city solutions.

\section{Digitalisation approach}

Vejle Municipality does not have a general digitalisation strategy but, as with many other municipalities in Denmark, it has a digitalisation strategy for the education sector, The Digital School 20162020. Vejle is part of the 100 Resilient Cities global network and has developed a resilience strategy, Vejle's Resilience Strategy. The strategy has four strategic pillars: the co-creating city, the climate resilient city, the socially resilient city and the smart city. Particularly within the smart city pillar, there is a focus on digitalisation.

\section{Region of Southern Denmark}

Population: 1222370 (2018)

Area: $12260,30 \mathrm{~km}^{2}$

Density: 100/km2

Municipalities: 22

Administrative centre: Vejle (55 000 inhab-

itants)

Regional strengths: Sustainable energy

(especially energy efficient technologies

and offshore energy), robot technology,

automation, health and social innovation,

experience economy, technological

development, design processes and

creative thinking

Smart city initiatives fall under the responsibility of the Department for Environment and Planning in the Municipality of Vejle. The department has a long list of project ideas and have implemented several. According to the Head of Department, the process of developing the Resilience Strategy has made it possible to be more ambitious with urban development projects, e.g., climate adaptation measures that simultaneously develop attractive recreational areas. With the development of the strategy, the different public administrations gained a better understanding of each other through discussions about resilience. This has made it easier to find common ground today in connection with urban planning and development projects.

The Department for Environment and Planning's approach to digitalisation is to implement smaller projects to create better conditions for citizens and businesses by adding digital functions to existing municipal services, rather than implementing large systemic solutions. The department gained inspiration for this approach and several of the projects they have implemented from a study trip to Amsterdam and Eindhoven. One example involves the implementation of intelligent lighting at a main street with bars and restaurants in Vejle. The lighting is now controlled according to the time of night and the number of people on the street. The use of warmer lighting at certain times has been shown to create a quieter atmosphere. Another example is that the municipality installed a sensor initially at the City Hall to track how many people walked past. Today, sensors are set up all over town to collect data and visualise how people move in town. The data is used by City Vejle (the 
local retail association) and by the department in their communication with local politicians to improve planning processes.

The municipality has invested in a 3D cave, which has made it possible to visualise planned urban development projects for politicians. The 3D system is also used as a communication tool between Environment and Planning Department and businesses that wish to expand. The Green Tech Centre is a significant local partner engaged in green business development and innovation. They often serve as a 'matchmaker' when the skills of a private business are required in the public sector. Green Tech Centre also promotes the smart city and resilience agenda of Vejle, attracting approximately 6000 visitors per year from Denmark and abroad. About 30 green profile companies, which have more than 200 employees, rent office space at Green Tech Centre. Green Tech Lab is a business incubator for startups, where businesses have access to testing, demonstration and prototyping production facilities.

Vejle Municipality has an ongoing cross-departmental competence development project called 'service with purpose'. Through training sessions, the staff will develop a stronger understanding of how to combine digital solutions with stronger customer service. As an example, it was realised that citizens wanted staff to sit down with them and instruct them on how to use the digital services. Another example is that the municipality has removed the automatic selection menu from its contact telephone number, replacing it with reception staff to redirect calls. Thus, the municipality has aimed to remain service-minded and meet the needs of citizens while test new digital tools, but also is willing to improve or remove digital functions that do not enhance the user experience or improve efficiency.

\section{The regional context and collaboration}

The Region of Southern Denmark has not developed an overall regional digitalisation strategy, but digitalisation as a means for innovation and regional development is present in other strategies. For example, it is part of the Innovation Strategy for Region of Southern Denmark, which includes a focus on digitalisation in health care. As well as a focus on sustainable energy and an experience economy, The Regional Growth and Development Strategy includes an emphasis on robotics and innovation in health care and welfare. Digitalisation is a cross-cutting perspective in this strategy.

The Region of Southern Denmark founded a Digitalisation Committee in January 2018. The committee will promote digitalisation and the use

Southern Denmark has developed a strong innovation environment and cluster collaboration, with an international impact in the health and welfare and robotics sectors, and strong exports in industrial electronics.

Source: shutterstock.com 
of IT solutions in the health-care sector. IT also deals with IT and information security. One of its upcoming tasks is to investigate the development of a regional digitalisation strategy and, longer term, consider implementation issues, including how such a strategy would fit with the national and local strategies. Through its IT department, the Region of Southern Denmark is collaborating with the hospitals' IT departments, as digitalisation is a key tool in developing the health-care sector. Digitalisation is seen as a means to achieve productivity increases in health care, a perspective that has been important since the regions were formed a little over 10 years ago.

An innovation environment in the related fields of robotics and health care is centred on the city of Odense. It is in proximity to the large-scale hospital that is currently under construction, as well as to the University of Southern Denmark, the Danish Technological Institute, which has a strong research environment for robotics, the cluster organisation WelfareTech, and Healthcare Denmark, which is working to promote Danish health-care solutions internationally, as well as to different business support organisations. The Health Innovation Centre of Southern Denmark (SDSI), a project organisation under the auspices of the Region of Southern Denmark, is a part of this environment and a key actor on the Region's behalf in promoting innovation in the health-care sector. The SDSI's overall goal of improving the patient experience includes a focus on digitalisation.

The Region of Southern Denmark is focused on enhancing the use of telemedicine. One potential initiative is the installation of video equipment in the offices of local doctors, enabling them conduct consultations with patients in their own homes. SDSI oversees implementation of the video communication.

Another example of the development of a product/solution being facilitated by SDSI is a geriatrics toolkit for carrying out tests on elderly patients in their own homes. The idea was derived by a professor in gerontology working at Vejle University Hospital and the University of Southern Denmark. Often, geriatrics patients are admitted into hospitals for less than 48 hours. The admissions cause stress for many of these patients, who consider it unpleasant. The toolkit would enable tests to be carried out in their homes instead, avoiding hospital admission. It is currently being tested in patients' homes and SDSI has the overall project management responsibility. SDSI collects data from the different measurement equipment in the patient's home and stores it in a database that can be accessed by the responsible doctor, the hospital and the municipality. This enhances the well-being of patients and there is also an economic benefit to the municipalities in reducing health-care costs. There is potential to implement the solution across Denmark and adapt it to other patient groups.

In general, co-operation on digitalisation between municipalities and the Region of Southern Denmark is not pronounced. The health-care sector, where there is a natural need for co-ordination between the region and the municipalities, is the exception.

Vejle is part of the Danish Citypack collaboration, together with the other four of Denmark's largest cities. The aims of this collaboration are to foster the development of intelligent cities, influence an upcoming national Smart City Strategy, develop intelligent solutions and provide inspiration and a point of entry for companies that wish to collaborate on the same themes and solutions as the City Pack cities (Citypack, 2018).

\section{Challenges and opportunities}

The challenges of ageing populations, which put pressure on the health-care and welfare systems, are being felt in the Nordic Region and beyond. Moreover, urban planning increasingly requires more efficient and multi-purpose solutions that can combat the effects of climate change, while simultaneously creating attractive urban environments. The case study of the Region of Southern Denmark has demonstrated examples of how public-private collaboration can be organised to implement digital solutions in the health-care system and in smart city initiatives.

Using digitalisation as a tool to improve efficiency in the public sector, while meeting the demands of citizens and businesses, calls for new opportunities for public-private collaboration. The case study has demonstrated different approaches to organising such collaboration. In the case of health care, this is centred on a triple-helix cooperation environment, which makes it possible to facilitate digital solutions, which may also have commercial value, from the hospitals and test the solutions in collaboration with the patients and doctors who are the end users. In the case of smart city digital solutions, the focus is placed on imple- 
menting step-by-step solutions to improve the communication of the Environment and Planning Department with citizens, businesses and politicians, while also facilitating business development, e.g., the retail sector, which has gained a new tool for planning based on customer behaviour.

For the Department for Environment and Planning at the municipality, the implementation of small-scale initiatives and innovations are highlighted as an opportunity for public authorities. The national Digital Strategy 2016-2020 is being implemented in different ways to streamline approaches across public authorities. However, the head of department has argued that it is not the large-scale strategies and system solutions that drive digital innovation. Rather, step-by-step changes that facilitate the conditions for citizens and businesses have an impact. This approach to digitalisation calls for awareness and strong leadership by public authorities to establish a culture of promoting incremental changes in dialogue with the end users. Embracing the transformation and change that digitalisation entails-for citizens, for co-workers and for everybody-is one of the challenges that lies ahead.
In the light of the reform of the Danish business support system, it will no longer be possible for the Region of Southern Denmark to co-finance business development initiatives. However, as the regions are running the hospitals, the Region of Southern Denmark will continue to work on health-care innovation. Regarding new technologies, this work is mainly undertaken by SDSI. The role of the Region considering its responsibilities that cut across health care and business development is uncertain, as the laws have not yet been passed by the parliament (as of November 2018). It seems as if the Regions will maintain responsibility for developing regional development strategies in the areas of health innovation, public transport, culture, education, environment, infrastructure, development of the peripheral areas, nature and recreational purposes, green transition, climate adaptation and cross-border collaboration. Health care will remain the responsibility of the Region and, notably, health-care innovation, which is closely linked with business development, is one of the areas where there is an apparent challenge and opportunity associated with the reform process. 


\subsection{TAMPERE REGION/ CITY OF TAMPERE}

by Linda Randall and Tuulia Rinne

\section{About the case study area}

Tampere was established as an industrial town in the mid-19th century, as factories could exploit the rapids of Tammerkoski which factories for hydropower (City of Tampere, 2015). A brownfield city until the 1990s, it has evolved over the past 15 years to become an example of a medium-sized post-industrial Nordic city that has not only survived, but is thriving. This success can largely be attributed to its ability to adapt and transform to changing economic conditions. In the context of the digital transition, it can also be explained by the region's particular industrial trajectory, most

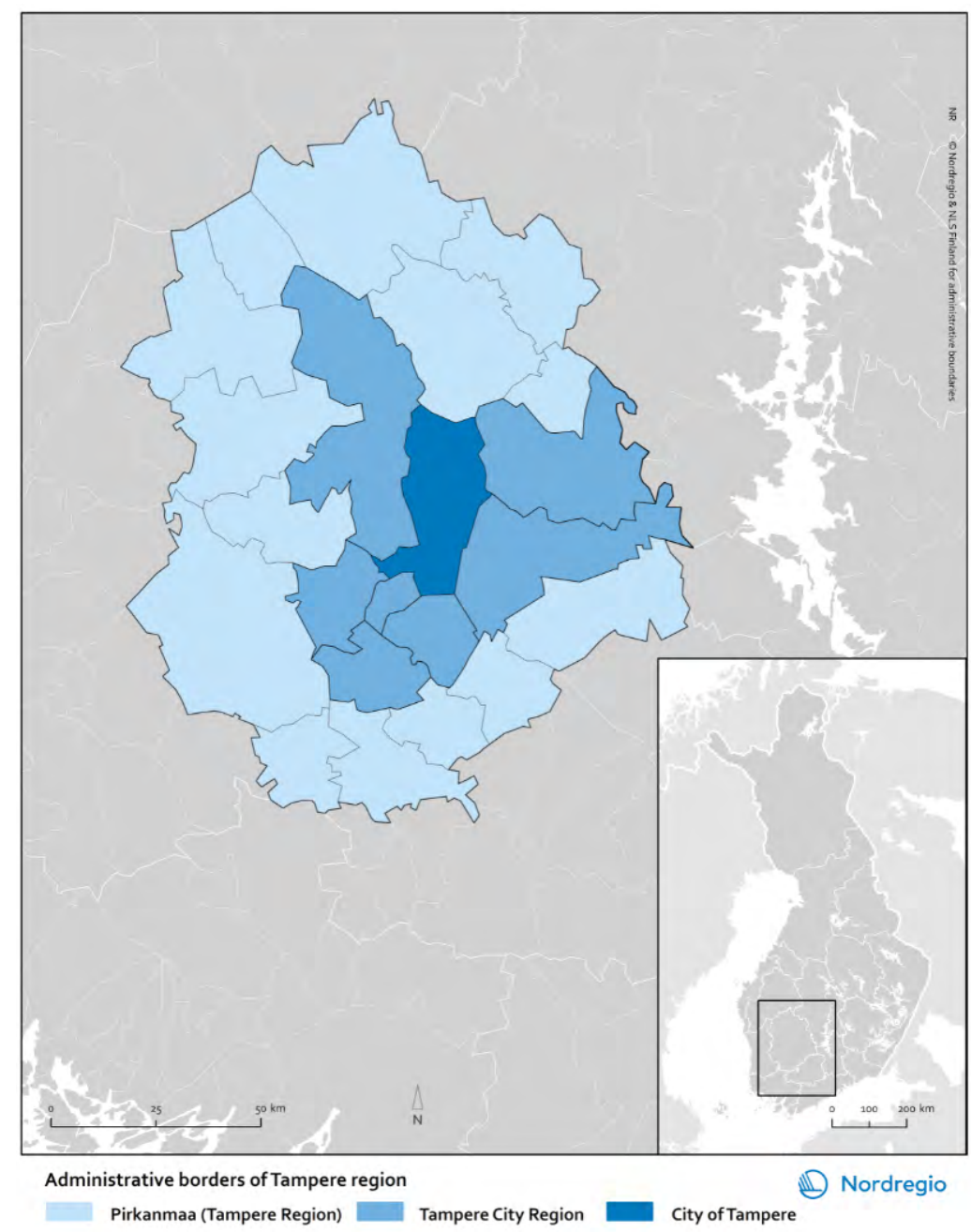

Tampere Region (Pirkanmaa in Finnish)

Population: 512081 (2017)

Area: $14613,23 \mathrm{~km}^{2}$

Density: 40/ $\mathrm{km}^{2}$

Municipalities: 22

Administrative centre: Tampere

Regional strengths: ICT, engineering, game

industry, strong startup culture

notably the presence, and subsequent decline, of the technology and communications giants, Microsoft and Nokia, who, at their height in 2007, supplied $40 \%$ of the world's mobile phones (BBC, 2016). This history, combined with the relatively broad skills base, which is constantly being renewed through the city's four higher education institutes, ${ }^{16}$ puts Tampere in a unique position to capitalise on digital trends. The city has developed a reputation for being bold-both from the perspective of investing in infrastructure and promoting growth, and with respect to testing new technologies and solutions.

From a geographical perspective, there are several ways to conceptualise Tampere (see Map 2). At the municipal level, the City of Tampere with its 231853 inhabitants is the largest city in the region and the third largest in Finland (Statistics Finland, 2017). Tampere City Region has a population of 385301 (2018) and is made up of the City of Tampere and its seven neighbouring municipalities (Tampere City Region, 2018). Tampere Region (Pirkanmaa, in Finnish) has a population of just over 500000 (see Map 2) making it the second most populous of Finland's 19 regions (Council of Tampere Region, 2017). Despite these official boundaries, several interviewees for this project stressed
Map 2. Administrative borders of Tampere region. Source: Eeva Turunen / Nordregio.
16 Tampere University of Applied Sciences, Tampere University of Technology, University of Tampere \& Police University College. 
the fluid nature of the 'region' in the context of digitalisation, disputing the value of fixed spatial boundaries. In line with this, the case study presented here is not strictly focused at a particular administrative level and instead frames Tampere as a 'smart city region'. This framing acknowledges the City of Tampere as an important central node while at the same time considering the potential for 'smartness' to extend beyond the urban fabric and encompass the regional economy as a whole.

The region's administrative organ, the Council of Tampere Region (Pirkanmaan liitto in Finnish), focuses primarily on regional planning and development. However, this will change substantially following the administrative reforms currently underway in Finland (see Box 1). Regional development is also supported by Business Tampere, the economic development agency of Tampere City

\section{Box 1. Regional reform in Finland}

Finland is heading towards one of its most substantial administrative reforms in history. The reforms will involve greater and more clearly defined responsibilities at the regional level, most notably, the transfer of the responsibility for social and health-care service delivery from the 311 municipalities to 18 newly established regions. From a regional development perspective, it is hoped that the reforms will challenge the previously centrally driven nature of Finnish public policy. At the same time, there is some concern that the renewed focus on service provision will detract from the regional development role that is currently the regional authorities' primary concern. Thus, from the perspective of digitalisation, a big question is how to ensure that the digitalisation is prioritised in policy making and not crowded out by the focus on service delivery. This aside, the centralisation of social and health-care services no doubt offers an opportunity to address the compatibility of ICT systems in the area of digital public services, a task that has been challenging in the past because of historic investments in a broad array of different systems. The regional governments are expected to be elected in 2019 and the reform to come into full force in January 2021 (The Ministry of Finance, 2018).
Region, which plays a key role in promoting the region to potential investors, supporting collaboration between existing companies and building up ecosystems in the region. Some of the tools used for this include hackathons (one company presents a challenge to teams of private people, students and companies, who come up with different solutions over a two- to three-day period); pitching by invitation (again, companies present a challenge, but companies with specific expertise related to the problem are given three or four months to develop a solution and win the contract); and pitching days (one company gets the chance to hear 20-30 pitches in one day). Business Tampere's key focus areas are: the experience economy (film making, virtual reality, games and the idea of Tampere as really attractive place to live); smart city solutions (the city as a platform/test bed); and renewing industry (matching ICT companies with solutions with the more traditional manufacturing industry to 'make the future happen faster').

\section{Digitalisation approach}

Understanding Tampere's approach to digitalisation requires first placing it in the context of the region's industrial development trajectory. As noted above, Nokia and Microsoft played an important role in this. These flagship companies shaped the current environment for digitalisation in two key ways. First, Nokia and Microsoft acted as incubators for ICT skills in the region for nearly 15 years-they developed skills within the existing population and attracted high-tech, skilled workers from abroad. These years were also formative in developing strong networks and a shared working culture among a population ideally sized to maintain them. However, from 2008, Nokia began to lose its position as an industry leader and was forced to lay off over 10000 employees, or $19 \%$ of its workforce. In Tampere alone, more than 2500 people lost their jobs. By the end of 2013, the region faced a unique problem-an oversupply of highly-skilled and experienced, unemployed tech talents (O'Brien, 2012).

The events that followed can largely be attributed to the redundancy programmes of the two companies, Nokia Bridge and Microsoft Polku (which means path in English). These programmes not only provided substantial support to exiting employees but, more importantly, did so in a way designed to encourage entrepreneurship. This included training programmes and personal coaching. 


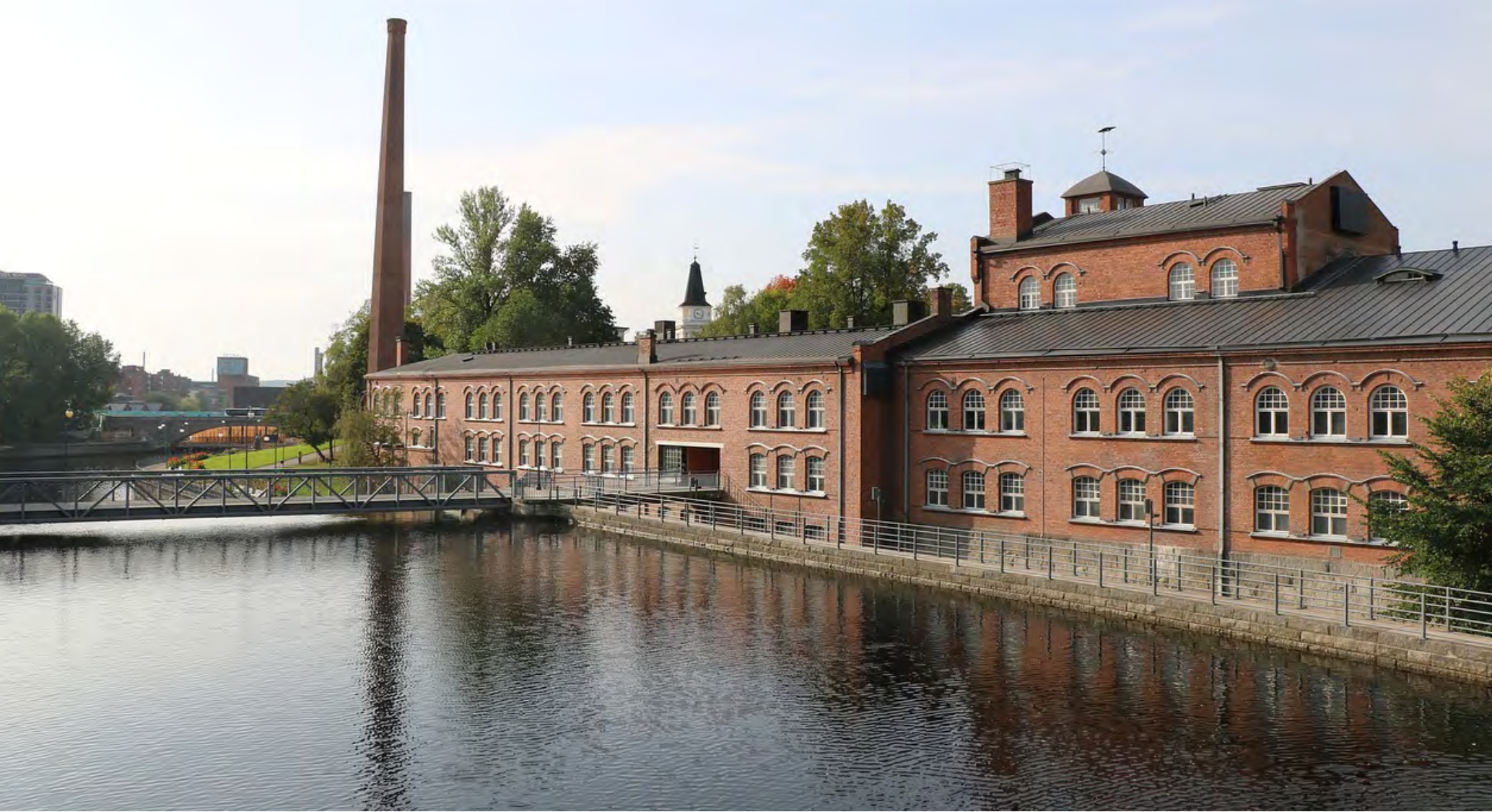

A brownfield city until the 1990s, Tampere has evolved over the past 15 years to become an example of a medium-sized post-industrial Nordic city that has not only survived, but is thriving. Source: pixabay.com

The companies also allowed redundancy packages to be structured so that they were paid out over a longer period of time, functioning more like a wage than a lump sum. This approach, combined with the high calibre of those who were being laid off, resulted in excellent preconditions for new and innovative business models and startups to emerge. At the same time, the region became attractive to foreign companies seeking world-class expertise available in large teams. As a result, the talent that was once concentrated within two large multinationals is now spread across a myriad of different sized companies and startups, both homegrown and international. This transition has been important in building the long-term economic resilience of the region and has created the perfect preconditions for the work on digitalisation that is currently underway. Responding to the crisis also brought a range of regional development and business actors together, creating foundational relationships.

Given this history, it is perhaps no surprise that digitalisation has been a core element of regional development policy in Tampere for at least 20 years. Rather than a specific policy area, the Council of Tampere Region's current regional development programme identifies digitalisation as one of three global mega-trends alongside resource wisdom and occupational restructuring (Council of Tampere Region, 2017). Digitalisation is defined in the programme as: 'involv[ing] the transformation of work and lifestyles through tools to enhance the use of information, especially computers and other digital devices, through the whole society, in areas such as housing, services, mobility, goods production, entertainment and health-care practices' (Council of Tampere Region, 2017: 21). The region's smart specialisation strategy, incorporated in the implementation plan, lays out four key areas: digital manufacturing, smart city solutions, circular economy, and well-being and health services and systems, all of which are boosted by new digital technologies and intelligent solutions.

At the municipal level, the core driver of digitalisation work is the Smart Tampere programme for 2017-2021, the essence of which is summarised in its three-word tag-line: 'Grow.Smart.Together'. The starting point for programme development was to identify the region's strengths and consider ways to build on these, with the aim of making Tampere the most well-known small-to-mediumsized smart city in the world. Currently, there are more than 300 companies involved in the program, with 37 official partners ranging from big companies to small startups. Smart Tampere was 
officially launched in 2016 with two components, the digitalisation programme and the ecosystem program..$^{17}$

The digitalisation programme aims to make everyday life easier for residents through userfriendly digital services, with the goal of making most city services digital by 2025 . Despite the name, only about $20 \%$ of the work done under the digitalisation programme is about technology. The other $80 \%$ is about people-specifically, managing change. Twenty motivated and reformist employees from different departments have been relieved of their regular workloads and required to dedicate $100 \%$ of their time to renewing their domain. New ideas are piloted on a small scale and, if effective, are scaled up across the organisation or department. These 'change managers' also meet as a group to network and discuss operational modes, i.e., what works and what doesn't. Similar to the regional level, the municipality has a long history working with digitalisation and conceptualises technology as a vital tool through which to realise other policy priorities, rather than as a distinct policy area in-and-of-itself. Examples of areas where pilots may take place include: customeroriented services, renewal of payment systems, digital learning environments, health and performance promotion, renewal of land-use processes, renewing the courses of action in employment activities and effective space utilisation.

The ecosystem programme has a more outward focus and aims to create clusters around seven central themes (see Figure 4). Each theme has a leader, a relevant actor from the field in question who is generally not from the city administration. For example, the director of Infotripla Oy, a company providing transport system services targeted to smart mobility and transport, is responsible for developing the smart mobility ecosystem. There are also examples of theme managers who work part time for the project and part time as practitioners in their field. Although most actors within the ecosystem programme are from outside the city administration, the city itself still plays an important role, acting as a 'living lab' for new ideas, both physical (e.g., new tramways) and non-physical (e.g., data). Using the city in this way

17 A third sub-programme, Sustainable Tampere, was added in autumn 2018 to promote sustainability and business cooperation. As this occurred after the regional case study visit, it is not explored in this research. provides opportunities for companies to test new solutions, making the smart city a place where new ideas are born, not just implemented. It also means that Tampere residents are direct beneficiaries of innovation in the region. Several interviewees suggested that Tampere is an ideal size for this kind of work.

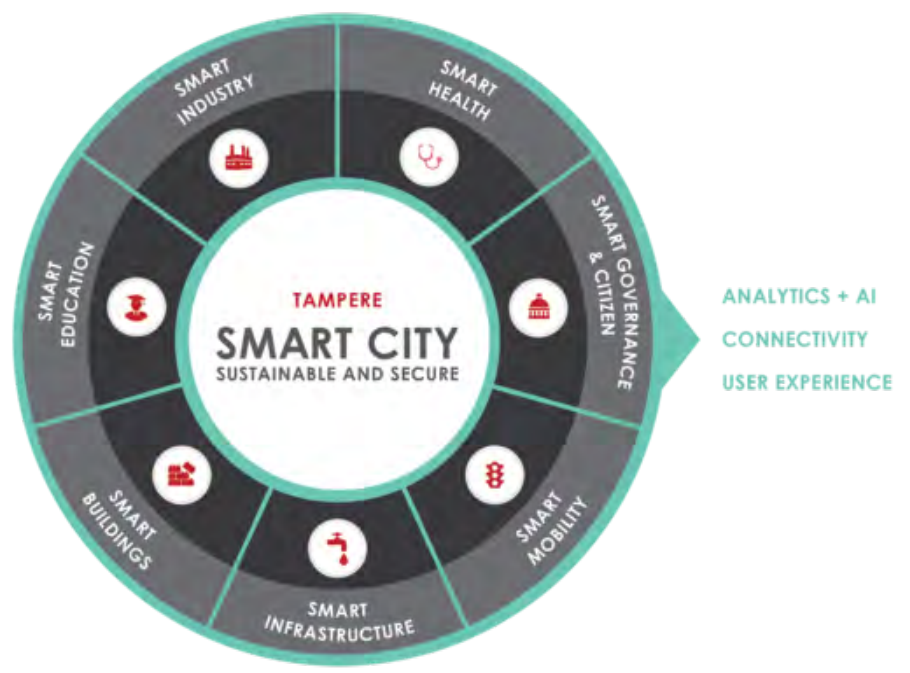

Figure 4. Elements of Smart Tampere ecosystem programme (Source: Tampere Municipality)

Although Smart Tampere is funded and operated by the municipality, its scope is not necessarily confined within municipal boundaries. The Smart Tampere team work closely with the Regional Council and Business Tampere, and many of the programme partners operate outside the municipality. Core funding for the programme comes from the city budget and it is currently funded until 2021. Participation in national and EU funded projects provides an opportunity to explore specific project areas in more depth. Care is taken to ensure that this work is targeted, and that the team only invest time in applying for project funding that is well aligned with existing goals.

The higher education sector also plays an important role in Tampere's digital transition. The new Tampere University (expected to open 1 January 2019), together with the Tampere University of Applied Sciences, will form a new university consortium and higher education community during 2019, with some 35000 students and 5000 staff. The new university community plays an essential role in digitalisation through various means, such as creating and providing new relevant knowledge, developing and providing accessible servic- 
es and tools to develop competences of the digital era through R\&D partnerships and providing open infrastructure and collaborative innovation platforms. The university community-wide vision 2023 for digitalisation will guide the future development of the global digital campus. The vision is concerned with renewal in the areas of learning and teaching, research, administration and management and collaboration with the surrounding society and ecosystem.

\section{The regional context and collaboration}

Interviewees were excited about the genuine opportunity that digitalisation presents for multidisciplinary, multi-sectoral endeavours. The complexity and cross-cutting nature of digitalisation makes it incredibly difficult for one person or team to do it alone. This creates new possibilities for collaboration both within the region and beyond it. As explained by one interviewee:

'It means, e.g., that Smart Tampere programme is not only looking to Finland or to Tampere Region when they are looking for a smart city solutions or platforms. They are open for global offerings, for big corporations or smaller companies from anywhere. It means also that when we are developing our innovation environments related to digitalisation, we would like to keep them open not only for companies and people from our region but also globally. It means also that we have been encouraging some of our innovation platforms to go global, create a global network where digital talent can get connected globally to our ecosystems.' (Petri Räsänen, Council of Tampere Region)

The political climate for this work is also good. Digitalisation is an issue with broad political support-most politicians are aware that many of the changes will happen with or without their support and are eager to find proactive ways to respond. Although the initiatives and ideas are very much driven from the local level, Tampere's digitalisation work aligns with and is well supported by the national government, with the region generally viewed as a front-runner in the national context. For example, Tampere is one of the first municipalities to begin using the national service infrastructure and is the only city region with co-operation between municipalities for shared ICT infrastructure. The agreement on regional data administration, which includes the City of Tampere and eight of its neighbouring municipalities, has been in place since 2008 (it was renewed in 2014) and has been of benefit to both the larger and the smaller municipalities in the region. Another good example of the national support for locally and regionally driven action on digitalisation is the 6Aika (6 Cities in English) initiative, which commenced in 2014 and will run to 2020. It involves the six largest Finnish cities collaborating on smart city solutions, with the aim of creating new know-how, business and jobs (6Aika, 2018).

\section{Challenges and opportunities}

Perhaps the most important thing to understand about the Smart Tampere programme is that, much like digitalisation itself, it is designed to be a vehicle for transformation rather than an activity per se. The aim is to facilitate sustainable, longterm, structural change-to make Smart Tampere a place and not a program. This is undoubtedly a significant challenge and there is a risk that the culture of innovation being fostered will not be maintained without the programme to act as a driver post-2021. However, several elements of the work being undertaken directly mitigate this risk. First, the multi-sectoral and multi-stakeholder nature of the work is already challenging established ways of working. For example, co-operation between the city, students and research institutes in city development is an integral part of the smart education ecosystem (Smart Tampere Ecosystem, 2017). Second, as described above, the ecosystem programme encourages clear ownership of the different ecosystems by industry leaders, who have a clear interest in maintaining these ecosystems beyond any allegiance to the Smart Tampere program. Similarly, initiatives under the digitalisation programme are led by department representatives who will return to their ongoing positions once the Smart Tampere programme comes to an end. Third, from Smart Tampere to Tampere3 to the work of Business Tampere, the focus is on bringing people together to share their expertise and work towards tangible goals. Uniting people for a specific purpose that is in line with the interests of their everyday work not only encourages multidisciplinary work but paves the way for future, mutually beneficial collaboration.

Another closely associated challenge is reconciling the fast-paced nature of technological change with the long process of culture change. This again reinforces the importance of the hu- 
man element of digitalisation and the $20 \%$ technology/80\% people analogy mentioned above. Although people may be supportive of trialling something new at a smaller scale, scaling up a successful pilot is often more challenging, particularly when this involves the transformation of existing work roles. Good support from management (including resources) helps, emphasising the importance of department heads in leading the process and working closely with their teams to address any fears and concerns.

Despite these challenges, there is a clear sense of optimism in Tampere. Although there were no attempts to downplay the trauma of the period following the Nokia and Microsoft lay-offs, it was clear that these events are now seen in a new light: as creating new possibilities, opportunities to build regional economic resilience and a chance to tell a new story about entrepreneurship and entrepreneurial spirit in the region. Unemployment rates in the region are still high compared with Denmark or Iceland, e.g., but they are improving.

Overall, Tampere is in a strong position to take full advantage of the benefits of digitalisation. The challenge now is to show that it can be donethat there are in fact actions that the city and region can take to influence the course of this global mega-trend. 


\subsection{REYKJAVÍK}

by Linda Randall \&

Hjördís Rut Sigurjónsdóttir

\section{About the case study area}

Iceland has two levels of administration, national and local, but no formal governance structure at the regional level. Instead, regional development interests are represented by the Association of Local Authorities in Iceland and most municipalities are also members of independent regional organisations. Regarding digitalisation, there is no evidence of a regional approach and there is no formal strategy addressing digitalisation from the regional perspective. Interestingly, several interviewees noted that, because of its small population, it is perhaps useful to think of the whole country as one 'region' with respect to this issue. At the local level, despite evidence of some small initiatives happening around the country, Reykjavík is the only municipality in Iceland working with digitalisation in a holistic and co-ordinated manner. Given these considerations, this case focuses on the City of Reykjavík, using the national context (as opposed to the regional) as a backdrop.

Reykjavík is the capital city of Iceland and the world's northernmost capital of a sovereign state. The Icelandic population is concentrated in the capital region, with 126000 persons (2018), over one third of the population, living in Reykjavík (Statistics Iceland, 2018). The centre of economic life is situated in the greater Reykjavík area, including administration, commerce, services, industries, transport and communication, as well as the country's main cultural and educational institutions.

\section{Digitalisation approach}

Reykjavík Municipality began developing digital services in 2002, when around 30 digital processes were put in place and maintained by the IT department. At this time, the mentality around digital services was 'open a self-service portal and let it take care of itself' (interview 2018). The digital tools were implemented sporadically to support analogue functions and there was little long-term thinking about how to develop a digital approach. The overarching view was that digitalisation was something that would just happen. However, in 2016, the city council realised that change was required, as the existing digital functions had become outdated and the failure to develop new so-
Greater Reykjavík ('The Capital Region')

Population: 217711 (2018)

Area: $1062 \mathrm{~km} 2$

Density: $213 / \mathrm{km} 2$

Municipalities: 7

Administrative centre: Reykjavík

Regional strengths: tourism, creative and knowledge -based industries, fisheries, services, energy production, commerce, education and R\&D

lutions was resulting in pressure from citizens, who were increasingly dissatisfied with council services.

There was broad political agreement that a digital approach was the key to improvement and, in January 2017, the Digital Service Centre (Rafræn pjónustumiðstöð in Icelandic) was established (Reykjavík City Council, 2016). Its aim is to make digital services people's first choice, with self-service ultimately superseding face-to-face in front-line services.

Today, three local policies support digitalisation in various ways: information policy, service policy and an Internet policy. These policies emphasise high-quality digital services, access to information, transparency and openness, higher service levels and increased public participation.

The Digital Service Centre sits within the Office of Service and Operations alongside the IT Department and the Document Management Team. It commenced with only two employees but this had grown to 10 by April 2018. The team also employs many freelance workers, particularly for technical issues, allowing for flexibility and agility in its approach. The previous unsystematic approach and lack of long-term thinking has now been replaced with a commitment to digital first and an understanding that realising this commitment requires hard work, dedication and a proactive policy approach. The team has two distinct 'user groups'-the citizens of Reykjavík and the staff of Reykjavík Municipality. It is divided into three socalled 'disruptive' units: the smart city unit, the digital service team and the service-disruption team.

The smart city unit was the first of the disruptive units. It has two team members, one focused on bringing together different departments to implement digital solutions within the city, and another dedicated to securing external funding to further support and grow this work. Connected- 
ness is seen as a central component of the smart city but, interestingly, this does not just refer to digital connectedness. It also concerns connectedness between the functions of the city and those who provide them-making the smart city into a city that perceives the whole picture and gets people to think differently.

This is seen as the key distinction between becoming a truly smart city and simply being a city that works with many IT solutions and projects. A concrete example of this is the 'smart trashcans' project that has been implemented recently. The solution required collaboration between the smart city team and the maintenance team and resulted in trashcans being emptied once a week instead of twice a day, which freed municipal staff up to take on other roles within the city. Another component of the approach is creating an environment for innovation within Reykjavík. This includes working with established companies interested in using the city as a 'test bed', but also providing opportunities for individuals and startups to test and launch novel ideas. As one interviewee stated:
In my opinion, if Reykjavík is not doing this, trying to be smart and trying to make an environment where startups and entrepreneurs can thrive, we will basically lose a lot of brain power ... If you don't have an environment that people can thrive in and get jobs that fit them, we will lose these people and we will turn into a place that only has tourism, fisheries and these kinds of jobs. (Óskar Sandholt, Reykjavík Municipality)

The next team is digital services. This team is working on making all council services digital. As noted above, there are currently 30 municipal processes that are fully electronic, from front-end to back office and back to the citizen. Originally, the aim was to take the same approach for all 100150 processes within the municipal government. However, it became apparent that the scale of this task was beyond the organisation's capacity for change and the process came to a standstill. In response, the team decided to begin by focusing exclusively on front-end services, with the aim of eliminating every PDF file on the website by late

At the local level, despite evidence of some small initiatives happening around the country, Reykjavik is the only municipality in Iceland working with digitalisation in a holistic and co-ordinated manner. Given these considerations, this case focuses on the City of Reykjavik, using the national context (as opposed to the regional) as a backdrop. Source: pixabay.com

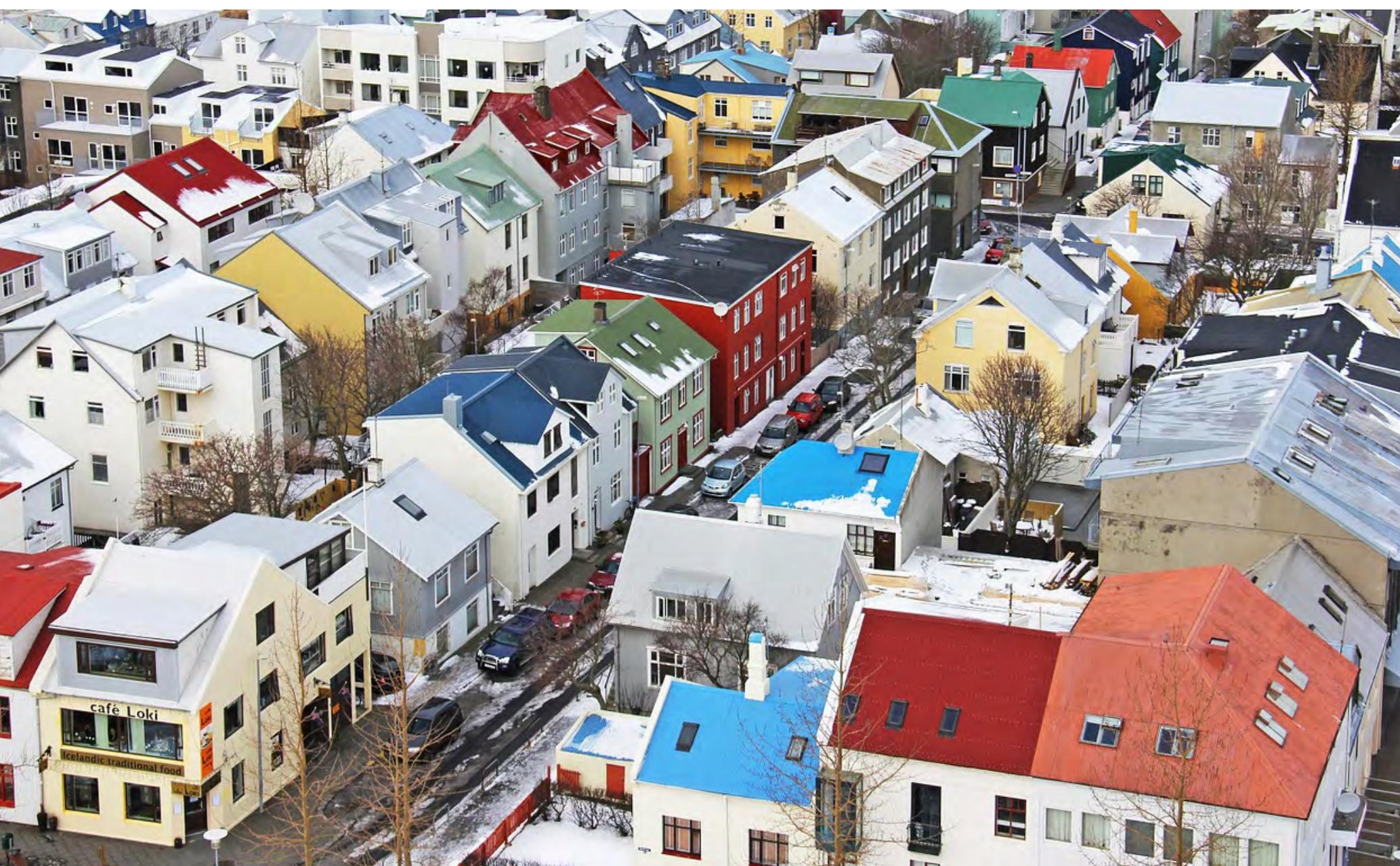


2018. The intention with this approach is twofold. First, it will dramatically improve the experience of citizens interacting with the city. Second, it will demonstrate progress and create positive momentum behind the broader and far more challenging task of digitising the work that goes on behind the scenes.

This is where the latest team, service disruption, comes in. The service-disruption team are using a 'design-thinking' approach to completely reimagine the way that city services are delivered and run. Although digital solutions are likely to be an important tool, the process puts the customer at the centre, not the technology. It involves taking each service and going through an iterative, customer-centred process to determine the best possible approach. As an example, the call centre had been criticised for long wait times and poor service. They have now implemented a process whereby customers can leave their contact numbers immediately and have their call returned by the person to whom they wish to speak. Internal processes are also being disrupted. For example, the city maintenance staff, who previously had no system at all to manage their tasks, are now working with Indriði the robot. Municipal staff explain their problem to Indriði, who logs them into a system where they are assigned to members of the maintenance team. Indriði provides several notifications to the staff member throughout the process, including informing them when the task has been resolved. People were sceptical of this process at first but its introduction was eased by making it humorous and fun; the robot's name Indriði is based on an old Icelandic comedy series and it uses catch phrases from the character.

Interestingly, aside from the IT department, none of the team have technical backgrounds. Their job is more about working with people, managing change and creating disruption. Contractors are brought on board for the technical elements and there is a conscious effort to work with younger people and with startups. These companies can offer lower cost and greater efficiency, are flexible enough to adapt to the style and 'run fast', as well as giving a dynamic and 'hip' feeling to the work. Public procurement laws can be a challenge to implementing such an approach as they tend to unintentionally have a bias towards larger, more established companies. This has been addressed by breaking the work down into smaller projects that can be put into action more quickly. Other departments have begun to use some of the same contractors. Having a mix of 'old and new blood' within the team was also cited as an important success factor.

Until recently, Reykjavík Municipality's work with digitalisation largely occurred behind the scenes. This changed in April 2018, when the city hosted its first Smart City conference. The conference was the first outward step in presenting Reykjavík as a smart city and was attended by over 400 people, with another 1700 following the online broadcast. Apart from city employees, the conference visitors included entrepreneurs, politicians, people from well-established companies, universities and municipalities and employees from the ministries and official institutions. New solutions for innovative infrastructure and services were presented, including smart lighting and selfdriving cars. As part of the conference, another event, Hack the City, was held, attracting nearly 200 participants who attempted to derive solutions to address problems faced by the city (Reykjavík City Council, 2018). Again, this approach represents a shift in thinking. Rather than 'what do we do and how can we do it better?', the question becomes 'what problems are we facing and how are these best tackled?' The event was also seen as a way to create some 'buzz' in the city and 'see what happens'.

\section{The national context and collaboration}

There was not a strong sense of collaboration between different levels of government in Reykjavík. Some municipal-level informants reported feeling that there was a lack of focus at the national level and suggested that, following the success of the work that has occurred in the past 18 months, Reykjavík could actually be a model to inspire national transformation. The greatest collaboration between municipalities in Iceland has occurred through the development of the regional plan. As noted in the Introduction, the plan largely deals with issues related to physical planning (e.g., transport) and there is currently no collaboration evident on digitalisation. One way in which Reykjavík Municipality is working to increase collaboration and transparency between municipalities is by using all open-source programmes (it is the only municipality in Iceland doing so). This means that if another municipality wants to implement a similar service platform, they can easily do so. 
In addition, the digital service team have hosted meetings with neighbouring municipalities for the purpose of knowledge-sharing.

Reykjavík University plays an important role in supporting the needs of Icelandic society and industry. The university works closely with industry and with international experts to identify what is ahead and to attempt to prepare for it. Currently, the university is working on making its educational offerings more flexible and current, as well as making courses available to people of all ages (see Box 2). Although people are experts in their own fields, they often have no idea, e.g., how to use big data. The university aims to provide people with the tools to do their job better in the context of technological development or, in other words, to be the bridge between society and the digital revolution. This includes working with people on how to do business in a different way (e.g., legal and ethical frameworks). The municipality is also working to contribute to the development of knowledge in the field, with a team member dedicated to developing and executing a research agenda.

\section{Box 2. Children and young people at Reykjavík University}

Reykjavík University runs summer courses for children as young as six, with the aim of getting them excited about the technology that sits behind the devices and applications that they interact with every day. The course was created by students in a psychology course at Reykjavík University in 2010. The students won an entrepreneur competition in 2011 for their concept and shortly after, a company was created around their idea, called Skema. Reykjavík University took over the project in 2017 and the inventor is the project manager. Efforts are also underway to integrate the course into the school system, so it will be available all year round.

Within the digital service team, there has been a concerted effort to hire younger people. This can be a challenge in a context that puts a high value on experience and tends to offer lower wages to less experienced candidates (young people are paid better on the private market).

\section{Challenges and opportunities}

Although the city's work with digitalisation has broad political support, this support is not necessarily very focused-no one is against the work, but there are no passionate allies advocating for specific actions or outcomes either. There is a sense that this issue becomes lost among the more mundane issues. The strong penetration of technology means that there is some resistancemany people are using these tools in their daily lives and there is somewhat of a gap between how the general public is using technology and the pace of transformation in government and public services, which are still trying to catch up.

As noted above, digitalisation work sits within the Office of Service and Operations. A significant challenge for this office is that, despite its name, it has little control over the way services are delivered within the city, with the majority of city functions being delivered by other departments. As such, an important first step has been overcoming inertia and getting others on board to support the need for change. The root of this challenge was described in several ways.

First, the simple reality is that change management is a slow and difficult process. The connectedness that the Digital Service Centre team is trying to achieve is as human as it is digital and thus, it requires both the introduction of new processes within existing team structures, and encouraging new ways of working that challenge these existing structures and bring new constellations of people together. The reality is that many people have been doing things a certain way for a long time and they are not necessarily ready for change. This is also a challenge in the private sector, where embracing digital change may require people who have been considered to have the answers for a long time to admit a degree of vulnerability, step outside their comfort zone and learn new skills. At the same time, many people are simply so busy with their day-to-day activities that they struggle to make time for something new. Changing processes takes a long time-it is not just about making it digital, you must look at every element of a process (which can even take one or two years). From a technical perspective, existing systems can be entrenched and there is often resistance to replacing something that was time consuming and expensive to implement.

Within the municipality, the service policy has been a useful tool as it provides a clear directive 
from the elected officials that digital processes should be the first choice for both users and staff. Starting with the front end has also been a good way to gain a head start, by improving the customer experience, obtaining some momentum and then moving to the longer process of working with the back office. Starting with the departments that show the most enthusiasm (or the least resistance) has also been a good strategy. In both the public and the private sectors, the need to 'keep up' was cited as a means of overcoming resistance to change. In the public sector, there was a sense that once a sufficient number of departments had renewed their services, the gap in quality between these departments and the ones that were more resistant to change would act as a driver for change. In the private context, the story is similar, but the motivator is financial-if the business is not doing well, there is no choice but to change. Ultimately, the key ingredient for success was to avoid compromise-go all the way and be prepared to fight for what you want.

Interestingly, the director of the service and operation department stressed the importance of not leaning on cost savings as a political motivator. First, it was considered that political support was more likely to be channelled and effective if it was based on a belief in the end goal-in this case a better city for the citizens of Reykjavík. In addition, the change management challenges described above are likely to be magnified if department heads believe that the change will involve downsizing their team. Finally, and perhaps most importantly, digitising services and processes takes time and requires investment (e.g., getting the right people on board to do the job). Even if there will be savings in the long term, trying to realise these too quickly is likely to act as a barrier to getting the job done.
When it comes to opportunities, Reykjavík's position as the national capital puts it in a strong position to take advantage of digital opportunity and become, as one interviewee put it: 'an interesting place, for interesting people'. The city has a highly educated and relatively diverse population, creating fertile ground for innovation. At the same time, being a relatively small city on a global scale means that there are likely to be fewer barriers to experimentation and change. However, change will not happen by accident and there is a risk that without the right environment, the brightest minds will take their talents elsewhere.

The increasing automation of menial tasks allows for high value creation with minimal labour inputs, which is vitally important in a country with high labour costs, low unemployment rates and a small population. Open data provides opportunities for individuals to innovate in ways that were previously only possible with access to substantial resources. Thinking at a more local scale, digitalisation can be used to improve quality of life. For example, a recent collaboration between Reykjavík Municipality and a local startup has resulted in the development of a sensor-based solution to support independent living for elderly residents. Sensors are fitted strategically around the home and gradually learn the behaviour of the resident, alerting someone if the routine changes (e.g., medicine cabinet not opened at the usual time). Importantly, although the solution itself is technical, it would not have come about without the shift in thinking that allowed for this style of collaboration between the municipality and a previously unlikely partner. Continuing to challenge old ways of working and trying new ways will be key to the ongoing success of digitalisation work in Reykjavík. 


\subsection{FINNMARK/VARDO}

by Mari Wøien and Linda Randall

\section{About the case study area}

Located by the Barents Sea, and bordering Russia and Finland, Finnmark is the northernmost region in Norway and sits in a geographically important and interesting position, particularly from an international security and military perspective. It is simultaneously the largest Nordic region, in geographical scope, and the smallest, by population (SSB, 2018a). The region is part of the larger Sápmi area, which stretches across northern Norway, Sweden and Finland, to Murmansk Oblast in Russia. The historical importance of the fishing industry in the region has resulted in the majority of settlements occurring along its coastline. Fishing remains an important industry alongside the military and the oil and gas sites in Hammerfest (SNL, 2018). Finnmark continues to be dominated by small and 'very small' enterprises with a steady increase of startups in the years between 2011 and 2015 (SSB, 2018a). The survival rate of new enterprises after the first 5 years is $32.6 \%$, one of the highest in the country (SSB, 2018b).

\section{Finnmark County}

Population: 76228 (2017)

Area: $48637 \mathrm{~km} 2$

Density: $1.55 / \mathrm{km} 2$

Municipalities: 19

Administrative centre: Vadsø

Largest city: Alta (20 635 inhabitants)

Regional focus areas: Fisheries and

aquaculture, culture, tourism, oil and gas,

military, agriculture, energy and mining

As well as a harsh climate, periodical difficulties in local industries have contributed to a net outmigration from Finnmark since the 1980 s, which has added to a growing range of societal issues. The largest group of migrants leaving Finnmark are young students or recent graduates. Traditionally, this group has been dominated by young women, but an increasing number of young men have been leaving the county in recent years (Finnmark County Municipality, 2015).

Finnmark's location and population structure provide a great opportunity to explore digitalisation in the context of remote and sparsely populated areas. To do this effectively, this case study

During the socio-economic crisis, Vardø municipality was aware that it had limited power to create more jobs as a response to the crisis. Instead, it chose to focus on what it could address, such as improving the standard of education, health care and cultural activities. Source: shutterstock.com

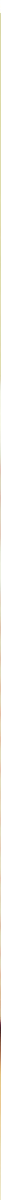


takes a dual focus-considering the region as a whole (policies, co-operation and overall innovation environment) as well as focusing in more detail on a specific local context-the municipality of Vardø. Vardø Municipality has been selected as a point of interest within the region for two reasons. First, the municipality provides an extreme example of the challenges faced by many Nordic rural municipalities. From 2000 to 2010, a fisheries crisis and the loss of a local army base saw Vardø's population shrink from 3200 to just 2 200, a reaction that significantly exceeded even the direst predictions of Statistics Norway. Unemployment rose to $30 \%$, Vardø's school was ranked one of the 40 worst in the country and the national government was forced to take over the city's finances. Second, the work of Vardø Municipality to stave off this crisis is instructive in demonstrating the role that digitalisation can play in turning such a situation around.

\section{Digitalisation approach}

Vardø Municipality's digital transformation began in the context of its need to respond to the socioeconomic crisis described above. Importantly, the implementation of digital technology was not a goal, but rather a strategy through which to achieve the broader goal of improving quality of life and creating opportunities for the people of Vardø.

The municipal administration was aware that it had limited power to create more jobs as a response to the crisis. Instead, it chose to focus on what it could address, such as improving the standard of education, health care and cultural activities. The theory was that if the administration could make Vardø a better place to live, economic prosperity would follow. Improvements included renovations of municipal buildings, developing a new school, a new kindergarten, a new health-care centre with modern facilities, a new retirement home and a municipal pool. Moreover, fibre-optic cables were provided to all households. At the same time, tough decisions had to be made. A new school was made possible through the amalgamation of three existing schools into one, a single kindergarten replaced four and the municipal staff was reduced from 240 to 160 . The debts resulting from these investments have been well served and the municipal budget has been stable since 2015 . These improvements were made possible by the restructuring of the municipal economy, including centralising the school system and the kindergartens, and taking up loans in the period 2005-2009. The economy saw an upturn in 2009.

Perhaps the most interesting element of Vardø's digitalisation work is the ambition to deliver worldclass education through the introduction of iPads as a teaching tool. The initiative was inspired by similar work in Bærum Municipality in the south of Norway and received broad support from parents and school staff from the outset. Importantly, the idea was proposed to teaching staff as a potential solution and alternatives (e.g., PCs) were discussed prior to the decision to go ahead with iPads. The idea was also approved (enthusiastically) by the student council. Once everyone was on board, Apple-certified

\section{Box 3. Hallgeir Sørnes's (Deputy of Vardø municipal administration) five tips for a digital transformation:}

- Choose standardised solutions:

It is cheaper and easier to get the right competencies when setting the system up, and it facilitates an easier recruitment process when most people already have some previous knowledge of the software and the tools

\section{- Capitalise on the positives:}

Define what the objectives should be beforehand, and make sure it is followed through. If a company has decided to go paperless, it must stop buying printers - Make sure all parties are on board early on:

Make sure that everybody understands that a digital transformation is only $20 \%$ technology and $80 \%$ organisational development. Management and co-workers need to be on board to define how and in what way the workplace and the team structures should change. It needs to be done in a dialogue

- Learn from others:

Establish a good dialogue with other municipalities and ensure that your municipality has the right competencies on board

- Use e-learning:

Have video conference meetings when needed. This may include teaching the new programmes 
instructors were brought in to support teachers to make the most of the new tools and every student and teacher was given an iPad. Students submit their work on the iPad and teachers respond online, enabling an efficient and transparent feedback process. Interestingly, although teachers are more available to their students, most report that they spend less out-of-school hours working than they did before. Students can more easily work at their own pace and ability level without creating additional work for teachers or singling students out that need extra help-they simply work on different applications simultaneously. This method has also encouraged more collaboration between students (e.g., providing feedback on assignments prior to submission). Parents are in a better position to provide support as they have insight into the learning process via apps.

As noted above, Vardø Municipality's success is underpinned by its focus on technology as a means to achieve its broader social and financial goals, rather than seeing the technology solutions as an end in themselves. In the example above, the iPads were simply a tool through which to enable a new culture of teaching and learning that would improve the quality of education. Goals were clearly defined from the outset and, in terms of efficiencyenhancing goals, there was a concerted effort to ensure the savings were realised-for instance, as one interviewee emphasised, one cannot invest in the technology to go paperless and then keep the printers; realising the savings is what makes it possible to justify and fund the next transformation.

Setting clear goals for the implementation of digital tools in Vardø Municipality did not necessarily require the development of a detailed, longterm plan. The authorities emphasised in the interview for this project that there is also a need for an agile and flexible approach. For example, although the aim may be to improve quality of life for residents, the specific actions through which this goal will be achieved will constantly change. This is demonstrated by a recent survey of the elderly residents of Vardø, which revealed that many felt insecure about being home alone. In response, the municipality is trialling smart watches that allow the user to make direct contact with a care provider in the event of an accident.

Wherever possible, the municipality uses free services to support its work (e.g., Facebook's authentication platform for public Wi-Fi access) and, even when purchasing solutions, the preference is always to go with an existing (generally cloudbased) solution. The municipality does not develop any customised platforms or systems. There are several benefits to this. First, there are cost savings, both in the initial purchase and in maintaining the system. Second, this approach substantially reduces the time it takes to realise a project, as the tool is ready to go. Third, when recruiting and training new staff, there is a better chance that people will already be familiar with the tools. Access to e-learning is also an important pre-requisite for introducing any new tool. This approach ensures that the municipality has access to high-quality training for its staff in a flexible way, without the expense of bringing in an expert from Oslo for long training seminars.

\section{The regional context and collaboration}

At a regional level, there are three key components to digitalisation work: provision of digital infrastructure, digitalisation of county services and business development. In the context of such a sparsely populated region, the provision of digital infrastructure is both vitally important and incredibly challenging. When work began on the augmentation of the Internet infrastructure in 2002, there was only one link to Finnmark through Troms County and important links to hospitals and other public services were missing. This prompted a collaborative project called IT Finnmark, which was a collaboration between the municipalities, the university college in Finnmark and industries, to ensure better Internet access in the county. As a result, several initiatives leading to the expansion of the fibre-optic cables and a coastal line were built and merged. After successful lobbying from Finnmark County, the national government created a common funding source through the national programme 'Broadband for all'. This funding source allowed municipalities and regions to access up to $60 \%$ of the necessary funds for digital infrastructure. Between 10 and 12 municipalities in Finnmark participated in this initiative.

Finnmark County is also working to digitalise its internal structures and processes. This work is guided by its Digitalisation Strategy for 2015-2018 (Po̊ vei inn i Fremtiden) and seeks to increase the efficiency and user-friendliness ('smart on the inside, simple on the outside') of public services, and to publicise the strategic opportunities that digitalisation has for businesses (FFK, 2015). The strategy has led to the recent establishment of a Digi- 
talisation Council, composed of representatives from each department. The council has mapped the current working processes across the county administration, implemented project methods to align with the national standards and used training to change mindsets and attitudes towards digital solutions among its employees to speed up and co-ordinate the county's digital strategy. Action plans for the digital agenda are published annually and are tied to the regional budget. Funding is also allocated on an annual basis to accommodate the fluid nature of digital goals and priorities, which are determined in consultation with business. The financial plan for 2015-2018 has proposed setting aside five million Norwegian Kroner to implement processes for digitalisation. Finnmark County also takes part in the County Administrative Optimal Services (Fylkeskommunale Optimale Tjenester) collaboration with five or six other county administrations. This collaboration has resulted in the development of several IT systems, including Rett i Mappa ('straight into the folder'), a system for streamlining student documentation and tailored learning for teenagers with special needs or learning disabilities.

Finnmark County Council plays an important role in supporting industrial development within the region, largely through its engagement with Innovation Norway, which helps funding entrepreneurs and businesses. Innovation Norway is a state-owned development bank, partly owned by the counties, with 13 regional offices across the country. The region is largely comprised of small businesses, with no companies over 100 employees. As such, clusters and networks play an important role and digital connectivity is vital. The introduction of fibre-optic cables was crucial to the sustainability of existing businesses and the establishment of new companies in the region. In Sør-Varanger, e.g., several IT startups have emerged in recent years, stemming from existing IT companies and the growing IT environment in the region. There is another strong IT sector on the other side of the county in the city of Alta, springing from the university campus and the competence centres in the city, particularly within the area of construction. In terms of funding instruments, Innovation Norway has the power to direct resources into promising businesses on behalf of the county council and the state. The inclusion of sustainability goals and references to digitalisation generally reflects favourably on applications.
One of Innovation Norway's primary concerns is tourism, and Innovation Norway's office in Finnmark is no exception. Although still in its early stages, Innovation Norway in Finnmark is looking into the use of digital tools to prepare tourists for the often harsh and dire arctic climate. These digital tools are primarily aimed at safety and rescue services, and there have been dialogues with Svalbard regarding their approaches to digitalisation in tourism.

Although both the regional and the municipal levels work actively with digitalisation, a relationship between the local and regional levels is absent. In terms of digital strategies, neither the municipal nor the county's strategies coincide. Thus, the closest link between the two levels is perhaps through the establishment of businesses, often aided by Innovation Norway. At the municipal level, one of the key elements of Vardø Municipality's digitalisation work is its contemporary approach to collaboration. When Vardø Municipality describes its key collaborations, it bypasses the neighbouring municipalities and looks to collaborators on a wider, national scale, as well as to partners outside the country's borders.

\section{Challenges and opportunities}

For Vardø Municipality, getting 'everyone on board' was both an important challenge that needed to be overcome in the beginning, and a crucial enabler for future work. The crisis that was the starting point for the work was both a help and hindrance. On the positive side, there was a general understanding that decisive action was necessary if the situation was to improve, given that the community had essentially hit rock bottom. At the same time, the dire nature of the situation meant that many of the decisions would result in substantial change and much of it was not perceived positively at the time. For example, before the iPad programme could be implemented, there was a fierce and passionate battle to save the two schools that were being closed through the consolidation efforts. Ultimately, once decisions received enough support to pass, they were supported by the community and, now that the situation has begun to turn around, public confidence in new initiatives has improved.

Although it was difficult initially, gaining support from everyone within the affected organisations for the new approach (e.g., the school in the case of the iPad programme) by providing encour- 
agement and support and making time for discussions, was the true key to success in the Vardø case. Building confidence and an association between change and good outcomes was vital. This emphasises Vardø's mantra that technology is only $20 \%$ of digitalisation, with organisations and people being the true enablers of change.

When it came to making the most of opportunities, Vardø's small size was among the key enablers. Put simply, gaining widespread support is much more achievable when there are fewer minds to change. Being small also makes it relatively easy to implement changes quickly. For example, if the trial of the smart watches for seniors discussed above is successful, the municipality can go ahead and order one for every elderly resident in its care tomorrow. The small scale of the purchase removes the need for lengthy approval and procurement processes that would be unavoidable for a larger municipality. This also applies to opportunities for e-learning.

A concerted steering effort from the municipal side was important for making tough decisions and also some bold choices: e.g., the augmentation of the school, the swimming pool, the iPads and so on. Department heads, the chief executive officer and the municipal administration's deputy were the key drivers of the work. Such change agents were vital in an environment going from bad to worse and they were invaluable in turning reactive organisations into proactive ones.

By 2016, the socio-economic situation in Vardø had completely turned around. There were fewer early school leavers and nearly all student has continued their education, either through apprenticeships, at universities or through military service, or they had jobs. The unemployment rate $(5 \%)$ is in line with the national average, the number of people on social benefits has decreased and the municipal budget is under control. Finally, although it is far from a return to pre-crisis levels, Vardø's population (approx. 2130 persons) has remained stable since 2009.

Examining the bigger picture, co-operation remains a substantial challenge in Finnmark. This includes a weak co-operation culture between municipalities and also appears to reflect a distrust in the ability of national policy to fully understand and cater to the needs of remote communities. This situation is not helped by the politically contentious merger pending between Finnmark and Troms County (see Box 4). With respect to the mu- nicipal-regional relationship, the non-hierarchical structure and weakly aligned policy frameworks have tended to limit conversation between the two administrative levels. This limits opportunities for innovation at the local level to 'trickle up' to regional policy in, e.g., education. ${ }^{18}$ Moreover, regional services and municipal public services are administered through different online portals.

\section{Box 4. Troms and Finnmark: A politically contentious regional merger}

In 2017, the Norwegian government decided to start the work on merging the Finnmark and Troms counties. The merger is part of a reform based on two parliamentary resolutions to decrease the number of counties. Contrary to development in North and South Trøndelag, where a voluntary merger is occurring, Finnmark and Troms will be merged without consent from the county councils. Although loyal to the government's decision and having followed their recommendations to appoint representatives to the interim new county council, Troms stated that it would not voluntarily merge with Finnmark if Finnmark opposed the merger. It became evident that Finnmark did oppose the merger when, despite the parliamentary decision on the matter, it hosted a referendum on the merger in April 2018. The response rate was overwhelmingly negative, with $87 \%$ of respondents opposing the impending merger. Although many of the processes were underway, the referendum resulted in a halt of all work in relation to the merger. The internal processes and procurement efforts for the merger must be in place by the 1 January 2020. Although the work continues internally in the two counties, progress so far has been limited and may affect the long-term outcomes.
18 In Norway, primary education is managed at the municipal level, whereas secondary education is the purview of the counties. 


\subsection{REGION SKÅNE/ HELSINGBORG}

\author{
by Anna Berlina and Laura Fagerlund
}

\section{About the case study area}

Skåne is the southernmost and the second largest county in Sweden by population. Skåne is a leading agricultural and food producing region in Sweden, with agricultural land covering almost half of the region's territory (48\%) (OECD, 2012). As in other industrialised countries, Skåne is undergoing a structural transformation resulting in increasing importance of the service sector in the economy and declining importance of agriculture and manufacturing (in terms of employment).

Skåne's tertiary sector is the largest of the economic sectors, generating $66 \%$ of the value added in the region and accounting for $80 \%$ of the employment. In the aftermath of the financial crisis, large companies such as Sony, Ericsson and AstraZeneca withdrew or downsized, leading to a rise in SME capacity and highly qualified labour in IT and mobile technologies were then dedicated towards new development areas, such as health tech and game development industries (Nilsson et al., 2017).

Skåne has an advanced regional innovation environment supported by large and varied cluster initiatives in Skåne within life science, ICT, new media, creative industries, maritime technology and cleantech, with the support of leading universities and research centres (e.g., European Spallation Source).

To the west, Skåne shares a border with Denmark, which can be reached across the Öresund Bridge between Malmö and Copenhagen in less than an hour, or by ferry between Helsingborg and Helsingør (Regionfakta, 2018). The closeness between the two countries provides unique opportunities for regional co-operation and economic growth, which are promoted by the Greater Copenhagen and Skåne Committee. Greater Copenhagen is home to Scandinavia's largest recruitment base of high-skilled employees and is one of the world's most innovative cross-border regions (Business Region Skåne, 2015; Nilsson et al., 2017).

The Helsingborg and Malmö municipalities stand out for their digitalisation work in Skåne and act as role models for the region as a whole. For this reason, this case study focuses on the local example of Helsingborg Municipality. Helsingborg

\section{Skåne County}

Population: 1340415 (Sept 2017)

Area: $11035 \mathrm{~km}^{2}$

Density: $120 / \mathrm{km}^{2}$

Municipalities: 33

Administrative centre: Malmö (280 415

inhabitants)

Regional strengths: life sciences, food sector, telecommunications. New areas: health tech and game development (Nilsson et al., 2017; Regionfakta, 2018)

has a long-term focus on digitalisation for which it received several awards, including 'the best IT municipality in Sweden' in 2015 and 'the leading ecommerce city in southern Sweden' in 2016.

Helsingborg is the second largest municipality in the Skåne region by population (140 000 inhabitants). It is located at Sweden's closest point to Denmark, only $4 \mathrm{~km}$ away from the Danish city of Helsingør, which can be reached by ferry. Its location indicates the historical importance of harbour and trade activities. Today, the strongest economic sectors in Helsingborg are retail, logistics and transport, life science, tourism, cleantech and digital commerce (Business Helsingborg, 2018).

\section{Digitalisation approach}

The digitalisation journey in Helsingborg began with the outbreak of the financial crisis about a decade ago, when Palle Lundberg took his position as the new Head of the City. Under his leadership, the municipal administration has put a great deal of emphasis on curiosity, change, the Internet and digitalisation as means to foster innovation and development in the municipality. Helsingborg's task was formulated by Lundberg as 'looking into how we can use the possibilities of the Internet to solve our problems'.

Perhaps the most interesting element of Helsingborg's digitalisation work is its ambitious attempt to gain support from all municipal employees (and citizens) in unleashing the opportunities of digitalisation by encouraging a culture of change, testing, failing and continuous learning and taking a rather fluid and unstructured (decentralised) approach to digitalisation. The overarching aim of digitalisation initiatives in the municipality is to improve the quality of life for the citizens and achieve organisational change in the municipal administration and its departments. 


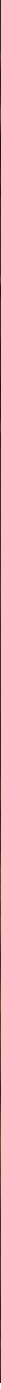

In the aftermath of the financial crisis, large companies in Skåne region withdrew or downsized, leading to a rise in SME capacity and highly qualified labour in IT and mobile technologies were then dedicated towards new development areas, such as health tech and game development industries. Source: unsplash.com

The City of Helsingborg has focused heavily on internal and external branding, marketing itself as a creative, vibrant, digitalised, global and forward-thinking city to attract investors, tourists and workers and to improve the quality of life of its citizens. These goals are apparent in the Vision 2035 for Helsingborg, which acts as a common policy for employees and leadership in the municipality. As part of the vision, digitalisation should provide a coherent, flexible and individual service to every citizen. Digitalisation is viewed as a crosscutting development process in the local administration across nine departments, with around 10000 employees in total, and it is not addressed as a separate theme.

There are several key actors spurring the work on digitalisation in the municipality, including the Head of the City, the Director for Digitalisation, the Head of Future and the Programme Director for Smart Helsingborg. However, an overall co-ordinating body is non-existent. There is no overarching organisa- tion or department responsible for strategic planning, co-ordinating or evaluating the digitalisation initiatives. This approach was deliberately chosen by the municipality to avoid creating new systems and to stimulate working in a more agile and decentralised way.

The approach to digitalisation in the municipality is based on three main principles. The first principle is turning away from strategies and plans and turning to testing and learning. The aim is to challenge the traditional ways of working and promote organisational change within the municipality and its administration. 'Think big, start small, then fail or scale fast' is the philosophy of Helsingborg. Helsingborg does not have a digitalisation strategy, as the municipality has put its time and resources into taking concrete actions, which it finds more valuable.

The second principle implies shifting away from thinking about IT and systems to thinking about people and needs. This approach promotes 
a move away from the creation of heavy systems and highlights the significance of the societal aspects of digitalisation for Helsingborg, in addition to the technological change. The citizens play a crucial role in the process as the overarching goal is to develop user-friendly services for the individuals that improve the quality of life in the municipality.

Finally, the third principle promotes digitalisation 'shifting from somebody else's responsibility to everybody's responsibility'. This approach emphasises the importance of the active participation and engagement of all employees of the municipality and citizens in the digitalisation process. It aligns well with Helsingborg's aim to become the municipality with the world's most engaged citizens.

These principles help to reframe digitalisation so that it is not regarded as something complicated, big and expensive, but as something that is natural in everybody's everyday life. More specifically, the digitalisation work in Helsingborg is anchored in five focus areas, which mainly deal with digitalisation as a tool for improving leadership, collaboration, transparency, services and learning, as described below:

1. 'My Helsingborg' platform: aims at providing better services to the citizens

2. 'Smart Helsingborg' platform: allows individuals and actors to create services and value in the city

3. Mobilisation: fostering interaction, learning and collaboration among different actors, arenas and channels

4. Abilities: introducing new methods for development and exploration. Aims to raising the digital competence throughout the whole organisation and different departments. For instance, digidel is a physical platform that was created to raise digital awareness and competence in the city, where everybody can try, borrow and become acquainted with the latest technologies

5. Information: developing a common definition of and management process for key data about customers and individuals. Open Data Initiative is a long-term project aimed at making data from the city freely accessible to all residents

Perhaps the key success factors in Helsingborg's work with digitalisation were the enabling leadership that encourages testing, failing and learning, and the long-term commitment and support from the political level. As the Director for Digitalisation in Helsingborg stated, 'Do not start with technology or the solution, start with the leadership and the communication'; this encapsulates the lesson for successful digitalisation work arising from the Helsingborg case.

\section{The regional context and collaboration}

The digitalisation initiatives are most pronounced at the city level in Helsingborg. The 'city' is described as a collaborative platform/test bed in which everyone is invited to participate, both individuals, organisations and companies, by contributing their own resources and developing services and creating value for others (Helsingborg, 2017).

Currently, there are weak interactions and synergies between the municipal and regional levels in working with digitalisation issues. Moreover, Helsingborg's digitalisation priorities are not inspired by or aligned with the national Digital Agenda. The collaboration on digital initiatives at the city-to-city level (e.g., the EU Urban Agenda) and in the framework of a Greater Copenhagen was described as more important and relevant for Helsingborg.

Since 2016, the Swedish-Danish border region, which consists of 22 Swedish and 46 Danish municipalities, has been marketed as 'Greater Copenhagen' to increase its international recognition and attract investments and startups (Greater Copenhagen, 2018). Improving digital infrastructure and strengthening digital competencies are among the priorities foreseen in the action plan for Greater Copenhagen 2018-2019 (The Greater Copenhagen and Skåne Committee, 2017).

Region Skåne is among the few counties in Sweden that have not drawn up a regional digital agenda yet. Instead, the Region has focused on increasing connectivity and broadband infrastructure in its 33 municipalities and, in recent years, digital health care. To compensate for the lack of the digital agenda, Region Skåne is currently undertaking an overarching analysis of the status of digitalisation in its 33 municipalities, as well as mapping the activities of the business sector and academia. The intention is to identify the specific tasks and areas for Region Skåne that would be relevant for promoting digitalisation in the regional context.

Although its more pronounced work on digitalisation commenced relatively recently, Region Skåne has indirectly supported the digital transformation. For example, since 2011, it has provided 
financial support to cluster organisations and incubators through a regional cluster development programme. The Region also strongly encourages cross-cluster collaboration.

The cluster organisation Mobile Heights brings together representatives from the public and private sectors and academia to encourage new synergies and collaborations. The key focus areas are future digital health, smart digital society and smart materials, as well as facilitating talents supply to Skåne. Among the concrete examples of its work, Mobile Heights assists member companies to sell smart city solutions to the municipalities, as well as facilitating co-operation among the local universities and the municipality in the smart city context.

Innovation Skåne works under Region Skåne by supporting innovation, startups and regional development, acting as both incubator and accelerator. One focus area is facilitating the development of health-tech companies ('health-care entrepreneurship') with the aim of improving health care and solving societal problems in the region and globally.

\section{Challenges and opportunities}

Talent supply is the overall challenge for supporting innovation ecosystems in the region, as Stockholm remains the main 'pull' centre in Sweden for startups and venture capital. At the same time, there are good opportunities for building on the existing expertise, knowledge and competencies in the telecom business in Skåne to become a powerhouse for the loT, health-tech innovations and startups. Fortunately, the workforce from the mobile industries in Skåne is highly capable in applying its competencies and skills to other digital businesses. The Mobile Heights cluster company, mentioned above, acts as a facilitator of this process, working actively to bridge the gap by accelerating education and attracting talents and startups.

Being part of the Greater Copenhagen area assists Skåne in attracting venture capital and startups. However, the passport control introduced in the Öresund area in 2015 resulted in declining cross-border labour mobility, which affected labour market integration and co-operation and the business environment.
For the public sector in particular, attracting people with the specific competences required is among the key challenges in supporting digitalisation. People with socio-technological skills, who can work in an interdisciplinary manner, will be in high demand in future. To increase the attractiveness of jobs in the public sector and to attract talent, the City of Helsingborg has put significant efforts into employee branding. It launched an Innovation Hub 'Hbg Works', which is a co-working space for the municipal employees. Innovation Hub aims at fostering creativity and collaboration within and across different municipal departments and the private sector.

Regarding other consequences of the transformation of the labour market, the authorities in Helsingborg and Region Skåne prefer to talk about the 'change of tasks' in the public sector rather than a loss of jobs. Here, the challenge is to change the employees' mindset, so that rather than feeling threatened by digitalisation, they regard it as a development opportunity in their occupation.

When considering the specific challenges for Helsingborg, the municipal authorities consider that fear of failure and a lack of courage to try and learn are the main obstacles to the digitalisation process in the municipality.

Despite Sweden scoring high at the EU level for connectivity, the digital infrastructure in remote areas of Skåne remains a challenge, with around $30 \%$ of rural areas left without fibre infrastructure. In these areas, the cost of infrastructure development is higher than the revenues. Developing infrastructure in remote areas is among the focus areas for Region Skåne in the following years. According to the regional broadband strategy, 95\% of the region should have access to at least 100 megabits/second by 2020 (Region Skåne, 2018).

The lack of standardisation in the public sector is another roadblock to digitalisation in Region Skåne and a challenge for Sweden as a whole. Creating clear standards rather than developing one centralised system for everyone would ensure that the digital tools and solutions developed by the municipalities and regions are compatible (e.g., in the health-care sector), are able to communicate with each other and can be used across different authorities and municipalities. 


\section{Findings}

This report has provided a conceptual overview of This report has provided a conceptual overview of digitalisation in the context of sustainable Nordic regional development, as well as highlighting the national priorities and focusing on several regional case studies. This fourth and final section presents the key findings of this work as it relates to different actors within the Nordic regional development landscape; and provides answers to the research questions that were introduced in the introduction.

\subsection{What are the focus areas of digitalisation strategies in Nordic regions?}

\section{National level}

Digitalisation has become a prominent issue on the agenda of the national governments in the Nordic Region in recent years. It is a horizontal priority that cuts across different policy areas, ministries and levels of government. Although the specific priorities of digitalisation strategies differ between countries, some similarities across the themes can be observed.

Digitalisation of public services with the purpose of enhancing efficiency in the public sector and improving quality of services, as well as promoting business development, is the most common focus area across the national digitalisation strategies in the Nordic Region. This is followed by accelerating the digital transformation of the business sector, SMEs in particular. In connection to this, digitalisation is referred to as a driver for the growth and competitiveness of the industries and businesses. Both priorities are included in the three key objectives of the Nordic co-operation on digitalisation, set out in the declaration for digitalisation The Nordic-Baltic Region: A Digital Front-Runner. The third most common focus area that has gained significant attention in the Nordic national digitalisation strategies is facilitating development of digital competencies and skills.

Digital infrastructure, more specifically, developing a centralised IT architecture and ensuring interoperability between IT systems is high on the agenda in Iceland, the Faroe Islands and Greenland. These countries and independent territories have chosen to use the Estonian X-Road system for the public digital architecture.

\section{Local/regional level}

At the local/regional level, digital technologies were primarily seen as tools to fulfil existing responsibilities and realise local and regional goals. As such, specific priorities varied, based on the issues that were most pressing in each specific place, and mirrored the tasks and responsibilities of the authority in question. In line with this, informants consistently described digitalisation as a cross-cutting policy theme as opposed to a specific policy area. At the same time, it was possible to identify several digital focus areas that were consistent across the cases, including:

Digitising government services. The beneficiaries of these programmes are generally residents and other service users, although actions tended to be internal. Emphasis was put on service improvement and increased quality of life for residents, rather than on reducing cost. However, cost saving through increased efficiency was clearly a catalyst at times.

Digital infrastructure. Ensuring equal access to digital infrastructure was most relevant at the regional level and was a particular concern in rural and remote areas. Connectivity was an important pre-condition for increased competitiveness, accessibility and attractiveness of the rural and remote areas and a first step to bridging the urbanrural digital divide.

e-health (health tech and telemedicine). Digitalisation is a key tool in developing the healthcare sector, as it is seen as means of increasing productivity and improving patients' experiences. There are unlimited opportunities for developing health-care entrepreneurship with both regional and global markets.

- Creating 'smart' cities. This was a common notion, particularly at the municipal level. Interestingly, the 'smartness' was thought to be less about 
technology and more about co-operation between actors to optimise city functions and respond to local challenges. A desire to utilise the city as a test bed and a driver of local innovation was also common.

- Promoting public participation. The use of digital tools to encourage new forms of exchange and dialogue with the residents, as well as their participation in decision-making and community life, was common, particularly at the city level.

- Growing local business and startup culture. This was largely the purview of regional business associations and generally included hosting different types of networking and problem-solving events (e.g., hackathons), providing seed funding or supporting businesses to navigate public institutions and legislation.

'I think we're talking about the new generation of smart cities that are smart in mindset [...] I think we need to be smarter in the way we do things, not in the different solutions; how to involve others to do things better together.' (Björn Lahti, Helsingborg)

\subsection{How is digitalisation approached in Nordic regions?}

Perhaps the most consistent finding across the regional case studies was the idea that digitalisation is more a human process than a technical one. A common analogy was that digitalisation deals $20 \%$ with technology and $80 \%$ with people, with the people component largely involving a process of change management. Although this process looked different in each case, the following elements arose in various combinations in most cases and could be considered important success factors for working with digitalisation in a public sector context:

A specific internal team to support digitalisation work, supported by a trusted and visionary leader. This team's role was to support other parts of the organisation to adapt their work for the digital age, without taking on decision-making responsibility or ongoing tasks themselves (e.g., brainstorming potential solutions, creating mutually beneficial links between departments or recommending contractors for the technical components). Importantly, care should be taken when creating such a team that it does not create a perception that digitalisation is someone else's responsibility. Strong leadership driving digitalisation work is among the main prerequisites for success.

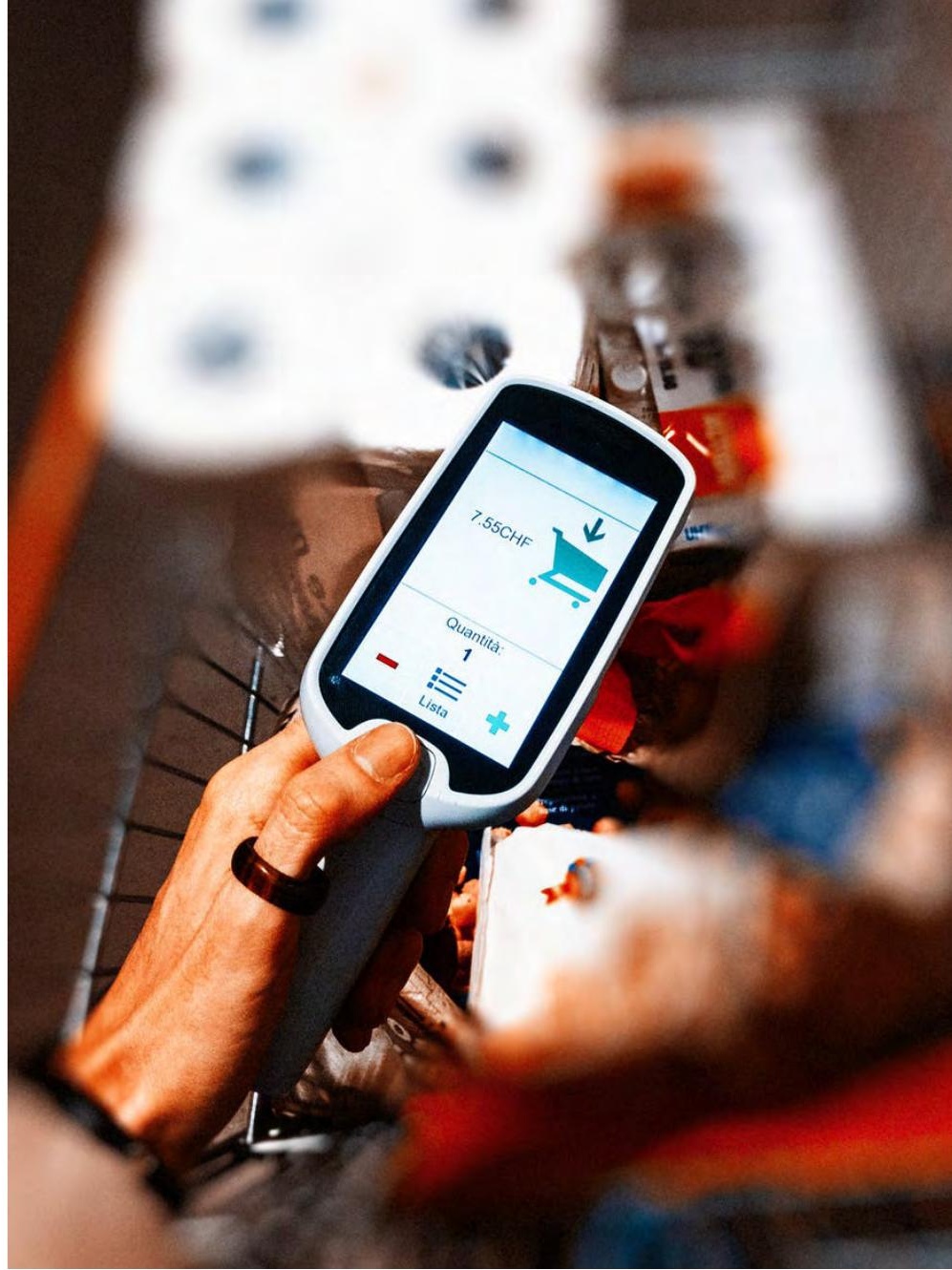

Source: pexels.com

'Imagine we have a pop band which has its own instruments and we're trying to make it into a symphony orchestra. We buy them new instruments and then we think that "there we have a symphony orchestra". But it requires a lot of work in change management. Some roles, competences, even people need to be reconsidered so that the new instruments are played well, and the band turns into a symphony orchestra. This is exactly the same here. Some might think that the new instruments mark a finished project even though the journey is only about to begin.' (Jarkko Oksala, Chief Information Officer at City of Tampere)

- A whole-organisation approach. Buy-in from department heads and front-line staff was important in overcoming inertia and fear of change and gaining widespread support. Wherever possible, leadership should come from those responsible for the long-term success of new initiatives (e.g., department heads) and those responsible for implementing change (e.g., front-line staff) should always be included in decision-making. It is vital that sufficient resources (particularly time) are dedicated to this work across the organisation. 
This may mean freeing staff from their regular tasks for a clearly defined period.

- Find achievable goals and 'just do it'. 'Think big, start small, then fail or scale fast' is the philosophy of Helsingborg that emphasises the importance of taking concrete actions (which may or may not bring promising results) and promotes a 'just-doit' approach.

- Create a shared sense of pride in the achievements. Developing an association between change and positive outcomes is an important motivator, inspiring bravery, overcoming negative attitudes and ensuring commitment to the process in the long run.

- Avoid strategy documents, targets and action plans that are too detailed or long-term in their approach. The fast-paced nature of digital change requires agility, openness and flexibility, which may be stifled by too rigid a policy approach. Setting clear goals but being flexible about how they should be achieved is important in creating an environment that fosters innovation and creativity. An exception to this is the provision of digital infrastructure, which obviously requires a degree of long-term planning.

- Take a customer-centred approach. Engaging residents in a dialogue and action as drivers of change is a common theme. In Helsingborg, one of the digitalisation principles was described as shifting 'away from thinking about IT and systems to thinking about people and needs', again emphasising the social nature of the digitalisation process.

Overall, it is important to acknowledge that, despite the fast pace of digitalisation, change management is a slow process that requires long-term commitment, strong political and institutional support and investment of resources. Without this, new initiatives are unlikely to result in the cultural and mindset change that is required to fully harness the opportunities associated with digitalisation. This change includes creating a culture of innovation, experimentation and bravery that can be sustained in the long term. It also means creating new ways of working, both within the public sector itself and in the way that public institutions work with other actors. As such, it is vital that decision makers understand that, even where improved efficiency is a driver of digitalisation work, initial investments need to be made and savings may not be realised for some time.

\subsection{How are regions dealing with the challenges and opportunities related to digitalisation? (particularly with respect to the green transition and labour market impacts)}

All interview participants noted the current and future labour market impacts of digitalisation and saw these as presenting both challenges and opportunities. Specific themes that were discussed across multiple cases included:

Embracing job change. Interview participants were both aware of and in agreement with current estimates around the potential for automation of existing labour market functions-including their impact on low-, middle- and even high-skilled professions. This trend was viewed as something policy makers needed to work with and respond to, rather than something to be fought against or reversed. Part of this is about shifting mindsets from a culture of fear to an enthusiasm about how different work roles can be improved by taking out the more menial elements.

- Exploring creative responses to unemployment. Finding new ways to support those whose skills have lost value in the labour market will be important in creating a socially inclusive digital future. The universal basic income was suggested as a potentially useful tool to support people to take greater risks, or more time, in getting back into the labour market. Redundancy packages designed to encourage entrepreneurship may also be helpful. Alongside this, there is a need to reduce the stigma around unemployment and to view these transitions as an accepted part of working life.

- Managing skills shortages. Skills shortages appear to be particularly pronounced in emerging industries associated with digitalisation, e.g., Al and machine learning. They were also a problem in more general areas, such as computer programming. In the regional cases, participants were more likely to describe skills shortages than skills mismatches. Those who can work well at the intersection of people and technology are in particular demand. This presents a great opportunity to make more space for women who are underrepresented in the ICT industry today and enhance inclusiveness.

- Attracting a younger and more dynamic workforce to the public sector. Some of the public authorities interviewed were critical about the rigid structures of the public sector and they considered the low attractiveness of public sector jobs to be a 
significant barrier to attracting the talents needed for driving digitalisation work.

New ways of thinking about education and training. Many participants suggested the need for a shift to competence-based learning and a greater focus on developing transferable skills (e.g., critical thinking and creativity) as opposed to training for specific, fixed professions. There was also support for the introduction of more flexible degree programmes that allow students to take unique, multidisciplinary combinations of courses (including industry-based learning) within a single degree program. Finally, there were calls for a renewed focus on lifelong learning, with higher education institutes working more actively with a broader subset of the community, as well as finding ways to acknowledge competences learned outside of institutional contexts.

- Retaining and reviving manufacturing industries. Automation and mechanisation offer opportunities for value creation that have the potential to be instrumental in supporting the retention of jobs in manufacturing and heavy industries within Nordic regions. Although automation may result in some job losses, it may also enable the retention or revival of industries that otherwise would be forced to move production offshore due to high labour costs.

- Opportunities for new business models that encourage more diverse regional economies. The most obvious example of finding new business models was Tampere, a region once heavily reliant on just two companies (Nokia and Microsoft) as providers of high-skilled jobs, which now hosts a diverse array of different sized companies, both homegrown and international. In Reykjavík, there was also evidence of municipal efforts to collaborate with smaller companies and startups (as opposed to the 'big two') to encourage fresh approaches and new ideas.

'Today, we are training people for jobs that we don't yet have names for. So, it is about training how to learn, it is about training capabilities, it is about training abilities, to take on different types of roles ... not saying, "I went through this training and now I'm only seeking this job". Horrendous idea. We are still seeing this especially in Finland, we have an $8 \%$ unemployment rate right when everything is heating up. It is not good, it has something to do with this mindset.' (Juha Latvala, Intopalo, Tampere)
When it came to the green transition, most interviewees were able to point at positive environmental outcomes as a result of digital initiatives. For example, digital services were regarded as a means to reduce physical travel, sensors and LED lights were used in combination to decrease energy use, smart transport solutions were provided and rubbish bins were emptied only when they were full. The underlying assumption in many cases was that smart solutions were, by their nature, green solutions, and the city itself acts as a 'living lab' for testing new ideas and solutions. At the same time, environmental sustainability appears to be an outcome of digitalisation rather than a driver. Interestingly, interviewees from Helsingborg Municipality described the city's environmental work as operating in a similar way to its digitalisation work-as a cross-cutting theme across all city functions.

Interviewees also raised the potential for digitalisation as a tool for socio-economic inclusion. Specific examples included:

Online services equal more accessible services. In the context of the high penetration of digital technology in Nordic societies, taking services online was considered synonymous, to an extent, with making them more accessible, particularly in rural areas and in the case of health care. HealthTech is also thought to be an important industry for the Nordic regions, with a number of high potential startups in Region Skåne (over 155), offering a variety of empowering solutions (HealthTech Nordic, 2018).

- The empowerment of youth and elderly residents. The iPad programme at Vardø School makes it easier for teachers to work with students at their own level, without the need to single out students for special classes. At the other end of the scale, most interviewees were resistant to the notion that elderly people are being left behind by digitalisation, with several pointing to new developments that allow for the use of technology without the need to learn new skills, e.g., voice recognition software and sensors, suggesting these as useful ways to increase autonomy and feelings of security among older residents. At the same time, reducing the amount of manual labour associated with caring has the potential to save resources that could be invested in social care instead.

- Increasing public participation and democracy. Digital tools have great potential to allow decision 


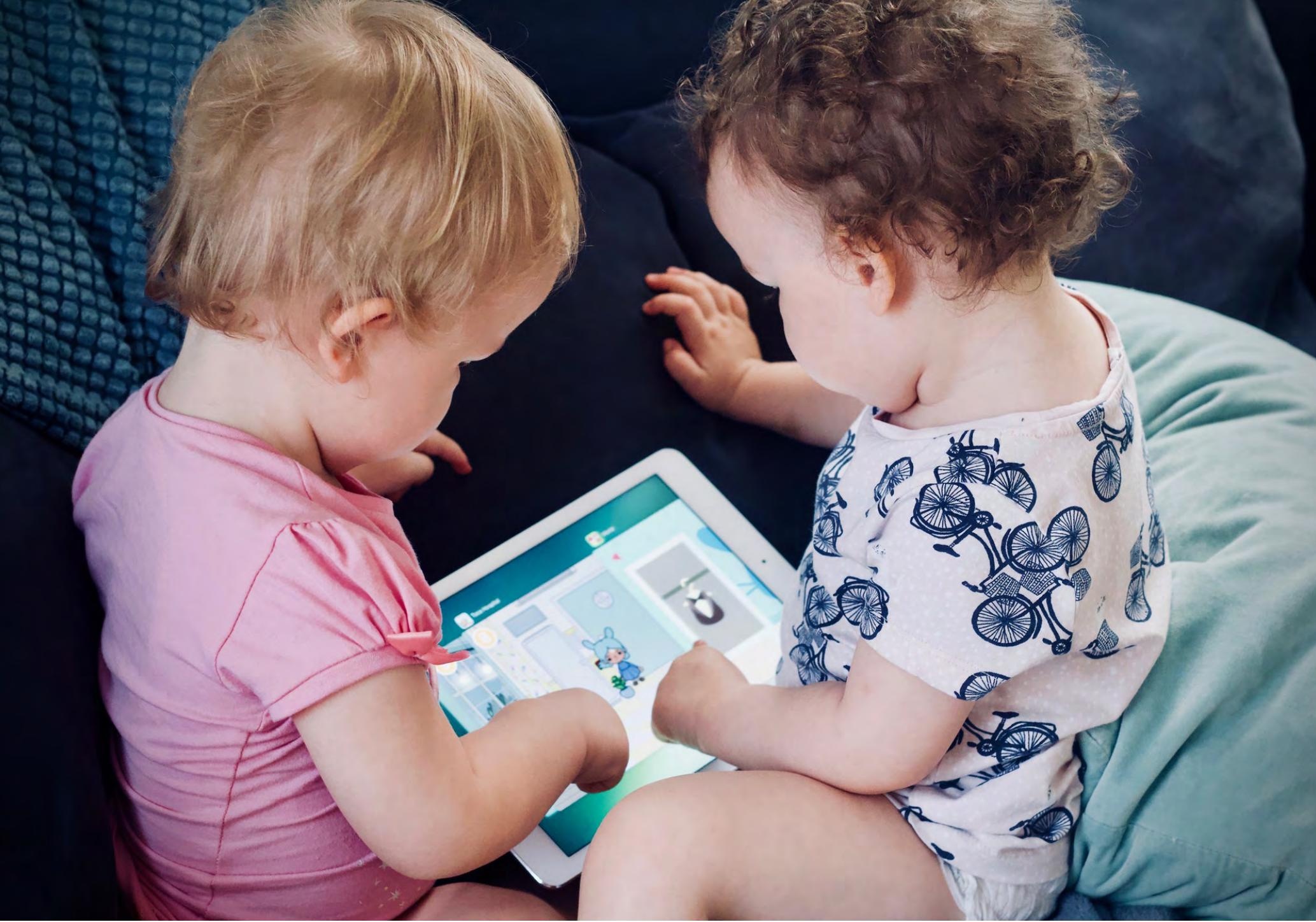

Source: unsplash.com

makers to reach out to citizens and vice-versa and have been an integral part of smart city initiatives. At the same time, the interviewees were critical about the potential threats associated with use of personal data and information in the digital society. The use of open data, e.g., although opening up many opportunities, also poses many uncertainties.

Interestingly, despite the fact that, as described above, the digitalisation process was conceptualised in the case study regions as being largely a human process, the work still appeared to be maledominated-at least at the upper levels. A shift towards a human-centric view of digitalisation (as opposed to a technology-centred approach) has the potential to be useful in opening up more opportunities for women in the digital transformation.

'To me, those digital solutions that I see in the future using $A$ l and everything, they will be safer, better, they will be the tools to develop better diagnosis, improved prevention, etc. So, it's really beneficial to mankind and it's also solutions that will be distributed throughout the world at low cost; it's affordable to everyone. This is a development that is accessible everywhere to everyone practically.' (Marianne Larsson, Innovation Skåne)

\subsection{Where are the strongest potentials for knowledge-sharing/ collaboration on digitalisation at the different governance levels?}

Digitalisation is clearly an issue with broad political support and it presents substantial opportunity for long-term collaboration across local, regional and even national borders. We need a stronger collaboration in all levels of governance because digitalization work is insufficiently coordinated in the public sector. What is less clear, however, is how the different levels of government should interact and which roles are best suited to each level. This research found that the most effective attempts 
to harness digital opportunity appeared to take a bottom-up approach, embracing technology as appropriate to respond to local challenges, needs and priorities. As such, digital priorities should be defined in line with the specific responsibilities of the governance level in question. The following provides a brief summary of potential roles for the different levels of government based on the findings from the case study regions. It also highlights the different actor constellations that may be advantageous in the digital age. It should be noted that interviewees often described what was desirable, and not all of these suggestions were happening in practice in each case.

\section{At the local level:}

- Digital technologies are adopted as appropriate to support the pursuit of goals that are locally defined though engagement with business and community.

Different types of actors work together on tangible projects seeking innovative solutions to local challenges, creating new networks and leading to new business opportunities.

- Municipalities undertaking similar tasks or facing similar challenges share ideas and learning (even across national borders). By increasing collaboration and coordination, municipalities may prevent repeating mistakes and save resources.

\section{At the regional level:}

- A consistent level of digital infrastructure is ensured, particularly with respect to rural areas.

- Support is provided to industry, new business development and smart specialisation in the context of digitalisation. This requires a stronger awareness of what is happening at the local level (e.g., the most promising 'smart' solutions, the fastest growing startups, promising 'smart village'style initiatives), providing links between municipalities and feeding local and regional priorities up through the higher levels of governance. It may also include working more closely with startups, enabling growth by supporting them to navigate public systems.

- Connections are created between industry and higher education institutes and open dialogue about the changing nature of work and learning is facilitated in a broad range of contexts.

- Dialogue between municipalities is promoted, encouraging collaboration on shared challenges and the interoperability of systems.

\section{At the national level:}

- Funding mechanisms are flexible, enabling digital investment that can be tailored to local needs. The capacity for different regions and municipalities to harness the benefits of digitalisation should be carefully considered, with greater support provided in areas with low absorption capacity.

- Policies that stifle the ways of working outlined in this research are examined and brought up to date for the digital age. For example, several interviewees described the way that current public procurement laws hampered their ability to work with younger companies or startups by being unintentionally bias towards larger and more established companies.

- Standards are developed to ensure electronic systems developed/used at other levels are compatible and secure (there is potential for Nordic or even EU co-operation on this in the future). Ensuring that systems are compatible implies easier communication across different authorities and municipalities, which will increase efficiency and reduce costs in the long term. It may also allow for more innovative uses of big data in the future. The introduction of standards, as opposed to the development of systems, was recommended by participants to ensure interoperability within and between the different levels of government, while simultaneously maintaining the freedom and flexibility to develop locally appropriate solutions. This work is particularly relevant in the context of the regional and municipal reforms currently ongoing in several Nordic countries.

'In the private sector, the companies have managed to create standards. The standards are needed so that everybody knows how to create products for that. That means that you will get an innovation level, you will get investments, you will get the money flowing in ... I can't just figure out why this whole standardisation thing hasn't been happening in the public sector, that would be perfect. That would change the whole game.' (Martin Güll, Director for Digitalisation in Helsingborg)

\section{At the Nordic level:}

- Connections are made between cities, regions and rural areas that face similar challenges. There is great potential for sub-national knowledge transfer, collaboration and promotion of success stories, particularly in the case of small- and medium-sized cities. According to many interviewees, 
these cities are ideally sized to act as test beds for digital solutions. They can experiment without making huge investments and their size eases the process of developing and maintaining collaborative relationships.

- Collaboration with national-level actors (such as occurred through Digital North) should focus on ensuring that national standards (described above) are compatible between countries, as well as within them.

- Joint advocacy and knowledge-sharing accelerates the digital transition at the EU level.

\subsection{Concluding remarks}

Digitalisation is a fast-pace irreversible process and is at the heart of the Fourth Industrial Revolution (World Economic Forum, 2016). Digitalisation is at the forefront of the national agendas in the Nordic Region and is high on the Nordic co-oper- ation agenda. The opportunities and challenges to digitalisation are many and have been widely studied. The added value of this study was the regional perspective on the digitalisation issues in Nordic regions. More specifically, the discussion on the key approaches, challenges and opportunities related to digitalisation and identifying the collaboration opportunities are intended to improve knowledge on how to foster the positive effects of digitalisation in other regions and encouraging joint Nordic learning based on this study. This study demonstrated that there are a variety of approaches to digitalisation at the regional and local levels, and that digitalisation is a cross-cutting issue across the departments and policy areas. Despite the relevance of national steering, this study revealed the importance of local embeddedness of digitalisation to truly become a driver for change. 


\section{References}

6Aika (2018) Smart Cities Work Together. In: 6aika. Available at: https://6aika.fi/in-english/ (accessed 19 November 2018).

Alm E, Colliander N, Deforche F, et al. (2016) Digitizing Europe: Why Northern European frontrunners must drive digitization of the EU economy. Boston Consulting Group, Stockholm. Available at: http://image-src.bcg.com/BCGDigitizing-Europe-May-2016_tcm22-36552.pdf.

Autor DH (2015) Why Are There Still So Many Jobs? The History and Future of Workplace Automation. Journal of Economic Perspectives 29(3): 3-30. DOI: 10.1257/jep.29.3.3.

BBC (2016) Nokia: Life after the fall of a mobile phone giant. Available at: https://www.bbc. com/news/business-35807556 (accessed 19 November 2018).

Berger T and Frey CB (2016) Structural Transformation in the OECD: Digitalisation, Deindustrialisation and the Future of Work. 193, OECD Social, Employment and Migration Working Papers, 30 September. DOI: 10.1787/5jlrO68802f7-en.

Borges, L. A.; Nilsson, K.; Tunström, M.; Dis, A. T.; Perjo, L.; Berlina, A.; Costa, S. O.; Fredricsson, C.; Grunfelder, J.; Johnsen, I.; Kristensen, I.; Randall, L.; Smas, L.; Weber, R. (2017) White paper on Nordic Sustainable Cities. Nordregio.

Business Helsingborg (2018) Digital commerce | Business Helsingborg. Available at: https:// businesshelsingborg.com/why/strong-sectors/ e-commerce/ (accessed 14 August 2018).

Business Region Skåne (2015) Thriving centre for international business | Skane.com. Available at: https://www.skane.com/en/thrivingcentre-for-international-business (accessed 16 August 2018).

City of Tampere (2015) Information on Tampere. Available at: https://www.tampere.fi/en/cityof-tampere/information-on-tampere.html (accessed 19 November 2018).

Citypack (2018) Danish Citypack. Available at: https://citypack.dk/english (accessed 20 November 2018).

Council of Tampere Region (2017) Pirkanmaa regional development program 2018 - 2020.
Degryse C (2016) Digitalisation of the Economy and its Impact on Labour Markets. SSRN Electronic Journal. DOI: 10.2139/ssrn.2730550.

Digital21 (2018) Digitale grep for norsk verdiskaping Samlede anbefalinger. Available at: https://digital21.no/wp-content/ uploads/2018/09/Digital21_strategi_2018.pdf.

Dølvik JE and Jesnes K (2017) Nordic labour markets and the sharing economy.: 61.

ENRD (2017) Workshop 1 - Rural Digital Hubs. How to ensure that they successfully help rural businesses seize the opportunities of digitisation? Available at: https://enrd. ec.europa.eu/sites/enrd/files/s4_ruralbusinesses-factsheet_digital-hubs.pdf. ESPON (2017) Policy Brief: The territorial and urban dimensions of the digital transition of public services. Available at: https://www. espon.eu/digital-transition (accessed 23 November 2018).

European Commission (2012) eHealth Action Plan 2012-2020: Innovative healthcare for the 21st century. Available at: https://ec.europa.eu/ digital-single-market/en/news/ehealth-actionplan-2012-2020-innovative-healthcare-21stcentury (accessed 23 November 2018).

European Commission (2014) Digital agenda for Europe. Available at: https://eige.europa.eu/ resources/digital_agenda_en.pdf (accessed 23 November 2018).

European Commission (2015) Communication from the Commission. A Digital Single Market Strategy for Europe. ,. Available at: https:// eur-lex.europa.eu/legal-content/EN/TXT/?qid= 1447773803386\&uri=CELEX\%3A52015DC0192 (accessed 23 November 2018).

European Commission (2016a) Blveprint for cities and regions as launch-pads for digital transformation. Available at: https:// ec.europa.eu/growth/industry/policy/digitaltransformation/role-cities-regions_en.

European Commission (2016b) Communication: EU eGovernment Action Plan 2016-2020

- Accelerating the digital transformation of government. Available at: https:// ec.europa.eu/digital-single-market/en/ news/communication-eu-egovernment- 
action-plan-2016-2020-accelerating-digitaltransformation (accessed 23 November 2018).

European Commission (2016c) Cork 2.0

Declaration: A better life in rural areas.

Available at: https://ec.europa.eu/agriculture/ sites/agriculture/files/events/2016/ruraldevelopment/cork-declaration-2-O_en.pdf (accessed 17 January 2019).

European Commission (2016d) Digital Entrepreneurship Monitor: Espoo as a digital launchpad. Available at: http://www. digitallytransformyourregion.eu/wp-content/ uploads/2016/10/Case-Study-Deep-DiveEspoo-v1.pdf.

European Commission (2016e) New Skills Agenda for Europe. Available at: https://ec.europa. eu/social/main.jsp?catld=1223 (accessed 23 November 2018).

European Commission (2016f) Urban Agenda for the EU - FUTURIUM. Available at: https:// ec.europa.eu/futurium/en/urban-agenda (accessed 23 November 2018).

European Commission (2017a) Europe's Digital Progress Report 2017. SWD(2017) 160 final. Available at: https://ec.europa.eu/ transparency/regdoc/rep/10102/2017/EN/ SWD-2017-160-F1-EN-MAIN-PART-1.PDF (accessed 17 January 2019).

European Commission (2017b) Innovation and digitisation key for strong and sustainable rural areas. Available at: https://ec.europa.eu/info/ news/innovation-and-digitisation-key-strongand-sustainable-rural-areas_en.

European Commission (2017c) The Digital Economy and Society Index (DESI). Available at: https://ec.europa.eu/digital-single-market/en/ desi (accessed 23 November 2018).

European Commission (2018a) Data protection. Available at: https://ec.europa.eu/info/law/ law-topic/data-protection_en (accessed 23 November 2018).

European Commission (2018b) Digital Education Action Plan. Available at: https://ec.europa. eu/education/education-in-the-eu/digitaleducation-action-plan_en (accessed 23 November 2018).

Finnmark County Municipality (2015) Kunnskapsgrunnlag for folkehelse i FinnmarkFinnmarku (in Norwegian).

Government of Åland (2017) Development and Sustainability Agenda for Åland.
Government Offices of Sweden (2017)

För ett hållbart digitaliserat Sverige - en digitaliseringsstrategi (in Swedish).

Government Offices of Sweden (2018) Regeringen genomför insatser för att stärka arbetet med digitalisering på regional nivå (in Swedish). Available at: https://www. regeringen.se/pressmeddelanden/2018/07/ regeringen-genomfor-insatser-for-att-starkaarbetet-med-digitalisering-pa-regional-niva/ (accessed 7 November 2018).

Greater Copenhagen (2018) Greater Copenhagen Committee. Available at: http://www. greatercph.dk/komiteen (accessed 13 August 2018).

Greenlandic Agency for Digitalisation (2018) Det digitale samfund: National digitaliseringsstrategi 2018-2021. Draft version sent for political hearing.

Hansteen K, Ølnes J and Alvik T (2016) Nordic digital identification (eID). Survey and recommendations for cross border cooperation. TemaNord 2016:508. Nordic Council of Ministers.

HealthTech Nordic (2018) HealthTech Nordic. Available at: http://healthtechnordic.com/ (accessed 23 November 2018).

Helsingborg (2017) Digitalisering i Helsingborg - 5 fokusområden. Available at: https:// digitalisering.helsingborg.se/digitalisering-ihelsingborg-5-fokusomraden/ (accessed 15 August 2018).

IoT Agenda (2017) What is smart city? Available at: http://internetofthingsagenda.techtarget. com/definition/smart-city (accessed 23 November 2018).

Kontur (2017a) Region Syddanmark. Available at: https://detgodeliv.regionsyddanmark.dk/ publikation/kontur-2017-region-syddanmark/ (accessed 20 November 2018).

Kontur (2017b) Vejle municipality. In: Det Gode Liv. Available at: https://detgodeliv. regionsyddanmark.dk/publikation/kontur2017-vejle/ (accessed 20 November 2018).

Kourtit K (2016) Super-Proximity and Spatial Development.: 18.

Manyika, J., Chui, M., Bughin, J., Dobbs, R., Bisson, P. and Marrs, A., (2013) Disruptive technologies: Advances that will transform life, business, and the global economy / McKinsey. San Francisco, CA: McKinsey Global Institute. Available at: https://www.mckinsey.com/business- 
functions/digital-mckinsey/our-insights/ disruptive-technologies (accessed 23 November 2018).

Ministry of Foreign Affairs, Trade and Industry and the Ministry of Finance (2018) The National Digitalisation Programme of the Faroe Islands.

Ministry of Trade, Industry and Fisheries (2017) White Paper 27 (2016-2017): The Industry Greener, Smarter and Creative.

Morgan K (2004) The exaggerated death of geography: learning, proximity and territorial innovation systems. Journal of Economic Geography 4(1): 3-21. DOI: 10.1093/jeg/4.1.3.

NCM (2017) About the Nordic Council of Ministers for Digitalisation (MR-DIGITAL). Available at: https://www.norden.org/en/information/ about-nordic-council-ministers-digitalisationmr-digital (accessed 20 November 2018).

Nilsson M, Lindell C, Sandin D, et al. (2017) Skåne Facts and Key Trends. Available at: https:// utveckling.skane.se/siteassets/publikationer_ dokument/skane_facts-and-key-trends.pdf.

NyTeknik (2018) Då rullas $5 \mathrm{~g}$ ut i svenska storstäder. Available at: https://www.nyteknik. se/digitalisering/da-rullas-5g-ut-i-svenskastorstader-6942053 (accessed 12 December 2018).

O'Brien KJ (2012) Nokia to Cut 10,000 Jobs and Close 3 Facilities. The New York Times, 14 June. Available at: https://www.nytimes. com/2012/06/15/technology/nokia-to-cut10000-jobs-and-close-3-facilities.html (accessed 19 November 2018).

OECD (2012) OECD Territorial Reviews OECD Territorial Reviews: Skåne, Sweden 2012. OECD Publishing.

OECD (2014) OECD Recommendation on Digital Government Strategies. Available at: http:// www.oecd.org/gov/digital-government/ recommendation-on-digital-governmentstrategies.htm (accessed 23 November 2018).

Region Skåne (2018) Digital infrastruktur - Region Skåne. Available at: https://utveckling.skane. se/utvecklingsomraden/samhallsplanering/ digital_infrastruktur/ (accessed 15 August 2018).

Regionfakta (2018) Branschstruktur -

Regionfakta Region Skåne. Available at: http:// www.regionfakta.com/Skane-lan/Naringsliv/ Branschstruktur/ (accessed 13 August 2018).
Reykjavik City Council (2016) Rafræn pjónustumiðstöð Reykjavíkurborgar (in Icelandic). Available at: https://reykjavik. is/frettir/rafraen-thjonustumidstodreykjavikurborgar (accessed 20 November 2018).

Reykjavik City Council (2018) Hack the city! How to morph your DMO business model and engage the city. Available at: https://fundur. reykjavik.is/sites/default/files/agenda-items/ ecm_dagskra.pdf.

Sabbagh K, Friedrich R, El-Darwiche B, et al. (2013) Digitization for Economic Growth and Job Creation: Regional and Industry Perspectives.: 8.

Scott AJ (2011) A world in emergence: Notes toward a resynthesis of urban-economic geography for the 21st century. Urban Geography 32(6): 845-870.

Smart Tampere Ecosystem (2017) Education and Research. Available at: http://smarttampere.

fi/en/smart-ecosystem-themes/smarteducation (accessed 19 November 2018).

SNL (2018) Finnmark. Store norske leksikon. Available at: http://snl.no/Finnmark (accessed 19 November 2018).

Soete $L$ (2006) Information and Communication Technologies and the New Regional Economy. In: Johansson B, Karlsson C, and Stough R (eds) The Emerging Digital Economy. Springer Berlin Heidelberg, pp. 21-32. DOI: 10.1007/3-54034488-8_2.

SSB (2018a) Befolkningsprofil. Available at: https://www.ssb.no/kommunefakta/kostra/ tjenesteomrade/befolkningsprofil (accessed 19 November 2018).

SSB (2018b) Nyetablerte foretaks overlevelse og vekst (in Norwegian). Available at: https:// www.ssb.no/virksomheter-foretak-ogregnskap/statistikker/fordem/aar/2018-10-18 (accessed 19 November 2018).

Statistics Finland (2017) Kuntien avainluvut muuttujina Alve 2018 ja Tiedot. Available at: https://pxnet2.stat.fi:443/PXWebPXWeb/ pxweb/en/Kuntien_avainluvut/Kuntien_ avainluvut_2018/kuntien_avainluvut_2018_ viimeisin.px/ (accessed 19 November 2018).

Statistics Iceland (2018) Population in Reykjavík by districts, sex and age 1998-2018. Available at: http://px.hagstofa.is/pxenpxen/pxweb/ en/lbuar/lbuar__mannfjoldi__2_byggdir__ 
Byggdakjarnarhverfi/MAN03301.px/ (accessed 20 November 2018).

Sveinbjornsson S and Jorgenrud M (2013) Vil gi SvarUT til alle. Available at: https://www. digi.no/artikler/vil-gi-svarut-til-alle/288461 (accessed 21 November 2018).

Tampere City Region (2018) Facts and figures. Available at: https://www.tampereenseutu.fi/ in_english/key-figures/ (accessed 12 November 2018).

The Danish Government (2013) Common publicsector strategy for digital welfare 2013-2020. Available at: https://www.rm.dk/siteassets/ sundhed/faginfo/center-for-telemedicin/ english/documents/strategy_for_digital_ welfare_2013_2020.pdf.

The Danish Government (2018) Strategy for Denmark's digital growth. Available at: https://investindk.com/insights/the-danishgovernment-presents-digital-growth-strategy.

The Greater Copenhagen and Skåne Committee (2017) Greater Copenhagen Action Plan 2018-2019.

The Ministry of Economic Affairs and Employment of Finland (2018) Work in the age of artificial intelligence. Four perspectives on the economy, employment, skills and ethics. Available at: http://julkaisut.valtioneuvosto. $\mathrm{fi} /$ bitstream/handle/10024/160980/ TEMjul_21_2018_Work_in_the_age.pdf.
The Ministry of Finance (2018) The regional government, health and social services reform is for all of Finland. Available at: https:// vm.fi/en/article/-/asset_publisher/hallitusmaakunta-ja-sote-uudistus-tehdaan-kokosuomelle (accessed 19 November 2018).

The Norwegian Government (2018) Regionreform. Available at: https://www. regjeringen.no/no/tema/kommuner-ogregioner/kommunereform/regionreform/ id2477186/ (accessed 21 November 2018).

The Triange Region (2018) The Triangle Region - A metropol of opportunities surrounded by amazing nature. Available at: http:// www.trekantomraadet.com/ (accessed 20 November 2018).

van Marion L and Honerud Hovland J (2015) The Nordic Digital Ecosystem. Actors, Strategies, Opportunities. Oslo: Nordic Innovation Publication. Available at: http://www. nordicinnovation.org/Global/_Publications/ Reports/2015/NDE_Web.pdf.

Wernberg $J$ and Andersson M (2016) State of the Digital Region 2016.: 34.

World Economic Forum (2016) Chemistry and Advanced Materials: at the heart of the Fourth Industrial Revolution. In: Digital Transformation. Available at: http://wef.ch/2igTqIM (accessed 17 December 2018). 


\section{Appendix I. Digital technologies with high transformative potential}

The table below highlights the 12 technologies with the greatest transformative power on a global scale by 2025, based on a report from the McKinsey Global Institute (Manyika et al., 2013). 'Transformative power' is defined as the technologies that will be the most likely to have a significant impact on the way people live and work and on industries and economies (Manyika et al., 2013). In many cases, the innovations with the greatest transformative potential rely on interactions with other technologies in the list. For example, 'big data', a commonly cited e-governance tool, relies on mobile connectivity and the IoT for the collection of data, cloud technologies for its storage and, in some cases, artificial intelligence/machine learning/advanced robotics to act on the information gathered.

\begin{tabular}{|c|c|c|c|}
\hline \multicolumn{4}{|c|}{$\begin{array}{l}\text { Summary of technologies enabling the digital revolution (developed based on Manyika } \\
\text { et al, 2013) }\end{array}$} \\
\hline Technology & What is it? & $\begin{array}{l}\text { Transformative qualities/ } \\
\text { implications }\end{array}$ & Application examples \\
\hline Mobile Internet & $\begin{array}{l}\text { Increasingly inexpensive } \\
\text { and capable mobile } \\
\text { computing devices and } \\
\text { Internet connectivity }\end{array}$ & $\begin{array}{l}\text { Increasingly inexpensive } \\
\text { and capable mobile } \\
\text { computing devices and } \\
\text { Internet connectivity }\end{array}$ & $\begin{array}{l}\text { Wearable smart phones; } \\
\text { health and wellness } \\
\text { applications; mobility } \\
\text { solutions }\end{array}$ \\
\hline $\begin{array}{l}\text { Artificial intelligence/ } \\
\text { machine learning }\end{array}$ & $\begin{array}{l}\text { Intelligent software } \\
\text { systems that can } \\
\text { perform knowledge- } \\
\text { based work tasks } \\
\text { involving unstructured } \\
\text { commands and subtle } \\
\text { judgements }\end{array}$ & $\begin{array}{l}\text { Intelligent software } \\
\text { systems that can perform } \\
\text { knowledge-based } \\
\text { work tasks involving } \\
\text { unstructured commands } \\
\text { and subtle judgements }\end{array}$ & \\
\hline Internet of Things & $\begin{array}{l}\text { Physical objects (e.g., } \\
\text { park benches and } \\
\text { lights) are connected by } \\
\text { networks of low-cost } \\
\text { sensors that allow them } \\
\text { to collect data and } \\
\text { monitor environments }\end{array}$ & $\begin{array}{l}\text { Physical objects (e.g., park } \\
\text { benches and lights) are } \\
\text { connected by networks } \\
\text { of low-cost sensors that } \\
\text { allow them to collect data } \\
\text { and monitor environments }\end{array}$ & $\begin{array}{l}\text { 'Smart' cities, offices and } \\
\text { homes, and agriculture, } \\
\text { food production and } \\
\text { resource efficiency }\end{array}$ \\
\hline Cloud technologies & $\begin{array}{l}\text { Supports other } \\
\text { functions by making the } \\
\text { digital world simpler, } \\
\text { faster and more power- } \\
\text { ful using computer } \\
\text { hardware and software } \\
\text { resources delivered } \\
\text { over a network or the } \\
\text { Internet }\end{array}$ & $\begin{array}{l}\text { Supports other functions } \\
\text { by making the digital world } \\
\text { simpler, faster and more } \\
\text { powerful using computer } \\
\text { hardware and software } \\
\text { resources delivered over a } \\
\text { network or the Internet }\end{array}$ & $\begin{array}{l}\text { Low-cost, user-friendly } \\
\text { storage of large amounts } \\
\text { of data though platforms } \\
\text { such as Dropbox, Google } \\
\text { Drive, OneDrive, and } \\
\text { others }\end{array}$ \\
\hline
\end{tabular}




\begin{tabular}{|c|c|c|c|}
\hline Advanced robotics & $\begin{array}{l}\text { Increasingly capable } \\
\text { robots with enhanced } \\
\text { senses, dexterity, and } \\
\text { intelligence used to } \\
\text { automate tasks or } \\
\text { augment humans }\end{array}$ & $\begin{array}{l}\text { Increasingly capable } \\
\text { robots with enhanced } \\
\text { senses, dexterity, and } \\
\text { intelligence used to } \\
\text { automate tasks or } \\
\text { augment humans }\end{array}$ & $\begin{array}{l}\text { Robots take on jobs } \\
\text { requiring high levels of } \\
\text { precision (e.g., surgery) }\end{array}$ \\
\hline $\begin{array}{l}\text { Autonomous and near } \\
\text { autonomous vehicles }\end{array}$ & $\begin{array}{l}\text { Vehicles that can } \\
\text { navigate and operate } \\
\text { with reduced or no } \\
\text { human intervention }\end{array}$ & $\begin{array}{l}\text { Potential to completely } \\
\text { transform ground } \\
\text { transportation, with } \\
\text { implications for urban } \\
\text { design (e.g., parking, } \\
\text { pedestrian vehicle } \\
\text { interface) as well as } \\
\text { service delivery in rural } \\
\text { areas }\end{array}$ & \\
\hline $\begin{array}{l}\text { Next-generation } \\
\text { genomics }\end{array}$ & $\begin{array}{l}\text { Fast, low-cost gene } \\
\text { sequencing }{ }^{19} \text {, advanced } \\
\text { big data analytics } \\
\text { and synthetic biology } \\
\text { ('writing' DNA) }\end{array}$ & $\begin{array}{l}\text { Potential for medical } \\
\text { advances that could } \\
\text { dramatically increase the } \\
\text { quality and length of life }\end{array}$ & $\begin{array}{l}\text { Can be used in agriculture } \\
\text { to produce high value } \\
\text { materials (e.g., biofuels) }\end{array}$ \\
\hline 3D printing & $\begin{array}{l}\text { Additive manufacturing } \\
\text { techniques to create } \\
\text { objects by printing } \\
\text { layers of material based } \\
\text { on digital models }\end{array}$ & $\begin{array}{l}\text { Potential disruption to } \\
\text { manufacturing/supply } \\
\text { chains. Medical advances } \\
\text { (e.g., printing organs). } \\
\text { Legal implications around } \\
\text { importation of goods (e.g., } \\
\text { printing weapons) }\end{array}$ & \\
\hline Advanced materials & $\begin{array}{l}\text { Materials designed } \\
\text { to have superior } \\
\text { characteristics (e.g., } \\
\text { strength, weight, } \\
\text { conductivity) or } \\
\text { functionality }\end{array}$ & $\begin{array}{l}\text { Still in R\&D stage. } \\
\text { Implications unclear }\end{array}$ & \\
\hline $\begin{array}{l}\text { Advanced oil and gas } \\
\text { exploration recovery }\end{array}$ & $\begin{array}{l}\text { Exploration and } \\
\text { recovery techniques } \\
\text { that make extraction } \\
\text { of unconventional oil } \\
\text { and gas economical }\end{array}$ & $\begin{array}{l}\text { Potential to hamper global } \\
\text { efforts on renewable } \\
\text { energy by increasing the } \\
\text { availability of fossil fuels. } \\
\text { Substantial environmental } \\
\text { risks }\end{array}$ & \\
\hline Renewable energy & $\begin{array}{l}\text { Generation of electricity } \\
\text { from renewable sources } \\
\text { with reduced harmful } \\
\text { climate impact }\end{array}$ & $\begin{array}{l}\text { Increased cost } \\
\text { effectiveness and } \\
\text { performance of existing } \\
\text { solutions along with } \\
\text { development of new } \\
\text { solutions }\end{array}$ & \\
\hline
\end{tabular}

19 Human genome sequencing took 13 years and cost $\$ 2.7$ billion to accomplish under the Human Genome Project. Today, it can be done in under 3 hours for $\$ 3,000$. 


\section{Appendix II. List of interviewees}

\begin{tabular}{|c|c|c|c|}
\hline \multicolumn{4}{|c|}{ National policy context } \\
\hline Country & Name & Title / Organisation & Date \\
\hline Denmark & Troels Johansen & $\begin{array}{l}\text { Digital Growth Policy, Danish Business } \\
\text { Authority }\end{array}$ & 28 August 2018 \\
\hline Finland & Jussi Nissilä & $\begin{array}{l}\text { Development Director, Ministry of } \\
\text { Economic Affairs and Employment }\end{array}$ & 10 July 2018 \\
\hline \multirow[t]{2}{*}{ Iceland } & Einar Birkir & Icelandic Government Ministry of Finance & 8 May 2018 \\
\hline & Kristjan Halldorsson & Icelandic Association of Local Authorities & 25 June 2018 \\
\hline Norway & Anne-Lena Straumdal & $\begin{array}{l}\text { Department of IT policy and Public Sector } \\
\text { Reform, Ministry of Local Government and } \\
\text { Modernisation }\end{array}$ & 15 August 2018 \\
\hline \multirow[t]{2}{*}{ Sweden } & Erik Joachimsson & $\begin{array}{l}\text { Department of Regional Growth and EU } \\
\text { Cohesion Policy, Ministry of Enterprise and } \\
\text { Innovation }\end{array}$ & 15 June 2018 \\
\hline & Gustaf Molander & $\begin{array}{l}\text { Department Secretary, Digitalisation Unit } \\
\text { at the Government Offices of Sweden, } \\
\text { Ministry of Enterprise and Innovation }\end{array}$ & 15 June 2018 \\
\hline Greenland & $\begin{array}{l}\text { Tom Nørregaard } \\
\text { Andersen }\end{array}$ & $\begin{array}{l}\text { Head of Department, The Greenlandic } \\
\text { Agency for Digitalisation }\end{array}$ & 6 August 2018 \\
\hline $\begin{array}{l}\text { The Faroe } \\
\text { Islands }\end{array}$ & Nicolai Mohr Balle & $\begin{array}{l}\text { Programme Manager, The National } \\
\text { Digitalisation Programme of the Faroe } \\
\text { Islands, Talgildu Føroyar }\end{array}$ & 11 July 2018 \\
\hline \multirow[t]{3}{*}{$\begin{array}{l}\text { Åland } \\
\text { Islands }\end{array}$} & Ronny Lundström & $\begin{array}{l}\text { Department of Finance, Government of } \\
\text { Åland }\end{array}$ & 19 June 2018 \\
\hline & Tony Asumaa & $\begin{array}{l}\text { Minister of Education and Culture, } \\
\text { Government of Åland }\end{array}$ & 19 June 2018 \\
\hline & Anders Ingves & Senior Advisor at Prime and United Minds & 9 August 2018 \\
\hline
\end{tabular}




\begin{tabular}{|c|c|c|c|}
\hline \multicolumn{4}{|c|}{ Regional case studies } \\
\hline Country & Name & Title / Organisation & Date \\
\hline \multirow[t]{8}{*}{ Denmark } & Ulla Varnerskov & Chief Resilience Officer, Vejle Municipality & 13 August 2018 \\
\hline & $\begin{array}{l}\text { Björn Snorri } \\
\text { Gudmundsson Bøg }\end{array}$ & $\begin{array}{l}\text { Development Consultant, The Region of } \\
\text { Southern Denmark }\end{array}$ & 13 August 2018 \\
\hline & Michael Sloth & $\begin{array}{l}\text { Technology \& Environmental Director, Vejle } \\
\text { Municipality }\end{array}$ & 13 August 2018 \\
\hline & Harald-Åge Mortensen & $\begin{array}{l}\text { Head of Digitalisation and Analysis, Vejle } \\
\text { Municipality }\end{array}$ & 13 August 2018 \\
\hline & Jeanette Kristensen & Innovation Consultant, Vejle Municipality & 14 August 2018 \\
\hline & Morten Lundgaard & $\begin{array}{l}\text { IT-director, The Region of Southern } \\
\text { Denmark }\end{array}$ & 14 August 2018 \\
\hline & Katrine Vedel & $\begin{array}{l}\text { Special Consultant, Health Innovation } \\
\text { Centre of Southern Denmark }\end{array}$ & 14 August 2018 \\
\hline & Søren Skaarup & $\begin{array}{l}\text { Senior Consultant, Business Technology \& } \\
\text { Digitalisation, Ramboll }\end{array}$ & 15 August 2018 \\
\hline \multirow[t]{9}{*}{ Finland } & Teppo Rantanen & $\begin{array}{l}\text { Executive Director of Economic Policy, } \\
\text { Competitiveness and Innovation, City of } \\
\text { Tampere (and Smart Tampere) }\end{array}$ & 22 February 2018 \\
\hline & Tero Blomqvist & $\begin{array}{l}\text { Smart Tampere Programme Director, City } \\
\text { of Tampere }\end{array}$ & 21 February 2018 \\
\hline & Reija Linnamaa & Director of Strategy, City of Tampere & 22 February 2018 \\
\hline & Jarkko Oksala & $\begin{array}{l}\text { Chief Information Officer, City of Tampere } \\
\text { (and Digitalisation Programme at Smart } \\
\text { Tampere) }\end{array}$ & 22 February 2018 \\
\hline & Petri Räsänen & $\begin{array}{l}\text { Director, Innovation and Foresight, the } \\
\text { Council of Tampere Region }\end{array}$ & 21 February 2018 \\
\hline & Katja Koponen & $\begin{array}{l}\text { Senior Business Advisor at Renewing } \\
\text { Industry, Business Tampere }\end{array}$ & 21 February 2018 \\
\hline & Heini Wallander & $\begin{array}{l}\text { Business Advisor at Renewing Industry, } \\
\text { Business Tampere }\end{array}$ & 21 February 2018 \\
\hline & Ilkka Haukijärvi & $\begin{array}{l}\text { Director of Project Development, } \\
\text { Tampere3 Process }\end{array}$ & 23 February 2018 \\
\hline & Juha Latvala & CEO, Intopalo Oy & 21 February 2018 \\
\hline
\end{tabular}




\begin{tabular}{|c|c|c|c|}
\hline \multirow[t]{5}{*}{ Iceland } & Halldór Auðar Svansson & Pirate Party & 24 April 2018 \\
\hline & Ari Kristinn Jónsson & Reykjavík University & 25 April 2018 \\
\hline & $\begin{array}{l}\text { Hreinn Hreinsson \& } \\
\text { Pröstur Sigurðsson }\end{array}$ & Reykjavík Municipality & 23 April 2018 \\
\hline & Einar Pórarinsson & Advania & 23 April 2018 \\
\hline & Óskar Sandholt & Reykjavík Municipality & 24 April 2018 \\
\hline \multirow[t]{6}{*}{ Norway } & Stine Loso & $\begin{array}{l}\text { Chief of Staff Office, Troms County } \\
\text { Municipality }\end{array}$ & 22 May 2018 \\
\hline & Thomas Larsen & $\begin{array}{l}\text { Manager of Digital Integration and } \\
\text { Development at Troms ICT Department, } \\
\text { Troms County Municipality }\end{array}$ & 22 May 2018 \\
\hline & Hermann Westlie & Manager of Department, Vadsø, Eltele & 23 May 2018 \\
\hline & Nina Martinsen & Headmistress at Vardø Skole & 23 May 2018 \\
\hline & Hallgeir Sørnes & $\begin{array}{l}\text { Deputy Chief of Administration in Vardø } \\
\text { Municipality }\end{array}$ & 24 May 2018 \\
\hline & Merete Susan Andersen & $\begin{array}{l}\text { Department Manager and Senior Advisor } \\
\text { on Sustainability, Innovation Norway }\end{array}$ & 31 August 2018 \\
\hline \multirow[t]{7}{*}{ Sweden } & Micco Grönholm & Head of Future, Helsingborg Municipality & 22 May 2018 \\
\hline & Björn Lahti & Head of Smart Helsingborg Program & 23 May 2018 \\
\hline & Marianne Larsson & $\begin{array}{l}\text { Director of New Industries and Innovation } \\
\text { Director HealthTech Nordic, Innovation } \\
\text { Skåne }\end{array}$ & 23 May 2018 \\
\hline & Lars Winther-Hanson & $\begin{array}{l}\text { Regional Broadband Co-ordinator, Region } \\
\text { Skåne }\end{array}$ & 24 May 2018 \\
\hline & Martin Güll & $\begin{array}{l}\text { Director for Digitalisation, Helsingborg } \\
\text { Municipality }\end{array}$ & 24 May 2018 \\
\hline & Aline Studemund & $\begin{array}{l}\text { Project Manager Innovation \& } \\
\text { Communications, Mobile Heights }\end{array}$ & 26 June 2018 \\
\hline & Ola Svedin & CEO, Mobile Heights & 26 June 2018 \\
\hline
\end{tabular}





\section{(1I) Nordregio}

P.O. Box 1658

SE-111 86 Stockholm, Sweden

nordregio@nordregio.org

www.nordregio.org

www.norden.org

ISBN: 978-91-87295-68-3

ISSN: 1403-2503

DOI: doi.org/10.30689/R2019:4.1403-2503 